\title{
WestVirginiaUniversity
}

THE RESEARCH REPOSITORY @ WVU

Graduate Theses, Dissertations, and Problem Reports

2003

\section{Performance evaluation of diesel particulate filters on heavy-duty vehicles}

\author{
Stephen George Rosepiler \\ West Virginia University
}

Follow this and additional works at: https://researchrepository.wvu.edu/etd

\section{Recommended Citation}

Rosepiler, Stephen George, "Performance evaluation of diesel particulate filters on heavy-duty vehicles" (2003). Graduate Theses, Dissertations, and Problem Reports. 1310.

https://researchrepository.wvu.edu/etd/1310

This Thesis is protected by copyright and/or related rights. It has been brought to you by the The Research Repository @ WVU with permission from the rights-holder(s). You are free to use this Thesis in any way that is permitted by the copyright and related rights legislation that applies to your use. For other uses you must obtain permission from the rights-holder(s) directly, unless additional rights are indicated by a Creative Commons license in the record and/ or on the work itself. This Thesis has been accepted for inclusion in WVU Graduate Theses, Dissertations, and Problem Reports collection by an authorized administrator of The Research Repository @ WVU. For more information, please contact researchrepository@mail.wvu.edu. 


\title{
Performance Evaluation of Diesel Particulate Filters on Heavy Duty Vehicles
}

\author{
Stephen G. Rosepiler \\ Thesis submitted to the \\ College of Engineering and Mineral Resources \\ at West Virginia University \\ in partial fulfillment of the requirements \\ for a degree of \\ Master of Science \\ in \\ Mechanical Engineering \\ W. Scott Wayne, Ph.D., Chair \\ Nigel N. Clark, Ph.D. \\ Mridul Gautum, Ph.D. \\ Ralph D. Nine, MSME \\ Department of Mechanical and Aerospace Engineering \\ Morgantown, WV \\ 2003
}

Keywords: exhaust after-treatment, diesel emissions, particulate matter 


\section{Abstract \\ Performance Evaluation of Diesel Particulate Filters on Heavy Duty Vehicles}

\section{Stephen G. Rosepiler}

Diesel particulate filters, or DPFs, are exhaust aftertreatment devices used to reduce exhaust emissions from diesel powered vehicles. Typical designs have a wall flow filter element downstream of an oxidation catalyst, which oxidizes a portion of the $\mathrm{NO}$ present in the exhaust stream to form $\mathrm{NO}_{2}$. The resulting $\mathrm{NO}_{2}$ aides in the combustion of the soot collected in the wall flow filter element allowing for the complete breakdown of the soot within typical diesel exhaust temperatures, thus limiting the required maintenance on the filter elements to the removal of non-combustible ash.

Three aspects of DPF performance were investigated: cold start performance, filter durability, and general efficiencies. The cold start performance evaluation determined that the filter elements trapped particulate matter prior to the DPF light-off temperature being reached, however there was no significant impact on white smoke emissions at any temperature range. The DPF light-off temperature was determined to be between $330^{\circ} \mathrm{F}$ and $450^{\circ} \mathrm{F}$ for the Engelhard DPX and between $375^{\circ} \mathrm{F}$ and $450^{\circ} \mathrm{F}$ for the Johnson-Matthey CRT.

The filter durability study showed a slight degeneration of DPF performance as age and accumulated mileage increased. However, a definitive DPF life span could not be determined due to inconsistencies in the data from one testing round to the next.

In the general efficiencies evaluation, $\mathrm{CO}$ emissions were reduced by greater than $84 \%$ for both DPF styles tested. HC emissions were reduced by $76 \%$ with the Engelhard DPX and by $81 \%$ with the Johnson-Matthey CRT. PM emissions were reduced by $94 \%$ and $82 \%$ by the Engelhard DPX and the Johnson-Matthey CRT respectively. No significant changes were recorded for total $\mathrm{NO}_{\mathrm{X}}(\mathrm{NO}+\mathrm{NO} 2)$ or $\mathrm{CO}_{2}$ emissions. 


\section{Acknowledgements}

I would like to thank my committee members, Scott Wayne, Nigel Clark, Mridul Gautum, and Ralph Nine, for their professional guidance and support. Additionally, I would like to thank Scott Wayne for giving me the opportunity to continue my education through graduate school and for the opportunity to work with the Transportable Emissions Lab.

Also, I would like to thank all of the engineers and technicians of the WVU Transportable Heavy-Duty Vehicle Emissions Testing Laboratory. Without your knowledge and expertise, the data collection for this thesis would have been impossible.

I would also like to thank all of my friends and office-mates, especially Nick. You have made the last several months much more enjoyable, both at work and outside of work.

Finally, I would like to thank my parents, brother, Joe, and fiancée, Amy. Without your continuing and never-ending encouragement, I would not have successfully made it through this part of my life. You will never understand how much your encouragement and support mean to me. Thank You! 


\section{Table of Contents}

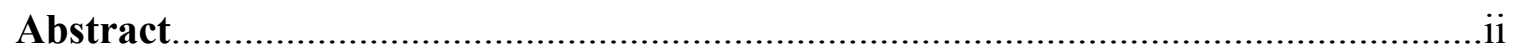

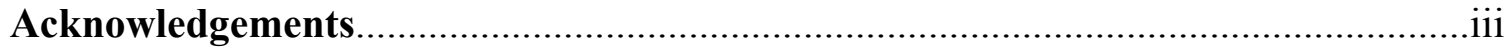

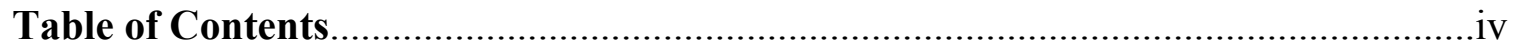

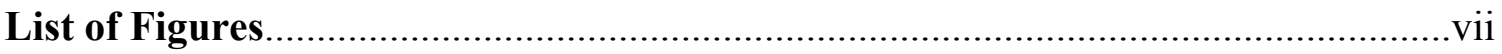

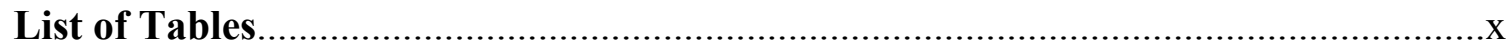

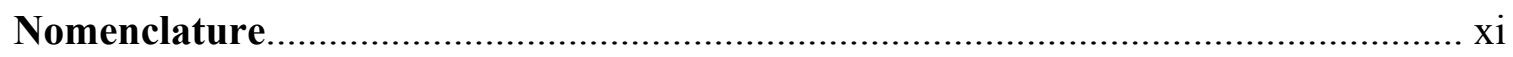

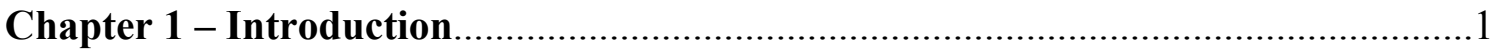

Chapter 2 - Literature Review.........................................................................

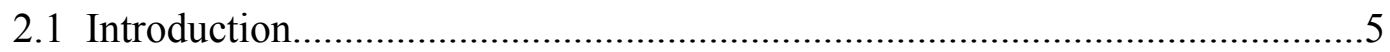

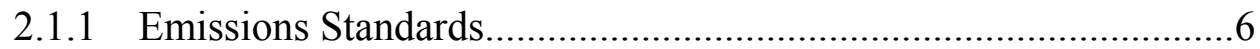

2.1.2 Cold Start Emissions and White Smoke........................................

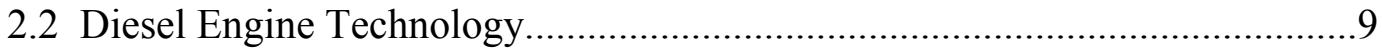

2.2.1 Improved Combustion Chamber Design.....................................9

2.2.1.1 Reduced Oil Consumption.............................................9

2.2.1.2 Increased Compression Ratio.........................................10

2.2.1.3 Improved Combustion.....................................................11

2.2.2 Improved Fuel Injection...........................................................12

2.2.2.1 Nozzle Geometry.......................................................12

2.2.2.2 Multiple Injections and Rate Shaping............................13

2.2.2.3 Electronic Unit Injection.............................................14

2.2.3 Turbocharger Improvements................................................ 14

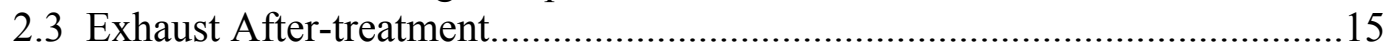

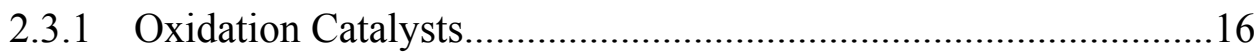

2.3.2 Lean $\mathrm{NO}_{\mathrm{X}}$ Catalysts..............................................................17

2.3.3 Selective Catalytic Reduction..................................................18

2.3.4 Exhaust Gas Recirculation...................................................19

2.3.5 Non-Thermal Plasma Catalysts................................................21

2.3.6 Diesel Particulate Filters............................................................23

Chapter 3 - Experimental Procedures and Equipment......................................26

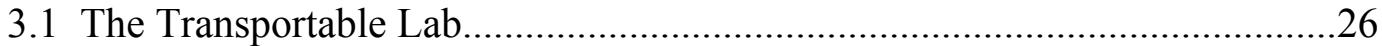

3.1.1 The Power Absorber Test Bed....................................................27

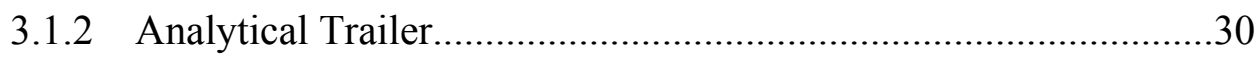

3.1.2.1 Dilution Tunnels........................................................... 31

3.1.2.2 Gaseous Emissions Analysis.........................................31 
3.1.2.3 Gaseous Emission Analyzers................................................33

A. Hydrocarbon Analyzer...................................................34

B. Oxides Of Nitrogen $\left(\mathrm{NO}_{\mathrm{X}}\right)$ Analyzer................................35

C. Carbon Monoxide Analyzers..........................................36

D. Carbon Dioxide Analyzer.............................................37

3.1.2.4 Particulate Matter Collection..............................................37

3.1.2.5 Fuel Economy Calculations...............................................39

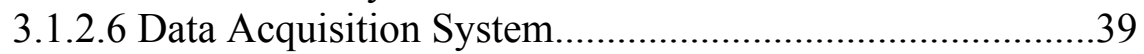

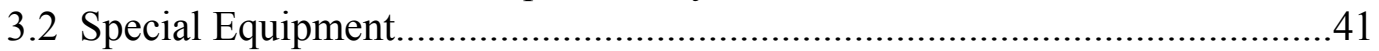

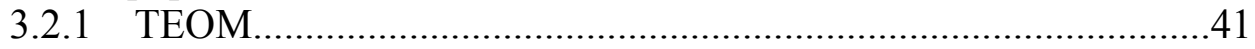

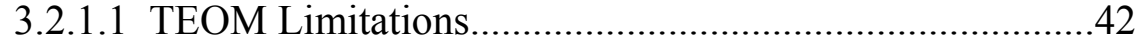

3.2.2 Smoke Opacity Meter...................................................................43

Chapter 4 - Test Vehicles, Driving Cycles, and Results............................................45

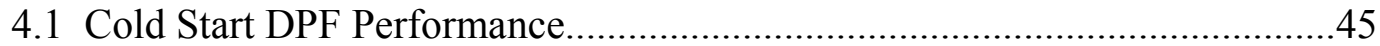

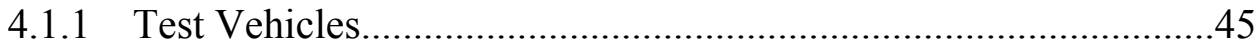

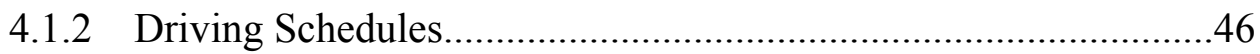

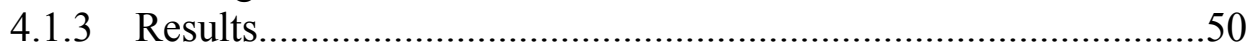

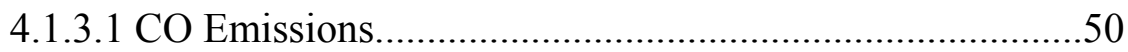

4.1.3.2 HC Emissions...............................................................52

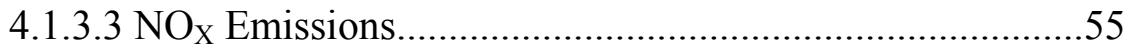

4.1.3.4 $\mathrm{CO}_{2}$ Emissions / Fuel Economy.........................................57

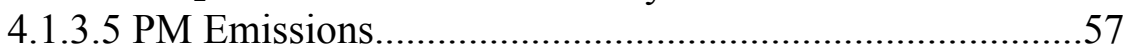

4.1.3.6 White Smoke Emissions.....................................................58

4.2 Long Term Durability Evaluation of Ralph's Grocery Fleet Vehicles...........59

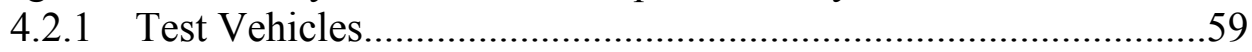

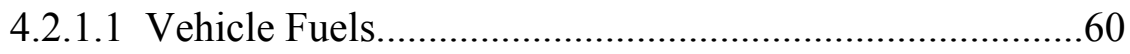

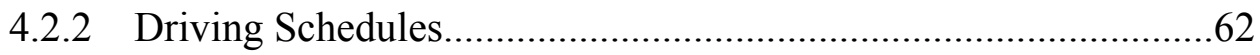

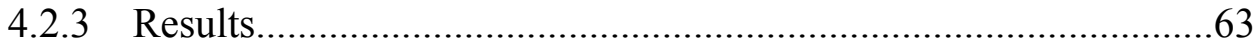

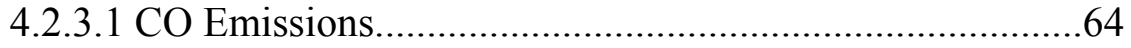

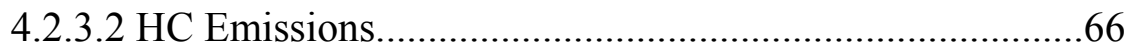

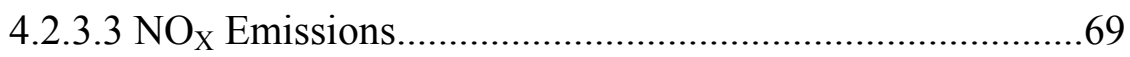

4.2.3.4 $\mathrm{CO}_{2}$ Emissions / Fuel Economy..........................................73

4.2.3.5 PM Emissions................................................................

4.2.4 Limitations of Study.................................................................

4.2.4.1 Vehicle and DPF Maintenance.........................................78

4.2.4.2 Test Vehicles................................................................

4.2.4.3 Test Consistency..................................................................79

4.3 General Performance Evaluation and Manufacturer Comparison....................80

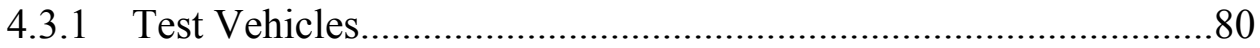

4.3.1.1 Westchester County Transit Authority (WCTA)................80

4.3.1.2 Washington Metropolitan Area Transit Authority

(WMATA) .................................................................8 81

4.3.1.3 New York City Department of Sanitation (NYCDOS).....81

4.3.2 Driving Schedules. 
4.3.2.1 BEELINE / 2BEELINE Cycle......................................83

4.3.2.2 WMATA / 2WMATA Cycle..........................................84

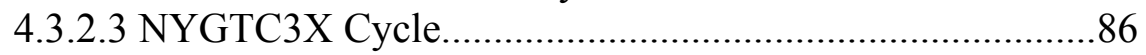

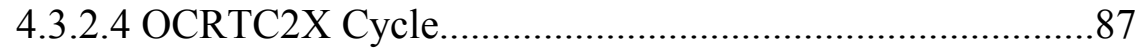

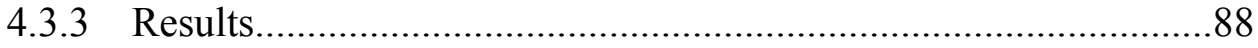

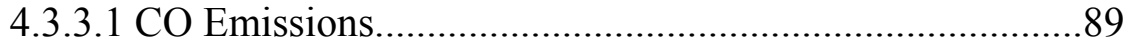

4.3.3.2 HC Emissions.................................................................90

4.3.3.3 $\mathrm{NO}_{\mathrm{X}}$ and $\mathrm{NO}$ Emissions............................................92

4.3.3.4 $\mathrm{CO}_{2}$ Emissions / Fuel Economy.....................................93

4.3.3.5 PM Emissions.............................................................95

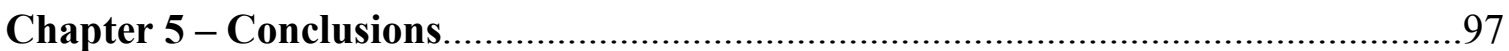

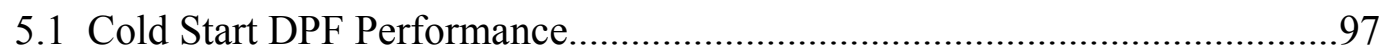

5.2 Long-Term Durability Evaluation..........................................................98

5.3 General Performance Evaluation and Manufacturer Comparison..................99

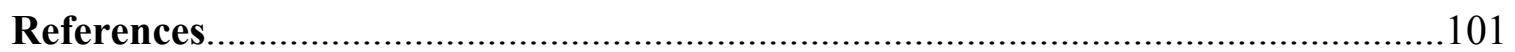

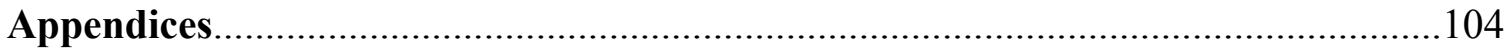

Appendix A: Analyzer Information....................................................... 104

Appendix B: Cold Start Data Summary .................................................106

Appendix C: Durability Study Data Summary ........................................ 108

Appendix D: General Performance Evaluation Data Summary..................112 


\section{List of Figures}

Figure 3.1: Hub adapters connecting the vehicle drive axle to the dynamometer unit of the Translab test bed.

Figure 3.2: Transit bus mounted on the test bed of Translab 1 connected to the analytical trailer for emissions testing.

Figure 3.3: Analyzer bench from WVU Translab 1

Figure 4.1.1: The 3CBD driving cycle utilized for hot start testing with WMATA transit buses as driven by WMATA bus 3722 .

Figure 4.1.2: The 2-5miles driving route developed by West Virginia University as driven by the WVU Mack

Figure 4.1.3: The WVU one-peak (WVU-1P) driving cycles as used for cold start testing on the Mack Tractor Truck.

Figure 4.1.4: Average $\mathrm{CO}$ emissions recorded during cold start test runs from WMATA Orion II transit buses, with maximum and minimum values shown as error bars.

Figure 4.1.5: Continuous $\mathrm{CO}$ emissions data from three WMATA transit buses.

Figure 4.1.6: Continuous CO emissions taken from the WVU Mack tractor truck during cold-weather cold start testing.....

Figure 4.1.7: Average $\mathrm{HC}$ emissions collected during cold start testing of the WMATA transit buses.

Figure 4.1.8: HC emissions from cold start testing of WMATA transit buses.

Figure 4.1.9: HC emissions from cold start testing of the WVU Mack tractor truck........54

Figure 4.1.10: Average integrated $\mathrm{NO}$ and $\mathrm{NO}_{\mathrm{X}}$ emissions in grams per mile collected from cold start testing of WMATA buses.

Figure 4.1.11: $\mathrm{NO}$ and $\mathrm{NO}_{\mathrm{X}}$ split shown from WMATA bus 3724 using an Engelhard DPX

Figure 4.1.12: TEOM data from the WVU Mack tractor truck from cold-weather cold-start testing 
Figure 4.1.13: Smoke opacity, smoke density, and exhaust temperature data from WMATA bus 3724 .

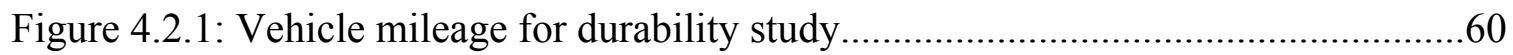

Figure 4.2.2: Scheduled speed vs. time for the CSHVR as driven by a test vehicle.........63

Figure 4.2.3: CO emissions from test runs using DPFs .64

Figure 4.2.4: $\mathrm{CO}$ emissions from trucks 5903 and 5904 running on ultra-low sulfur fuel without the DPFs. .65

Figure 4.2.5: CO emissions from trucks 5903 and 5904 running on CARB fuel without the DPFs. .65

Figure 4.2.6: $\mathrm{HC}$ emissions from test runs utilizing the DPFs. .67

Figure 4.2.7: $\mathrm{HC}$ emissions from trucks 5903 and 5904 running on ultra-low sulfur fuel without the DPFs. .68

Figure 4.2.8: $\mathrm{HC}$ emissions trucks 5903 and 5904 running on CARB fuel without the DPFs. .68

Figure 4.2.9: Round one $\mathrm{NO}_{\mathrm{X}}$ emissions using particulate filters...................................70

Figure 4.2.10: Round two $\mathrm{NO}$ and $\mathrm{NO}_{\mathrm{X}}$ emissions using particulate filters.....................70

Figure 4.2.11: Round three $\mathrm{NO}$ and $\mathrm{NO}_{\mathrm{X}}$ emissions using particulate filters...................71

Figure 4.2.12: Total $\mathrm{NO}_{\mathrm{x}}$ emissions from $\mathrm{ECD} / \mathrm{ECD} 1$ fueled test runs without DPFs.

Figure 4.2.13: Total $\mathrm{NO}_{\mathrm{X}}$ emissions from $\mathrm{CARB}$ fueled test runs without DPFs. .72

Figure 4.2.14: $\mathrm{CO}_{2}$ emissions from test runs with DPFs installed. .73

Figure 4.2.15: Fuel economy from test runs with DPFs installed . .74

Figure 4.2.16: $\mathrm{CO}_{2}$ emissions (left) and fuel economy (right) for non-DPF test runs using $\mathrm{ECD} / \mathrm{ECD} 1$ fuel.

Figure 4.2.17: $\mathrm{CO}_{2}$ emissions (left) and fuel economy (right) for non-DPF test runs using CARB fuel. .75

Figure 4.2.18: PM emissions from DPF-equipped test runs .76 
Figure 4.2.19: Engine-out PM emissions from non-DPF test runs using $\mathrm{ECD} / \mathrm{ECD} 1$ fuel.

Figure 4.2.20: Engine-out PM emissions from non-DPF test runs using CARB fuel.......77

Figure 4.3.1: BEELINE cycle driving cycle developed for WCTA..................................84

Figure 4.3.2: WMATA cycle developed for the Washington Metropolitan Area

Transit Authority..... .85

Figure 4.3.3: NYGTC3X cycled developed for the NY Department of Sanitation.

Figure 4.3.4: OCRTC2X developed for the Orange County Department of

Sanitation applied to the NYCDOS vehicles. .88

Figure 4.3.5: $\mathrm{CO}$ emissions from Engelhard DPX equipped vehicles................................89

Figure 4.3.6: $\mathrm{CO}$ emissions from Johnson-Matthey CRT equipped vehicles.....................90

Figure 4.3.7: HC emissions from DPX equipped vehicles.............................................91

Figure 4.3.8: $\mathrm{HC}$ emissions from CRT equipped vehicles..............................................91

Figure 4.3.9: $\mathrm{NO}$ and $\mathrm{NO}_{\mathrm{X}}$ emissions from the WCTA fleet vehicles tested...................93

Figure 4.3.10: Fuel economy from Engelhard DPX equipped vehicles...........................94

Figure 4.3.11: Fuel economy from Johnson-Matthey CRT equipped vehicles................94

Figure 4.3.12: PM emissions from Engelhard DPX equipped vehicles...........................95

Figure 4.3.13: PM emissions from Johnson-Matthey CRT equipped vehicles.................96 


\section{List of Tables}

Table 2.1: EPA Emissions Standards for Heavy Duty Diesel Engines (g/bhp-hr).............7

Table 2.2: Options for Engine Certification for $2004 \mathrm{NO}_{\mathrm{X}}$ Emissions.................................7

Table 4.1.1: Vehicles Tested for Cold Start DPF Performance Evaluation.......................46

Table 4.2.1: Vehicle Test Matrix for Durability Study..................................................61

Table 4.2.2: Fuel Properties for CARB, ECD, and ECD1 Diesel as Reported by the US Department of Energy Office of Transportable Technologies.............62

Table 4.3.1: Vehicle Information from General Performance Evaluation........................82 


\section{Nomenclature}

\begin{tabular}{|c|c|}
\hline$A C$ & Alternating Current \\
\hline ADC & Analog to Digital Converter \\
\hline BDL & Below Detectable Limits \\
\hline CARB & California Air Resources Board \\
\hline CBD & Central Business District \\
\hline CFR & Code of Federal Regulations \\
\hline CFV & Critical Flow Venturi \\
\hline $\mathrm{CO}$ & Carbon Monoxide \\
\hline $\mathrm{CO}_{2}$ & Carbon Dioxide \\
\hline CRT & Johnson-Matthey Continuously Regenerating Technology \\
\hline CSHVR & City-Suburban Heavy Vehicle Route \\
\hline DC & Direct Current \\
\hline DE & Diesel Exhaust \\
\hline DF & Dilution Factor \\
\hline DOC & Diesel Oxidation Catalyst \\
\hline DPF & Diesel Particulate Filter \\
\hline DPX & Engelhard Diesel Particulate Filter \\
\hline ECD & Emission Control Diesel \\
\hline ECM & Engine Control Module \\
\hline EGR & Exhaust Gas Recirculation \\
\hline EPA & United States Environmental Protection Agency \\
\hline EUI & Electronic Unit Injection \\
\hline FTP & Federal Test Procedure \\
\hline g/bhp-hr & grams per brake horsepower-hour \\
\hline GPS & Global Positioning System \\
\hline GVWR & Gross Vehicle Weight Rating \\
\hline $\mathrm{HC}$ & Hydrocarbon \\
\hline $\mathrm{HCO}$ & High Level Carbon Monoxide \\
\hline HFID & Heated Flame Ionization Detector \\
\hline LCO & Low Level Carbon Monoxide \\
\hline LED & Light Emitting Diode \\
\hline MPG & Miles Per Gallon \\
\hline NDIR & Non-Dispersive Infrared Analyzer \\
\hline NMHC & Non-Methane Hydrocarbon \\
\hline $\mathrm{NO}_{2}$ & Nitrogen Dioxide \\
\hline NO & Nitric Oxide \\
\hline NOx & Oxides of Nitrogen \\
\hline NREL & National Renewable Energy Laboratory \\
\hline NYCDOS & New York City Department of Sanitation \\
\hline $\mathrm{PAH}$ & Polyclic Aromatic Hydrocarbon \\
\hline PM & Particulate Matter \\
\hline QCS & Quiescent Combustion System \\
\hline RMS & Root Mean Square \\
\hline SCR & Selective Catalytic Reduction \\
\hline SMD & Sauter Mean Diameter \\
\hline
\end{tabular}


SOF

TEOM

Translab

USDOE

VOC

WCTA

WMATA

WVU
Soluble Organic Fraction

Tapered Element Oscillating Microbalance

WVU Transportable Heavy-Duty Vehicle Emissions Testing Laboratory

United States Department of Energy

Volatile Organic Compound

Westchester Count Transit Authority

Washington Metropolitan Area Transit Authority

West Virginia University 


\section{Chapter 1 - Introduction}

Diesel engines are well known for durability, excellent fuel economy, and unmatched torque generation at low engine speeds. For these reasons, diesel engines have long been the workhorses of the commercial transit and freight industries. Over 95 percent of all transit buses and virtually all over-the-road tractors on the road today are equipped with diesel engines (Kilcarr, 2001).

Despite their overwhelming popularity and widespread use, diesel engines face an uncertain future as emissions regulations become ever more stringent. The United States Environmental Protection Agency (EPA) has listed diesel exhaust emissions as a "cancercausing carcinogen". The EPA, California Air Resources Board (CARB), and various other international regulatory agencies have been regulating diesel exhaust emissions, particularly carbon monoxide, hydrocarbons, oxides of nitrogen, and particulate matter, for several decades in order to protect the environment and human health. These regulations have forced engine manufacturers to greatly reduce engine-out emissions through optimization of internal engine designs. However as reductions gained through continued design improvements began to stabilize, it was realized that exhaust aftertreatment might be the only way to meet or exceed the fast approaching 2007 EPA emissions standards. Chapter 2 of this thesis, the Literature Review, contains a review of existing and future emissions standards and techniques engine manufacturers have used to optimize engine designs to minimize engine out emissions.

Many types of aftertreatment devices have been developed for application to heavy-duty diesel engines, however the most popular of these devices are diesel oxidation catalysts and diesel particulate filters. Diesel oxidation catalysts, or DOCs, 
greatly reduce carbon monoxide and hydrocarbons, however they have little effect on oxides of nitrogen $\left(\mathrm{NO}_{\mathrm{X}}\right)$ and particulate matter $(\mathrm{PM})$, although the soluble organic fractions in the PM are reduced. These and other aftertreatment systems are discussed in Chapter 2 - Literature Review.

Diesel particulate filters, or DPFs, significantly reduce emissions of carbon monoxide, hydrocarbons, and particulate matter; yet still have little effect on total $\mathrm{NO}_{\mathrm{X}}$. Although total $\mathrm{NO}_{\mathrm{X}}$ emissions remain virtually unchanged, $\mathrm{NO}$ is reduced by conversion to $\mathrm{NO}_{2}$. The resultant $\mathrm{NO}_{2}$ produced is used to aid in the oxidation of the particulate matter that is collected on the internal filter walls. Although $\mathrm{NO}_{2}$ is reduced, $\mathrm{NO}$ and $\mathrm{NO}_{2}$ are not independently regulated by the EPA or CARB.

The main objective of this thesis was to investigate the operational performance of diesel particulate filters. To accomplish this, three aspects were investigated: cold start performance, durability, and general performance with a comparison of two DPF styles. The DPF styles studied were the Engelhard DPX and the Johnson-Matthey CRT. The Johnson-Matthey Corporation claims their CRT reduces particulate matter, hydrocarbon, and carbon monoxide emissions by greater than $90 \%$ while reducing $\mathrm{NO}_{\mathrm{X}}$ levels by $5-10 \%$. For passive regeneration, the CRT requires an exhaust temperature of greater than $260^{\circ} \mathrm{C}\left(500^{\circ} \mathrm{F}\right)$ for a minimum of $40 \%$ of the operating time and a $\mathrm{NO}_{\mathrm{X}} / \mathrm{PM}$ ratio of at least 20. Additionally, the Johnson-Matthey CRT requires less than $15 \mathrm{ppm}$ sulfur fuel and requires general maintenance and cleaning between every 60,000 and 100,000 miles (Johnson-Matthey, 2001).

The Engelhard Corporation claims their diesel particulate filter, the DPX, can reduce particulate matter, carbon monoxide, and hydrocarbon emissions by up to $90 \%$. 
Additionally, they claim the DPX regenerates within normal diesel operating temperatures and does not require low sulfur fuel. Engelhard makes no claims to $\mathrm{NO}_{\mathrm{X}}$ reductions and does not specify a routine maintenance schedule (Engelhard, 2002).

Each of the three investigation areas within the scope of this thesis had individual objectives. The intended purpose of performing cold start testing was to determine an approximate light-off temperature for the catalyst within the DPF, to quantify the general performance of the DPF before this light-off temperature was reached, and to determine if white smoke emissions were reduced by the DPFs. The durability study was performed in order to estimate the life cycle of each particulate filter type and to determine if a relation exists between DPF performance and accumulated vehicle mileage. The general performance study and product comparison was performed to evaluate the overall performance of the diesel particulate filters being tested and to determine if the corporate claims to performance were reasonable.

All tests for this evaluation were performed using the West Virginia University Transportable Heavy-Duty Vehicle Emissions Testing Laboratory (Translab). It is known that chassis dynamometer testing more accurately simulates "real world" engine emissions than does engine dynamometer testing, as engine dynamometer testing does not account for losses due to transmissions, differentials, and vehicle accessories, nor does it mimic engine transients sufficiently well. Details of the WVU Transportable Heavy-Duty Vehicle Emissions Testing Laboratory are given in Chapter 3 of this thesis, Experimental Procedures and Equipment.

Test vehicles for this evaluation included transit buses, over-the-road tractor trucks, and refuse trucks taken from five independent fleets. The fleets included West 
Virginia University (WVU), the Washington Metropolitan Area Transit Authority (WMATA), the Westchester County Transit Authority (WCTA), the New York City Department of Sanitation (NYCDOS), and Ralph's Grocery fleet in Riverside, California. Multiple driving schedules were utilized through out this testing. Most driving schedules were cycles or routes developed to simulate the duty cycle of a specific fleet, although some driving schedules were standard cycles, such as the Central Business District (CBD) cycle. Details pertaining to the test vehicles, the driving schedules, and experimental results are given in Chapter 4 of this thesis, Test Vehicles, Driving Schedules, and Results. Conclusions drawn from this data about the performance of diesel particulate filters are shown in Chapter 5 - Conclusions. 


\section{Chapter 2 - Literature Review}

\subsection{Introduction}

Diesel engines have long been known for their fuel economy and reliability. For these reasons, they have become the workhorses of the commercial trucking industry. Diesel engines are used to power the transportation of $94 \%$ of all freight shipped in the United States, and $95 \%$ of all transit buses and heavy construction equipment are diesel powered (Kilcarr, 2001).

In spite of this, diesel exhaust emissions have been found to have a great environmental impact and continue to be of concern to state, federal, and international air quality agencies. In 1998, the California Air Resources Board, or CARB, designated diesel particulate matter to be a toxic air contaminant (Chandler, et al., 2002). In the 2002 Health Assessment Document for Diesel Exhaust, the United States Environmental Protection Agency (EPA) listed diesel exhaust as a cancer causing carcinogen, finding “considerable evidence demonstrating an association between DE (diesel exhaust) exposure and increased lung cancer risk among workers in varied occupations where diesel engines historically have been used."

In this same report, the EPA listed the major gaseous components of diesel exhaust as carbon dioxide, oxygen, nitrogen, water vapor, carbon monoxide, nitrogen compounds, sulfur compounds, and numerous molecular weight hydrocarbons, including, but not limited to, aldehydes, benzene, 1,3-butadiene, polyclic aromatic hydrocarbons (PAHs), and nitro-PAHs. Additionally, diesel particulate matter was defined as solid particles having a center core of elemental carbon and absorbed organic compounds, as well as small amounts of sulfate, nitrate, metals, and other trace elements (EPA, 2002). 


\subsubsection{Emissions Standards}

Emissions regulation first began in 1955 with the passage of the Air Pollution Control Act of 1955. This was followed by the passage of various legislation throughout the 1960's, which included the creation of the 13 mode gaseous emissions cycle and the development of the first smoke standards (Richards and Sibley, 1988). The legislation increase of the 1960's lead to creation of the United States Environmental Protection Agency, EPA, through the Clean Air Act of 1970.

In an effort to standardize emissions testing procedures, the EPA developed the Code of Federal Regulations, Title 40: Protection of Environment, Part 86: Control of Emissions from New and In-Use Highway Vehicles and Engines (40CFR-PART 86). This document contains all of the testing procedures which must be followed by an emissions testing facility, as well as all federally mandated emissions standards.

The EPA has specified four diesel emissions components for regulation. They are carbon monoxide (CO), hydrocarbon (HC or NMHC for Non-Methane Hydrocarbon), oxides of nitrogen $\left(\mathrm{NO}_{\mathrm{X}}\right)$, and particulate matter $(\mathrm{PM})$. The present and future emissions standards are shown in Table 2.1. Emissions standards apply to an engine based on its original manufacture model year. The EPA mandates that all emissions must be reported in units of grams per brake horsepower-hour (g/bhp-hr). 
Table 2.1: EPA Emissions Standards for Heavy Duty Diesel Engines (g/bhp-hr) (Dieselnet, 2002)

\begin{tabular}{|c|c|c|c|c|}
\hline Year & H C & Co & $\mathrm{NO}_{\mathrm{x}}$ & $\mathbf{P M}$ \\
\hline \multicolumn{5}{|c|}{ Heavy-Duty Diesel Truck Engines } \\
\hline 1988 & 1.3 & 15.5 & 10.7 & 0.60 \\
\hline 1990 & 1.3 & 15.5 & 6.0 & 0.60 \\
\hline 1991 & 1.3 & 15.5 & 5.0 & 0.25 \\
\hline 1994 & 1.3 & 15.5 & 5.0 & 0.10 \\
\hline 1998 & 1.3 & 15.5 & 4.0 & 0.10 \\
\hline 2004 & \multicolumn{4}{|c|}{${ }^{*}$ See note * } \\
\hline 2007 & 0.14 & 15.5 & 0.2 & 0.01 \\
\hline \multicolumn{5}{|c|}{ Urban Bus Engines } \\
\hline 1991 & 1.3 & 15.5 & 5.0 & 0.25 \\
\hline 1993 & 1.3 & 15.5 & 5.0 & 0.10 \\
\hline 1994 & 1.3 & 15.5 & 5.0 & 0.07 \\
\hline 1996 & 1.3 & 15.5 & 5.0 & $0.05^{*}$ \\
\hline 1998 & 1.3 & 15.5 & 4.0 & $0.05^{*}$ \\
\hline 2004 & \multicolumn{4}{|c|}{${ }^{*}$ See note } \\
\hline 2007 & 0.14 & 15.5 & 0.2 & 0.01 \\
\hline
\end{tabular}

* - in-use PM standard 0.07

*note The 2004 emissions standard called for a reduction in $\mathrm{NO}_{\mathrm{X}}$ emissions, however two options are available for certification. These options are shown in Table 2.2. Again, all data is shown in $\mathrm{g} / \mathrm{bhp}-\mathrm{hr}$.

Table 2.2: Options for Engine Certification for $2004 \mathrm{NO}_{\mathrm{X}}$ Emissions (Dieselnet, 2002)

\begin{tabular}{|c|c|c|}
\hline o p tio & N $\begin{array}{c}\text { M C } \\
\text { N }\end{array}$ & N M H C \\
\hline 1 & 2.4 & $n / a$ \\
\hline 2 & 2.5 & 0.5 \\
\hline
\end{tabular}

The $2007 \mathrm{NO}_{\mathrm{X}}$ and NMHC standards are to be phased in on a percent-of-sales basis. Fifty percent for each from 2007 to 2009 and reaching 100\% compliance by 2010 . The 2007 PM standard will take immediate effect in 2007 (Dieselnet, 2002).

\subsubsection{Cold Start Emissions and White Smoke}

Cold start emissions concentrations, especially white smoke, hydrocarbons, and particulate matter, can vary significantly from emissions concentrations from a 
sufficiently warmed-up engine. These emissions need to be controlled in order to meet future emissions standards (Yassine, et al., 1996).

White smoke, often appearing as a white or blue haze in direct sunlight, consists of a mixture of fuel and lubricating oil particles in an unburned or partially burned state. The blue component is a result of excess lubricating oil in the combustion chamber caused by engine wear such as deteriorating piston rings or worn valve guides. The white component consists mainly of unburned hydrocarbons resulting from low gas temperatures in the combustion chamber during cold starts.

Black/gray smoke is essentially composed of carbon particles resulting from incomplete combustion of fuel. Incomplete combustion is often a result of an excessively rich condition caused by malfunctioning or dirty fuel injectors, restricted airflow into the engine, or from excessive cranking during cold start-up.

During engine start-up, fuel is injected into the combustion chambers during misfire cycles while the engine is being cranked by the starter motor. This fuel accumulates on the cylinder walls and piston bowls until the in-cylinder temperature reaches the combustion temperature of the fuel and combustion occurs. Upon combustion, the high temperature of the combustion products increases the rate of evaporation of the accumulated fuel and causes high concentrations of fuel vapor emission, part of which condenses into white smoke (Yassine, et al., 1996).

Some of the hydrocarbons and particulates remaining after combustion might be oxidized during the expansion and exhaust strokes. The rate of oxidation is dependent on the gas temperature and local equivalence ratio. Under warm-up conditions, oxidation reactions can be effective in reducing $\mathrm{HC}$ concentrations. However, during cold start 
conditions, the oxidation reactions are not effective due to the low in-cylinder temperatures (Yassine, et al., 1996).

$\mathrm{NO}_{\mathrm{X}}$ emissions can also be affected under cold start conditions, particularly in engines which have advanced timing when cold. By lengthening the ignition delay, timing advancement can cause an increase in $\mathrm{NO}_{\mathrm{X}}$ levels while other emission species remain relatively affected (Heywood, 1988).

\subsection{Diesel Engine Technology}

In efforts to control engine-out emissions in order to meet the new more stringent standards, engine manufacturers and researchers have made design changes to both engine designs, such as combustion chamber configuration, and to the design of many engine components, including fuel injectors and turbochargers.

\subsubsection{Improved Combustion Chamber Design}

Combustion chamber modifications are crucial to increasing the performance of a diesel engine, from an emissions standpoint as well as a reliability issue. Engine designers have at their disposal technological and computational advancements never before seen in the industry. These include computers and computer models which aid in testing, modeling, and optimization of new designs. These modifications and optimizations, which include reducing oil consumption, increasing the compression ratio, and improving combustion, are responsible for lowering both gaseous and particulate emissions.

\subsubsection{Reduced Oil Consumption}

Engine lubricating oil which remains on the cylinder walls during the expansion stroke, or oil which is otherwise introduced into the combustion chamber, can 
significantly influence engine-out PM emissions. Precision bore honing and enhanced piston ring designs can considerably reduce the amount of lubrication oil consumed during the expansion stroke, however modifications of this nature must be made very carefully as too little oil remaining on the cylinder walls can have a detrimental effect on engine reliability (Browning, 1997). For this reason, other mechanical components, such as valve guides, valve guide seals, and turbocharger seals, should be investigated for reducing oil consumption.

Another design aspect that should be addressed in an effort to reduce oil consumption is bore distortion. Bore distortion is a result of localized distortions caused by thermal and mechanical expansion of the cylinder walls due to the internal temperatures and pressures inside the combustion chamber. To prevent or cure bore distortion, significant and costly changes may be required in the cylinder block, cylinder sleeve, and cylinder head gasket designs. For this reason, this design aspect should be addressed in the early design stages of a new engine and is not a suitable area for retrofits to existing engines (Zelenka, et al., 1990).

\subsubsection{Increased Compression Ratio}

Increasing the compression ratio in a diesel engine has many favorable results. The increased compression ratio reduces the ignition delay period, thus reducing the amount of fuel burned in the premixed region and allowing increased injection timing retard. The increased injection timing retard allows for greater control over $\mathrm{NO}_{\mathrm{X}}$ production.

Additionally, an increased compression ratio increases the combustion temperature, thus reducing cold start PM and white smoke production. High compression 
ratios are most beneficial under a high speed / light load condition when ignition delay is the longest and under cold operating conditions (Browning, 1997).

\subsubsection{Improved Combustion}

There are two methods for improving combustion characteristics through intake air motion. They are intake swirl and quiescent combustion. Intake swirl focuses on forcing rotational motion in the intake air to increase air/fuel mixing and fuel atomization. The resultant completeness of combustion lowers PM output, allowing designers to take a more aggressive approach in reducing $\mathrm{NO}_{\mathrm{X}}$.

Quiescent combustion has been used in marine diesel applications where fuel consumption is of the utmost importance. Mitsubishi Motors Corporation has been working on an improved quiescent combustion system (QCS) for on-road heavy-duty diesel applications. This system does not rely on air motion to promote fuel atomization, but rather fuel spray momentum with a high-pressure fuel injection system. Engineers investigated both fuel system requirements, which will be discussed later in this thesis, and combustion chamber geometry in order to optimize the fuel efficiency and emissions production of this system.

After much calculation and modeling, researchers from Mitsubishi Motors Corporation decided that the optimum combustion chamber geometry was a largediameter toroidal type combustion chamber with a low swirl ratio. The low swirl ratio is associated with a smaller pressure loss across the intake port and had a higher flow coefficient, therefore the air flow could be enhanced and fuel consumption reduced. The large diameter bowl helped to prevent fuel spray from impinging on the cylinder walls prior to ignition, resulting in lower black smoke and $\mathrm{HC}$ emissions. It was also shown 
that a larger radius in the combustion chamber bottom (the piston bowl) is associated with lower smoke emissions under the low load condition. Thus implying that the fuel being injected into the chamber is being spread-out over the entire combustion chamber and burned more completely (Mori, et al., 2000)

\subsubsection{Improved Fuel Injection}

Fuel injection parameters can greatly impact the combustion process. Injection delay and air/fuel mixing can be affected by injection timing, pressure, duration, and rate, consequently having a large effect on engine-out emissions. In efforts to optimize the fuel injection systems, manufacturers will continue to investigate nozzle geometry, multiple injection and rate shaping, and electronic unit injection.

\subsubsection{Nozzle Geometry}

Nozzle hole diameter, the number of nozzle holes, spray angle, and the Sauter Mean Diameter are all important aspects to consider when reviewing nozzle geometry.. The Sauter Mean Diameter $\left(\mathrm{SMD}\right.$ or $\left.\mathrm{D}_{\mathrm{SM}}\right)$ is the diameter of the fuel droplet that has the same surface/volume ratio as the entire spray volume and is related to the atomization of the fuel. Hiroyasu and Kadota developed equation 2.1 as an empirical expression for the SMD.

$$
D_{S M}=A(\Delta p)^{-0.135} \rho_{a}^{0.121} V_{f}^{0.131}
$$

where $\Delta \mathrm{p}$ is the mean pressure drop across the nozzle, $\rho_{\mathrm{a}}$ is the density of the intake air, $\mathrm{V}_{\mathrm{f}}$ is the volume of fuel delivered per cycle per cylinder, and $\mathrm{A}$ is a nozzle dependent constant (23.9 for hole nozzles) (Heywood, 1988).

Researchers from the University of Wisconsin-Madison and Caterpillar Inc. found that the injection spray angle was directly related to the SMD and to $\mathrm{NO}_{\mathrm{X}}$ and $\mathrm{PM}$ 
formation. They found that a larger injection angle produces a narrower spray angle and a larger overall average SMD. Also, they found that the injection angle is proportional to $\mathrm{NO}_{\mathrm{X}}$ formation, yet has little effect on PM emission (Su, et al., 1995).

Similarly, a relation exists between nozzle hole size, hole number, and injection pressure. Small nozzle hole sizes, used in conjunction with high injection pressures, produce a small overall average SMD and reduce particulate emissions significantly. It was also shown that as injection pressure increases, $\mathrm{NO}_{\mathrm{X}}$ formation increases at almost the same rate. However, if the injection duration is extended while using a small hole diameter nozzle, the $\mathrm{NO}_{\mathrm{x}}$ production is decreased. Additionally, the number of nozzle holes should be matched to the fuel injection pressure and combustion chamber geometry to best utilize the intake air for fuel atomization (Browning, 1997; Mori, et al., 2000; Su, et al., 1995).

\subsubsection{Multiple Injections and Rate Shaping}

Rate shaping is a process used to optimize combustion and reduce emission production by manipulating the rate at which fuel is injected into the cylinder. The amount of fuel injected at the onset of injection is decreased to reduce $\mathrm{NO}_{\mathrm{X}}$ formation. The latter portion of injection is characterized by a fast injection rate, for particulate control, as the piston approaches top-dead-center and the highest combustion temperatures are reached. This method of rate shaping is known as pilot injection and has shown $50 \%$ reductions in ignition delay, allowing increased injection timing retard and good combustion stability (Khair, 1997).

A different approach to rate shaping employs multiple or split injections.

Multiple injections have been shown to simultaneously reduce $\mathrm{NO}_{\mathrm{X}}$ and $\mathrm{PM}$ emissions by 
$15 \%$ and $40 \%$ respectively. These results were demonstrated in the previously mentioned study performed by the University of Wisconsin-Madison and Caterpillar Inc. using a setup characterized by a double injection of $50 \%$ of fuel mass evenly distributed to two injections separated with a $10^{\circ}$ crank angle dwell (Su, et al., 1995).

\subsubsection{Electronic Unit Injection}

Electronic unit injection (EUI) possesses the ability to achieve high injection pressures, in the 1400-1900 bar range, and can specify injection parameters such as start of injection, injection duration, and rate shaping as a function of engine speed and load. These systems are often mechanically driven from the camshaft or fully electronically controlled by the engine control module. Electronically controlled common rail systems offer the advantage over the mechanical systems of being independent of engine speed, however they often have lower overall peak injection pressures.

The high injection pressure offered by these systems aid in fuel atomization and completeness of combustion, resulting in reductions in particulate emissions. However, the increased injection pressures often increase the accessory loading on the engine. In spite of this, it is felt that the improved combustion due to the higher injection pressures should counter this effect and result in no net increase in brake specific fuel consumption (Browning, 1997).

\subsubsection{Turbocharger Improvements}

Turbochargers have been proven to improve engine performance and brake horsepower without adversely affecting fuel consumption or emissions. Technological advancements in turbocharger design, including two-stage turbocharging and variable geometry turbocharging, have increased effectiveness in providing leaner air/fuel ratios 
under full load conditions and improving transient response at lower loads and speeds (Browning, 1997).

Researchers at the University of Wisconsin-Madison are also looking into the effects of boost pressure on emissions reductions. They have found that optimizing boost pressure leads to significant improvements in brake specific fuel consumption and particulate emissions. The decrease in particulate emissions is accredited to the increased availability of air for soot oxidation at elevated intake pressures from increased boost levels. It should be noted that the decrease in PM emissions was accomplished while holding brake specific $\mathrm{NO}_{\mathrm{X}}$ constant. It should also be noted that there exists a point at which boost pressures is optimized, and continued increase of boost pressures has a detrimental effect on particulate emissions as a result of reduced liquid spray and vapor penetration lengths within the combustion chamber (Tanin, et al., 1999).

\subsection{Exhaust Aftertreatment}

In spite of the advances in diesel engine design, manufacturers are looking to after-treatment to bring the emission levels to within acceptable limits. As emission regulations become more stringent, especially for $\mathrm{NO}_{\mathrm{X}}$ and $\mathrm{PM}$ emissions, aftertreatment will be the only way to build certifiable engines. There are numerous types of aftertreatment systems including diesel oxidation catalysts, lean $\mathrm{NO}_{\mathrm{X}}$ catalysts, selective catalytic reduction, exhaust gas recirculation, non-thermal plasma catalysts, and diesel particulate filters (Johnson, 2002). Each system has advantages and disadvantages which must be weighted before selecting an after-treatment system, however their use is inevitable. 


\subsubsection{Oxidation Catalysts}

Diesel oxidation catalysts (DOC) were once the premier choice for diesel exhaust after-treatment, however with ever tightening emissions standards, they are quickly becoming obsolete. DOCs are very effective in reducing $\mathrm{CO}, \mathrm{HC}$, aldehydes, and the soluble organic fraction (SOF), however they have little effect on $\mathrm{NO}_{\mathrm{x}}$ and limited effect on particulate emissions (Zelenka, et al., 1990). Additionally, oxidation catalysts produce sulfates through the oxidation of $\mathrm{SO}_{2}$ when exhaust temperatures exceed the $400^{\circ}$ centigrade unless fuel sulfur content is kept to a minimum; this drawback is quickly lessening in importance with the introduction and mandated use of ultra-low sulfur diesel fuel by 2006 .

In a study performed in Europe, diesel oxidation catalysts were shown to greatly reduce $\mathrm{HC}, \mathrm{CO}$, and formaldehyde emissions by $86 \%, 93 \%$, and $81 \%$ respectively. However, this study also demonstrated the DOCs lack of ability to substantially reduce particulate matter and $\mathrm{NO}_{\mathrm{X}}$ emission. PM was reduced by a mere $17 \%$ when using Swedish Class 1 fuel without sulfur and 19\% when the same fuel was doped to $0.05 \mathrm{wt} \%$ sulfur. No measurable $\mathrm{NO}_{\mathrm{X}}$ reduction was reported with either fuel (Hammerle, et al., 1995).

With the sizable emission reductions in $\mathrm{HC}, \mathrm{CO}$, and aldehydes, DOCs are good candidates for after-treatments systems when combined with another form of aftertreatment or with fuel-borne catalysts. A study performed by the Southwest Research Institute saw PM reductions from $0.073 \mathrm{~g} / \mathrm{bhp}-\mathrm{hr}$ to $0.042 \mathrm{~g} / \mathrm{bhp}-\mathrm{hr}$, a $42 \%$ reduction, using a fuel-borne catalyst. However this study also reported that for a diesel oxidation 
catalyst to be most effective, it must be approximately equal in volume to the engine displacement, meaning that for large diesel engines, the catalyst would be quite large and cumbersome (Khair \& McKinnon, 1999).

\subsubsection{Lean $\mathrm{NO}_{\mathrm{X}}$ Catalysts}

Lean $\mathrm{NO}_{\mathrm{X}}$ catalysts provide a catalytic reduction of $\mathrm{NO}_{\mathrm{X}}$ through a lean-fuel environment. Copper zeolite catalysts use hydrocarbons in the exhaust stream to reduce $\mathrm{NO}_{\mathrm{X}}$ emission at high temperatures, ranging from 425 to 550 degrees centigrade. This system has two major problems: 1) the system requires a significant amount of hydrocarbons in the exhaust stream to reduce NO substantially, approximately an $\mathrm{HC}$ to NO ratio of 4 to 1. 2) The system is very sensitive to sulfur poisoning from the absorption of $\mathrm{SO}_{2}$ and water inhibition (Browning, 1997). It has been determined that sulfur degrades the oxygen storage media, which in turn inhibits the formation of hydrogen in the water gas shift reaction. This, in turn, greatly detracts from the lean $\mathrm{NO}_{\mathrm{X}}$ catalyst's efficiency and requires a desulfation process to recover some of the lost efficiency. The catalysts never fully regenerate to $100 \%$ capacity, thus suggesting that they have a finite life (Johnson, 2002).

Another type of lean $\mathrm{NO}_{\mathrm{X}}$ catalyst utilizes a platinum based catalyst. This system operates at a lower temperature than the previously discussed system (200 to 300 degrees centigrade) and requires less $\mathrm{HC}$ to reduce the $\mathrm{NO}_{\mathrm{X}}$ (a 2 to 1 ratio). However, the platinum in this system produces sulfates from the fuel sulfur, increasing the particulate matter emission (Browning, 1997).

The significant problem with any lean $\mathrm{NO}_{\mathrm{X}}$ catalyst is the need for large amounts of hydrocarbons. Three systems have been developed to supplement the exhaust stream 
with the necessary HC's. The first strategy is to place an additional fuel injector into the exhaust pipe up-stream of the catalyst and inject diesel fuel directly into the exhaust stream. This system, however, encourages tampering since removal of the injector would not influence engine performance and would enhance fuel economy. Some promise has been shown utilizing this injection method, but substituting urea for the diesel fuel injected into the exhaust. This urea system has shown $\mathrm{NO}_{\mathrm{X}}$ reduction of 69 to $84 \%$ depending on the testing cycle being utilized (Hammerle, et al., 1995). The urea being injected does however pose its own set of drawbacks which will be discussed in section 2.3.3 - Selective Catalytic Reduction.

The second method of fuel supplementation is to increase the fuel volume being injected into combustion chamber during the normal injection process. Although potential tampering of this method is much less, large fuel penalties and increased $\mathrm{HC}$ emissions are likely.

The third, and most feasible, method is to inject additional fuel into the cylinder during the exhaust stroke. A more complex electronic fuel injection system would be needed to accomplish this method of fuel supplementation. It is estimated that a five percent increase in fuel consumption would be necessary to provide enough hydrocarbons for sufficient $\mathrm{NO}_{\mathrm{X}}$ reduction (Browning, 1997).

\subsubsection{Selective Catalytic Reduction}

Selective Catalytic Reduction (SCR) is an after-treatment system commercially applied to stationary diesel installations. It is being researched as a possible on-road method of reducing $\mathrm{NO}_{\mathrm{X}}$ production from heavy-duty diesel vehicles. This system injects ammonia in the form of a urea solution into the raw exhaust in order to 
supplement the exhaust hydrocarbons (Khair, 1997). The ammonia injection forces the chemical reactions necessary for the nitrogen oxides in the exhaust to convert to harmless nitrogen and water. The process has demonstrated $\mathrm{NO}_{\mathrm{X}}$ reductions as high as $90 \%$ in both the EPA's Federal Test Procedure (FTP) cycle and the New European Driving Cycle (Auto Emissions Magazine, Fall 1999).

SCR systems, in combination with diesel particulate filters, have also shown promise in simultaneously reducing diesel particulate matter and $\mathrm{NO}_{\mathrm{X}}+\mathrm{NMHC}$ (NonMethane Hydrocarbon) emissions. Southwest Research Institute reported PM emissions of $0.01 \mathrm{~g} / \mathrm{bhp}-\mathrm{hr}$ and $\mathrm{NO}_{\mathrm{X}}+\mathrm{NMHC}$ emissions of $1.1 \mathrm{~g} / \mathrm{bhp}-\mathrm{hr}$ using $368 \mathrm{ppm}$ sulfur fuel, an $86 \%$ and $73 \%$ reduction over the baseline measurements respectively. These data were recorded while testing a 1998 Detroit Diesel Series 60 12.7L turbocharged engine rated at $400 \mathrm{hp}$ at $1800 \mathrm{rpm}$. Khair \& McKinnon, 1999).

As promising as this system appears, it is not without its drawbacks. SCR systems produce highly elevated levels of $\mathrm{N}_{2} \mathrm{O}$ when compared to a standard diesel and over injection of urea leads to ammonia emissions. Also, vehicles utilizing an SCR system would have to be equipped with a bulky urea storage tank, on-board monitoring system, and precise control to avoid ammonia slip. Additionally, the urea solution utilized by this system is not commercially available at every refueling station and would require a large capital investment and infrastructure development in order to change this realization (Auto Emissions Magazine, Fall 1999).

\subsubsection{Exhaust Gas Recirculation}

Exhaust gas recirculation (EGR) has been around for many years in spark ignition applications and is, in fact, the principle technique for $\mathrm{NO}_{\mathrm{X}}$ emission control in these 
applications. However, with the increasingly stringent $\mathrm{NO}_{\mathrm{X}}$ limits being imposed in heavy-duty diesel engines, engine manufacturers are developing a sophisticated EGR system for direct-injected heavy-duty diesel engines.

EGR systems recycle exhaust gases into the air intake where it acts as a heat sink reducing the peak combustion temperature. The heat absorbed by the recirculated exhaust gases is thought to be proportional to the EGR flow rate $(m)$, the specific heat at constant pressure $\left(C_{P}\right)$, and the temperature gradient $(\Delta t)$. This relation is shown in equation 2.2. (Heywood, 1988; Khair, 1997)

$$
Q=\dot{m} C_{P}(\Delta t)
$$

The second positive aspect of EGR is its ability to effectively lower $\mathrm{NO}_{\mathrm{X}}$ concentrations in the vehicle exhaust. The burned gases that are introduced into the air intake displace oxygen introduced with the fresh air charge. $\mathrm{NO}_{\mathrm{X}}$ is formed as a function of nitrogen $\left(\mathrm{N}_{2}\right)$, oxygen $\left(\mathrm{O}_{2}\right)$, combustion temperature, and residence time in the $\mathrm{NO}_{\mathrm{X}}$ formation environment. This relation is quantified in equation 2.3.

$$
\frac{d(N O)}{d t}=K_{1}\left(N_{2}, O_{2}\right)-K_{2}\left(N O, N O_{2}\right)
$$

where $\mathrm{K}_{1}$ and $\mathrm{K}_{2}$ are combustion temperature dependent reaction rate constants. Controlling any of these basic variables will have a great effect on $\mathrm{NO}_{\mathrm{X}}$ formation, therefore reducing the oxygen content in the fresh air intake charge through displacement with exhaust gas will substantially lower $\mathrm{NO}_{\mathrm{X}}$ formation. Additionally, with EGR cooling, the temperature differential term of equation 2.2 can be increased, thus increasing the EGR heat absorption capacity and further reduce $\mathrm{NO}_{\mathrm{X}}$ formation. (Khair, 1997) 
However, exhaust gas recirculation has an adverse effect on particulate formation. EGR reduces the combustion rate making stable combustion more difficult to achieve. The stability of combustion is inversely proportional to particulate formation. Thus, in order for EGR to be effective in all aspects of emission reduction, it must be utilized with some other form of after-treatment, most likely diesel particulate filters. (Heywood, 1988; Khair, 1997)

\subsubsection{Non-Thermal Plasma Catalysts}

Non-thermal plasma catalysts are an after-treatment system that is still in the experimental stages. In these systems, exhaust gases pass through an intense field of charged particles, a plasma field, and are dissociated and ionized into more reactive particles. These particles are easily catalyzed downstream. A pair of electrodes is used to generate the plasma field with at least one electrode covered by a dielectric barrier such as alumina. A high voltage alternating current $(\mathrm{AC})$ is placed across the electrodes causing the gas in the gap between them to break down resulting in the formation of discharge streamers. The streamers rapidly travel across the gap creating electrons with a mean energy of three to four electron volts $(\mathrm{eV})$. When the streamers reach the barrier, charge accumulates on the surface and cancels the electric field so that the streamers are extinguished. (Hoard, 2001)

The electrons released by the plasma discharge result in a radical chemistry between species resulting the dissociation of gases in the exhaust. The predominant dissociation that takes place is that of oxygen $\left(\mathrm{O}_{2}\right)$. This is shown in equation 2.4.

$$
\mathrm{O}_{2}+e^{-} \rightarrow \mathrm{O}+\mathrm{O}+e^{-}
$$


The oxygen dissociation is the primary initiator of the plasma exhaust chemistry because of its rapid reaction rate with the hydrocarbons (HC) present in the exhaust. These reactions are very similar to those initiated by ultra-violet radiation in the atmosphere. The hydrocarbon-oxygen reactions result in the formation of aldehydes, including formaldehyde $\left(\mathrm{CH}_{2} \mathrm{O}\right)$ and acetaldehyde $\left(\mathrm{CH}_{3} \mathrm{CHO}\right)$, peroxy radicals $\left(\mathrm{RO}_{2}\right)$, and hydroxyl radicals $(\mathrm{OH})$.

Nitric oxide (NO) is reacted with the compounds mentioned above to form $\mathrm{NO}_{2}$. Some examples of these reactions are shown in equations 2.5 and 2.6.

$$
\begin{gathered}
\mathrm{NO}+\mathrm{O} \rightarrow \mathrm{NO}_{2} \\
\mathrm{NO}+\mathrm{RO}_{2} \rightarrow \mathrm{NO}_{2}+\mathrm{RO}
\end{gathered}
$$

Oxides of nitrogen $\left(\mathrm{NO}_{\mathrm{X}}\right)$ do not get converted to $\mathrm{N}_{2}$, but rather, through the reactions shown above, $\mathrm{HC}$ is oxidized and $\mathrm{NO}$ is converted to $\mathrm{NO}_{2}$. The presence of $\mathrm{HC}$ reduces the plasma energy required for $\mathrm{NO}$ to $\mathrm{NO}_{2}$ conversion and greatly reduces acid formation. The presence of aldehydes and $\mathrm{HC}$ require an oxidation catalyst to be utilized downstream. (Hoard, 2001)

In addition to $\mathrm{NO}_{\mathrm{X}}$ conversion, plasma catalysts can also be utilized for particulate removal. Since the plasma creates $\mathrm{O}$ and $\mathrm{OH}$ radicals and converts $\mathrm{NO}$ to $\mathrm{NO}_{2}$, it can be expected that soot particles will also be oxidized provided they remain in the plasma for a sufficient period of time. To ensure this, a device, using a bed of catalyzed beads, mechanically/electrostaticly traps the soot particles in the plasma field. Laboratory experiments have shown that this greatly reduced the size of particles being released from the vehicle exhaust. (Hoard, 2001) 
Plasma catalysts systems have shown high $\mathrm{NO}_{\mathrm{X}}$ removal, as high as $80 \%$ when combined with a suitable oxidation catalysts, and high particulate removal rates. Additionally, they can function properly over a wide temperature range, 150 to 500 degrees Celsius. However, these systems have only been demonstrated in laboratory environments and are still much too large for practical use (Auto Emissions Magazine, Fall 1999). An additional drawback of these systems is the adverse effect on fuel economy, the large power consumption and need for additional HC's are expected to reduce fuel economy, however this, as of yet, has not been quantified. (Hoard, 2001)

\subsubsection{Diesel Particulate Filters}

Diesel particulate filters, or DPFs, are the main focus of this thesis. Particulate filters were first investigated in the 1970's and were characterized by wall flow trap element designs that force exhaust gases to flow through the porous walls of the filter element, depositing the solid matter on the walls. These early filters were actively thermally regenerated through the use of a heating system in order to maintain good performance and fuel economy. The complex regeneration system and sophisticated controls had a very high cost, and the entire unit was plagued with reliability issues.

The feasibility of these systems was largely in question until the introduction of catalyzed fuel and the mingling of catalytic material with the accumulated soot lowered the ignition temperature from the $600^{\circ} \mathrm{C}$ to as low as $300^{\circ} \mathrm{C}$ and below. This technological advancement made the development of passive regeneration systems possible (Khair, 1997).

The typical design of a passive regeneration system consists of an oxidation catalyst, often a proprietary platinum $(\mathrm{Pt})$ unit, upstream of a wall flow filter. The 
catalyst portion of the DPF oxidizes a portion of the NO present in the exhaust stream to form $\mathrm{NO}_{2}$. The $\mathrm{NO}_{2}$ is then utilized to fuel the combustion of the soot collected in the wall flow filter. It has been proven that $\mathrm{NO}_{2}$ combusts soot at a much lower temperature than does $\mathrm{O}_{2}$, thus allowing the filters to regenerate and completely destruct the soot within normal operating temperatures of the heavy-duty diesel exhaust stream (Allansson, et al., 2000). It should be noted that ash generated from the combustion of lube oil is not combusted by the DPF and needs to be periodically removed from the filter walls by back flushing with compressed air.

These systems are relatively compact and can be retrofitted into existing vehicles with very little modification to the vehicle. For this reason, DPFs are at the forefront of the after-treatment market. However, some DPF styles require the use of ultra-low sulfur fuel, less than $15 \mathrm{ppm}$ in some cases.

This thesis will look at two specific styles of diesel particulate filters, the Engelhard DPX and the Johnson-Matthey CRT ${ }^{\circledR}$. The Engelhard unit advertises reductions in particulate matter, soluble organic fractions, and $\mathrm{CO}$ and $\mathrm{HC}$ by $90 \%, 98 \%$, and $90 \%$ respectively. This unit does not require the use of ultra-low sulfur diesel fuel or additives and operates at normal diesel operating temperatures. This diesel particulate filter system utilizes a catalyzed filter element in place of the oxidation catalysts. (Engelhard, 2002).

The Johnson-Matthey CRT $^{\circledR}$ (Continuous Regenerating Technology) advertises reductions in $\mathrm{PM}, \mathrm{HC}$, and $\mathrm{CO}$ of greater than $90 \%$ and advertises $\mathrm{NO}_{\mathrm{X}}$ reductions in the order of five to ten percent. This DPF requires a minimum exhaust temperature of at least $260^{\circ}$ centigrade and an engine-out $\mathrm{NO}_{\mathrm{X}} / \mathrm{PM}$ ratio of greater than 20 for proper 
operation. The CRT also requires the use of ultra-low sulfur diesel fuel. This diesel particulate filter system utilizes a platinum $(\mathrm{Pt})$ based oxidation catalyst upstream of a wall flow filter element with a cell density of $200 \mathrm{cells} / \mathrm{in}^{2}$. (Johnson-Matthey, 2001). 


\section{Chapter 3 - Experimental Procedures and Equipment}

\subsection{The Transportable Lab}

All tests performed for this thesis were performed using the West Virginia University Transportable Heavy-Duty Vehicle Emissions Testing Laboratories, also known as the Translabs. This system was a complete in-vehicle engine emissions testing facility that could be set up in a location near the home base for operations of the fleet being tested.

Standard operating procedures for the WVU Translab called for a minimum of a four-man crew to be on site for testing, consisting of a field engineer, a gas operator, a safety monitor, and a vehicle diver.

Upon receipt of a vehicle, the Translab crew performed a safety inspection of the vehicle, which included inspection of the vehicle tires, engine and transmission fluid levels, and exhaust system, and recorded vehicle information, such as the vehicle identification number, tire size, engine model number, and engine identification number. After the vehicle had passed the inspections, it was installed on the chassis test bed.

As set forth in the Translab protocol, triplicate runs were performed for each emissions test. Additional repeat runs were performed if the coefficient of variation for $\mathrm{CO}_{2}$ and $\mathrm{NO}_{\mathrm{X}}$ emissions exceeded $5 \%$ or whenever deemed necessary by the field engineer. A minimum of three test runs were averaged for each regulated emissions result in order to alleviate variation in the data. Exceptions to this protocol were cold start tests; due to the time limitations involved with cold start testing, particularly the required 12 hour minimum period prior to the start of any cold start test as specified in 
the CFR (40 CFR-PART 86), a single run was accepted for cold start runs if the field engineer viewed it as valid.

\subsubsection{The Power Absorber Test Bed}

The WVU Translab test bed allowed stationary simulation of a vehicle driving cycle. It consisted of two sets of rollers, one set for each drive axle, which allowed the tires to spin as the vehicle was held stationary with chains attached to the test bed, and a dynamometer unit, which monitored vehicle speed and affected loading.

The vehicle being tested was connected to the dynamometer unit directly through the drive axle using specially designed aluminum wheel hub adapters. To facilitate the hub adapters, the outside set of drive wheels were removed and the adapters bolted on in their place. To prevent tire and vehicle damage on single axle vehicles, hydraulic jacks were positioned on scales and used to support approximately $50 \%$ of the rear axle curb weight, the amount of weight traditionally carried by the outside set of tires. Figure 3.1 shows the hub adapters installed on a transit bus. Note the above-mentioned support jack in the lower left corner of the photograph. 


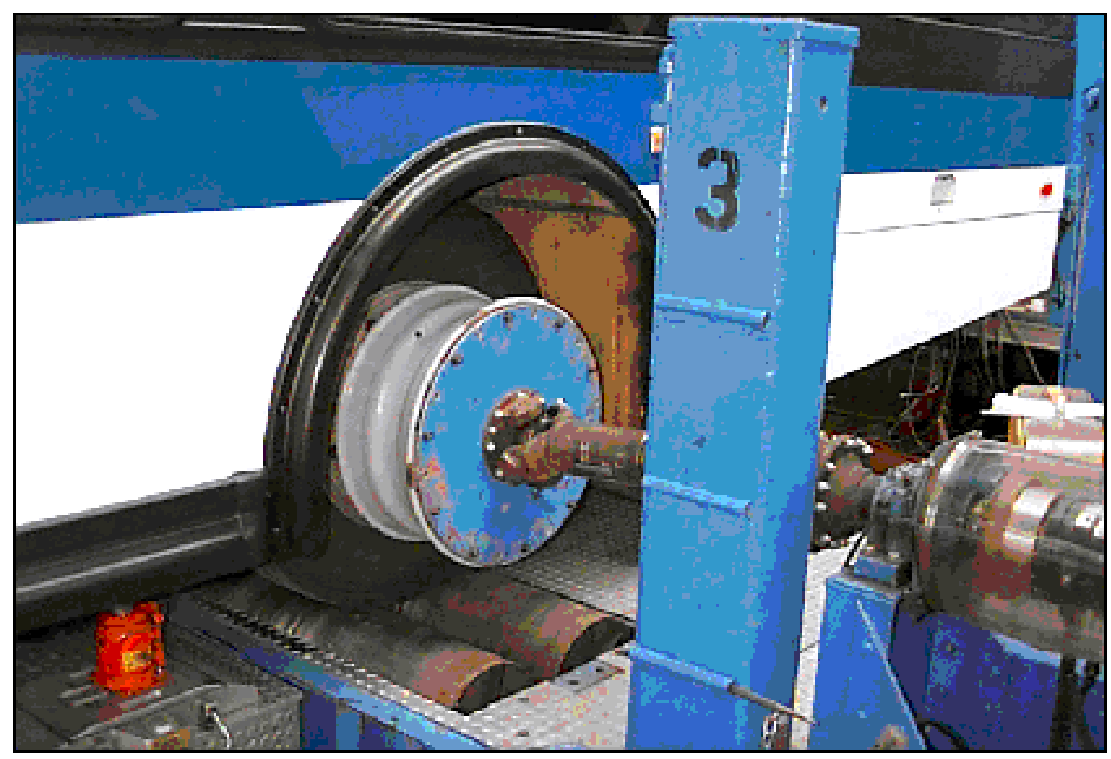

Figure 3.1: Hub adapters connecting the vehicle drive axle to the dynamometer unit of the Translab test bed.

The dynamometer unit consisted of speed and torque transducers, two power absorber units, and two sets of selectable flywheels. A Lebow torque and speed transducer was attached to each of the shafts connecting the hub adapters to the power absorber drivetrain. These transducers provided continuous speed and torque data to the computer and can be seen in the lower right corner of Figure 3.1.

The power absorber units were used to apply load to the vehicle during the test cycle in order to simulate road conditions and assist with braking. The power absorbers used were Mustang Dynamometer eddy current absorbers. They operate by applying a DC current to the stationary field coils of the absorber, thus creating a magnetic field. The iron rotors, which were connected to the drivetrain, rotated in this magnetic field generating eddy currents. These eddy currents produce a resultant force opposite to the direction of rotary motion. The Mustang Dynamometers can produced a maximum continuous load of 250 h.p. with a torque of 390 lb. ft. (Bata, et al., 1991). 
The sets of selectable flywheels were used to simulate vehicle inertia. Using the flywheels, an inertial load equal to the approximate vehicle test weight was applied. The inertial load could be applied in 250-pound increments, to a maximum of 60,000 pounds, by engaging any number of the eight steel flywheel disks in one of the 256 different combinations. These disks were bearing mounted on a solid steel shaft and were engaged using one of the four driving rotors (two flywheel disks per driving rotor, one located on either side). The flywheel settings, and corresponding inertial load, were determined using the tire size and gross vehicle weight in order to compensate for rolling resistance and vehicle momentum respectively. This was done using the method of equivalent energy where: (Bata, et al., 1991)

$$
\begin{aligned}
& K E_{\text {Flywheels }}=K E_{\text {Vehicle }}-K E_{\text {Syetem }} \\
& \frac{1}{2} I_{f} \omega^{2}=\frac{1}{2} m V^{2}-\frac{1}{2} I_{S} \omega^{2} \\
& I_{f}=\frac{m}{\omega^{2}} V^{2}-I_{S}
\end{aligned}
$$

Where:

$$
\begin{array}{ll}
\mathrm{I}_{\mathrm{f}}=\mathrm{mD}^{2} / 4-\mathrm{I}_{\mathrm{S}} & \mathrm{V}=\text { vehicle speed }=\mathrm{D} \omega / 2 \\
\mathrm{D}=\text { tire diameter } & \omega=\text { angular velocity of the tire } \\
\mathrm{m}=\text { vehicle mass (from the vehicle test } & \mathrm{I}_{\mathrm{S}}=\text { inertia of the system } \\
&
\end{array}
$$

The vehicle test weights were determined using one of two methods depending on the vehicle type. Vehicle test weights for transit buses were calculated by adding the vehicle curb weight and one half of the passenger load. The passenger load was determined by allowing $150 \mathrm{lbs}$. for each passenger and an additional $150 \mathrm{lbs}$. for the 
driver. Vehicle test weights for all other vehicle types, including road tractors and refuse trucks, was determined to be $70 \%$ of the gross vehicle weight for vehicles under 60,000 lbs. GVWR. For vehicles over $60,000 \mathrm{lbs}$ GVWR, 42,000 lbs (70\% of $60,000 \mathrm{lbs}$.) was used for the test weight.

\subsubsection{Analytical Trailer}

The other major component of the Translab was the analytical trailer. The analytical trailer was the device that housed the dilution tunnel, instrumentation, and analyzers for the emissions measurement system. Figure 3.2 shows the analytical trailer, dilution tunnel, and exhaust pipe system utilized by Translab 1 and their relation to the test bed.

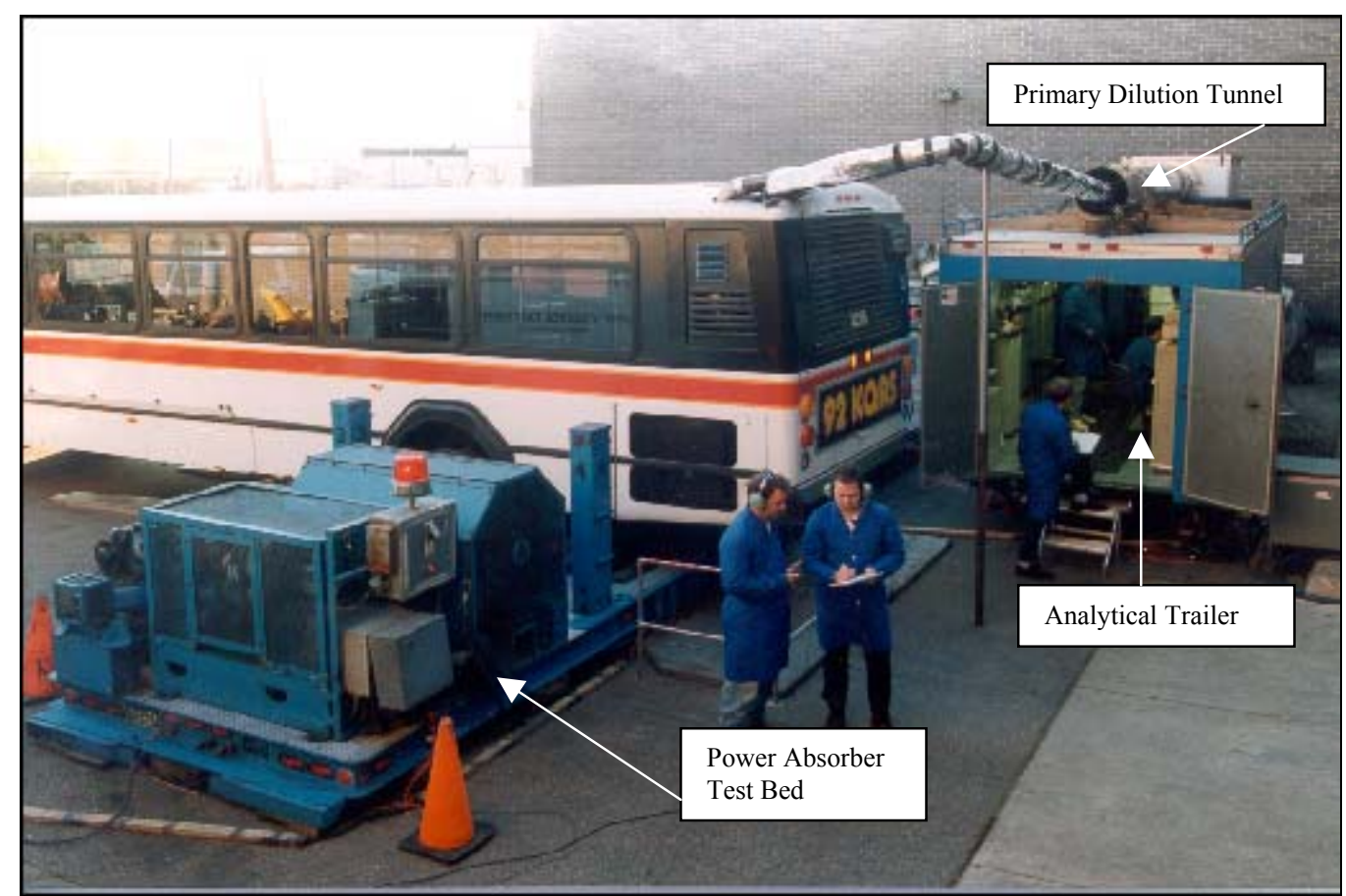

Figure 3.2: Transit bus mounted on the test bed of Translab 1 connected to the analytical trailer for emissions testing. 


\subsubsection{Dilution Tunnels}

The Translab utilized a full-scale primary dilution tunnel for gaseous emissions analysis. It measured 20 feet in length and 18 inches in diameter and was constructed of stainless steel. This geometric configuration allowed for greater than ten diameters of mixing length.

One end on the dilution tunnel was connected to a large blower through a flexible two-ply neoprene-polyester duct. This blower was used to draw the mixture of exhaust gas and air through the dilution tunnel. The flow rate of this diluted gas was controlled by a critical flow venturi system (CFV) located at the inlet of the blower. The other end of the dilution tunnel was open to allow the inlet of ambient air for dilution and the connection to the vehicle exhaust system.

A stainless steel secondary dilution tunnel was utilized for particulate matter collection. This secondary dilution tunnel measured three feet in length and three inches in diameter and was located in the front of the analytical trailer. It was connected to a stainless steel 70-millimeter filter holder and a mass flow controller as specified in the CFR.

Three heated probes were used to extract exhaust samples from the dilution tunnel. These probes were located in the same section of the primary dilution tunnel as the secondary dilution tunnel, approximately 15 feet from the main tunnel inlet (Hall, 2002).

\subsubsection{Gaseous Emission Analysis}

Translab measured carbon dioxide, carbon monoxide, oxides of nitrogen (NO and $\mathrm{NO}_{2}$ ), and hydrocarbons emissions with six independent analyzers. The analyzers were 
connected to the data acquisition system via analog-to-digital converters. The data acquisition system recorded continuous data from each analyzer throughout each test run.

In addition to the continuous emission data collected, the Translab also collected bag samples of dilute exhaust and background air. These bag samples were used as an integrated measure of the exhaust and background air samples collected during the duration of the test run. They were collected in 30 inch by 30 inch Tedlar bags by pumping the respective sample into the bag from the primary dilution tunnel. The flow rates for the bag samples were monitored and controlled by the gas operator or the field engineer and were varied depending upon the length of the test cycle. After the conclusion of each test run, the bag samples were then pumped through the analyzers and the respective concentrations were measured and recorded by the data acquisition system. The collection bags were then evacuated via a pump.

Background air sample data were used to correct the integrated continuous data for atmospheric conditions. This correction was performed by applying equation 3.4.

$$
\left[X_{\text {mass }}\right]=\sum_{i=1}^{n}\left[\frac{\left[X_{e}\right]_{i}}{10^{6}} \times\left(V_{\text {mix }}\right)_{i} \times\left(\text { density }_{X}\right) \times \Delta T\right]-\frac{[X]_{d}}{10^{6}}\left(1-\frac{1}{D F}\right) \times V_{\text {mix }} \times \text { density }_{X}
$$

where $\mathrm{X}$ represents the emissions species being evaluated, subscripts $\mathrm{e}, \mathrm{i}$, and $\mathrm{d}$ represent gaseous emission concentrations from the dilute bag, instantaneous values from the continuous data, and background air sample data values, respectively. $V_{\text {mix }}$ is the total dilute exhaust volume in cubic feet per test phase corrected to standard conditions, density $_{X}$ is the density of the emission species being evaluated, and DF refers to the dilution factor discussed in section 3.1.2.4. (40 CFR-PART 86). Emission species whose mass was determined to be less than or equal to zero were reported as "Below Detectable Limits". 


\subsubsection{Gaseous Emission Analyzers}

The WVU Translab operated six independent gaseous emission analyzers. Each analyzer was operated in the lowest range setting possible to give the best resolution in the data produced. The analyzers were recalibrated any time an operation range was changed, which coincided with the changing of the span gas concentration, or whenever deemed necessary by the field engineer. The analyzers were calibrated by running a known concentration of the appropriate span gas through a gas divider and injecting the resultant ratio of span gas and air into the analyzer being calibrated. The analyzers' output signals were recorded by the data acquisition system and compared with the known output signals for each concentration ratio. Necessary adjustments were made to the analyzers until agreement between the output signals was within acceptable limits.

Figure 3.3 shows the analyzer bench from Translab 1 that houses the low level carbon monoxide (LCO), high level carbon monoxide $(\mathrm{HCO})$, carbon dioxide $\left(\mathrm{CO}_{2}\right)$, and $\mathrm{NO}_{\mathrm{X}}\left(\mathrm{NO}_{\mathrm{X}} 1\right.$ and $\left.\mathrm{NO}_{\mathrm{X}} 2\right)$ analyzers and $\mathrm{NO}_{\mathrm{X}}$ efficiency tester. The hydrocarbon $(\mathrm{HC})$ analyzer is a free-standing unit and thus is not housed in this bench. Manufacturer information, model numbers, and ranges of operations for each analyzer are shown in Appendix A. 


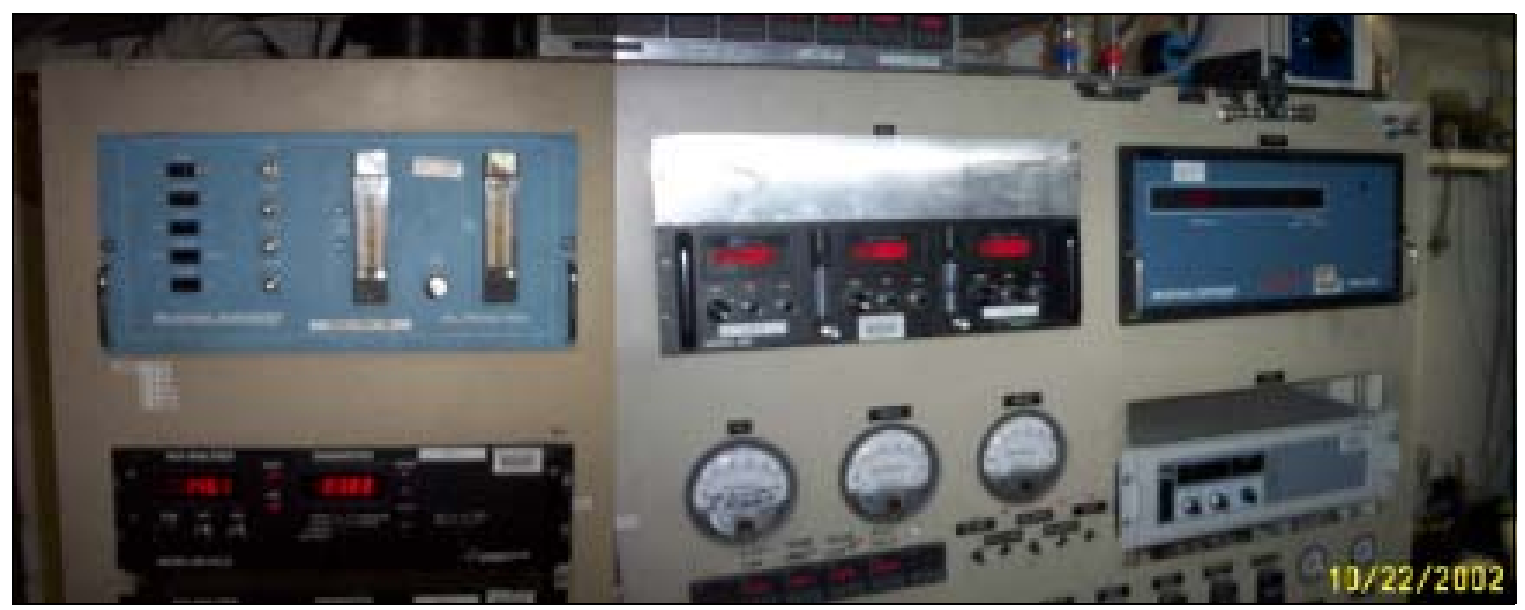

Figure 3.3: Analyzer bench from WVU Translab 1.

\section{A. Hydrocarbon Analyzer}

The total hydrocarbon (HC) measurements were made using a free-standing heated flame ionization detector (HFID). This highly sensitive detection method based the analysis on flame ionization of the hydrocarbon components of the diluted exhaust sample. This was accomplished by passing a regulated flow of the sample gas through a flame fueled by a regulated mixture of $\mathrm{HC}$ free air and a premixed fuel gas consisting of $40 \%$ hydrogen and $60 \%$ helium. The ionization process, which the hydrocarbon components of the exhaust sample undergo, created electrons and positive ions, which are collected by polarized electrodes. The collection of ions resulted in the flow of electrical current through the measuring circuitry in a rate proportional to the rate at which carbon atoms entered the burner, thus measuring the concentrations of hydrocarbons in the diluted exhaust sample (Evans, 2001; Hall, 2002).

In order to prevent condensation in the lines and equipment and the loss of highmolecular weight hydrocarbons, the $\mathrm{HC}$ sampling system was maintained at a temperature of $350^{\circ} \mathrm{F}$. 


\section{B. Oxides of Nitrogen $\left(\mathrm{NO}_{\mathrm{x}}\right)$ Analyzer}

The WVU Translab utilized two NO/NO analyzers. These analyzers were used to determine the concentrations of either: (1) nitric oxide (NO) or (2) NO and nitrogen dioxide $\left(\mathrm{NO}_{2}\right)$ which when measured together were denoted as $\mathrm{NO}_{\mathrm{X}}$. One analyzer was always operated in $\mathrm{NO}_{\mathrm{X}}$ mode and was labeled as $\mathrm{NO}_{\mathrm{X}} 1$, while the other analyzer was toggled between operation modes and was labeled as $\mathrm{NO}_{\mathrm{X}} 2$. To ensure appropriate agreement between the two $\mathrm{NO} / \mathrm{NO}_{\mathrm{X}}$ analyzers, they utilized the same sampling probe from the dilution tunnel.

These analyzers operated on the principle of chemiluminescent detection. In the $\mathrm{NO}$ mode of operation, sample $\mathrm{NO}$ from the diluted exhaust was converted to $\mathrm{NO}_{2}$ through the process of gas-phase oxidation. In order to stimulate the oxidation process, molecular ozone was produced within the analyzer from air or oxygen supplied from an external source. A characteristic of this reaction was the elevation of a portion of the $\mathrm{NO}_{2}$ molecules, approximately $10 \%$, to an electronically excited state, followed by the immediate reversion to the non-excited state. This reversion was accompanied by the release of photons which impinge on the photomultiplier detector, generating a low-level DC electrical current which was then amplified into the measurement signal recorded by the data acquisition system.

In $\mathrm{NO}_{\mathrm{X}}$ mode, the analyzers operated in the same fashion, except the sample was routed through a converter where the $\mathrm{NO}_{2}$ present in the sample was dissociated to form NO. Instrument response was proportional to the total NO present, including both the amount of $\mathrm{NO}$ initially present and the amount of $\mathrm{NO}$ dissociated from the present $\mathrm{NO}_{2}$. 
In addition to the two $\mathrm{NO} / \mathrm{NO}_{\mathrm{X}}$ analyzers, each Translab was equipped with a $\mathrm{NO}_{\mathrm{X}}$ efficiency tester. This piece of equipment was used to monitor how effectively the $\mathrm{NO} / \mathrm{NO}_{\mathrm{X}}$ analyzers were converting $\mathrm{NO}_{2}$ into $\mathrm{NO}$. The conversion efficiency was maintained at or above the 98\% level (Evans, 2001; Hall, 2002; Rosemount, 1991)

All components of the $\mathrm{NO}_{\mathrm{X}}$ sampling system were held at $235^{\circ} \mathrm{F}$ to avoid water condensation in the lines and equipment.

\section{Carbon Monoxide Analyzers}

The WVU Translab utilized two carbon monoxide (CO) analyzers, one for low $\mathrm{CO}$ concentration levels, labeled as LCO, and one for high CO concentration levels, labeled $\mathrm{HCO}$. Due to the wide range that $\mathrm{CO}$ can fluctuate during a test cycle, utilizing two analyzers allowed for better resolution of data produced. The two CO analyzers, along with the carbon dioxide analyzer, shared a single sample probe and heated line. In addition to maintaining the sampling system at $235^{\circ} \mathrm{F}$ to prevent condensation, a Hankinson gas dryer was utilized to prevent moisture from entering the analyzers.

Both CO analyzers were Non-Dispersive Infrared (NDIR) analyzers. This system functioned on the principle of selective absorption. In this process, infrared energy of a particular wavelength was transmitted through the emission sample. The CO in the sample absorbed the energy with wavelength of 4.5 to 5 microns, while energy of different wavelengths was transmitted through the sample. This "charged" sample then flowed through one of two parallel optical cells. The other optical cell was a sealed reference cell installed by the manufacturer and tuned to the wavelength of CO. The analyzer passed an equal energy infrared beam through each optical cell, and the 
difference in these two readings was the concentration of $\mathrm{CO}$ being measured from the diluted exhaust sample (Hall, 2002; Rosemount, 1991).

\section{Carbon Dioxide Analyzer}

The carbon dioxide $\left(\mathrm{CO}_{2}\right)$ analyzer utilized by the WVU Translab was of the same type as the CO analyzers, a NDIR. It shared sampling ports and heated lines and was also maintained at $235^{\circ} \mathrm{F}$.

This analyzer operated on the same principle as the $\mathrm{CO}$ analyzer, with the major differences being the reference cell and wavelength absorbed by the $\mathrm{CO}_{2} . \mathrm{CO}_{2}$ absorbs energy of wavelength measuring between 4 to 4.5 microns. As a result of this phenomenon, the reference cell was tuned to this wavelength rather than to the 4.5 to 5 wavelength for the CO analyzer (Evans, 2001; Hall, 2002).

\subsubsection{Particulate Matter Collection}

The primary method of particulate matter (PM) data collection was performed gravimetrically through the use of the secondary dilution tunnel. The secondary dilution tunnel provided cooling to the diluted exhaust mixture, in accordance with CFR 40, Part 86 , Subpart N, to a maximum filter-face temperature $125^{\circ} \mathrm{F}$. The dilute exhaust was pulled across two Pallflex 70-mm fluorocarbon coated fiberglass filters, a primary filter and a backup filter, by a rotary vane pump. The flow rates of the dilute exhaust sample and the additional dilution air were controlled by two Sierra mass flow controllers (Evans, 2001).

An environmental chamber was used to pre-condition and post-condition the filters for a minimum of 12 hours prior to weighing. The environmental chamber was maintained at $50 \% \pm 5 \%$ relative humidity and $70^{\circ} \mathrm{F} \pm 10^{\circ} \mathrm{F}$. The filters were conditioned 
in glass petri dishes to minimize the likelihood of being contaminated by outside sources. After conditioning, the filters were weighted using a microbalance with a sensitivity of $0.01 \mu$ grams.

Background PM samples were collected at the beginning and end of each testing day. This was performed to account for the amount of PM in the ambient air as well as to account for re-entrainment of PM from the dilution tunnel walls. These filters were treated as regular test filters with respect to pre- and post-conditioning. The background filter weights were used to correct the test particulate filter weights in accordance with CFR 40, Part 86, Subpart N using equation 3.5.

$$
P_{\text {mass }}=\left(V_{\text {mix }}+V_{s f}\right) *\left[\frac{P_{f}}{V_{s f}}-\left(\frac{P_{b f}}{V_{b f}} *\left[1-\left(\frac{1}{D F}\right)\right]\right)\right]
$$

where $\mathrm{P}_{\text {mass }}$ was the mass of the particulate emitted during the test phase, $V_{\text {mix }}$ was the total volume of dilute exhaust corrected to standard conditions, $\mathrm{V}_{\text {sf }}$ was the volume of sample removed from the primary dilution tunnel, $\mathrm{P}_{\mathrm{f}}$ was the combined weight of PM collected during a test cycle on both the primary filter and backup filter, $\mathrm{P}_{\mathrm{bf}}$ was the combined weight of PM collected on both background filters, $\mathrm{V}_{\mathrm{bf}}$ was the volume of dilution air sampled during the background test, and DF was the dilution factor, calculated from equation 3.6.

$$
\left.D F=\frac{13.4}{\left[C O_{2 e}+\left(H C_{e}+C O_{e}\right) 10^{-4}\right.}\right]
$$

where the subscript "e" identified a gaseous emission concentration collected from the dilute sample bag (40 CFR-Part 86). 


\subsubsection{Fuel Economy Calculations}

Fuel economy was calculated using a carbon-balance method. This method assumed that the total mass of carbon in the fuel was equal to the mass of carbon found in the exhaust. This method neglects the contributions of lubricating oil consumption to the exhaust carbon and the fuel carbon lost due to blowby, fuel seepage past the piston rings. These factors are minor and tend to counteract each other.

Using the total weight of hydrocarbons, carbon monoxide, and carbon dioxide collected during testing, the mass of carbon in the exhaust is given by equation 3.7.

$$
G_{S}=\left[\frac{12.011}{12.011+\alpha(1.008)}\right] H C_{\text {mass }}+0.429 C O_{\text {mass }}+0.273 C O_{2 \text { mass }}
$$

where $\alpha$ is the atomic hydrogen to carbon ratio of the fuel, assuming there is no sulfur, oxygen, or nitrogen present in the fuel, $\mathrm{HC}_{\text {mass }}$ is the total mass of hydrocarbons emitted in the exhaust, $\mathrm{CO}_{\text {mass }}$ and $\mathrm{CO}_{2 \text { mass }}$ are the total masses of carbon monoxide and carbon dioxide emitted, respectively.

The mass of carbon in the exhaust was then converted to a fuel volume and consequently into a fuel economy in units of miles per gallon (MPG) using equation 3.8.

$$
M P G=\left[\frac{g C / \text { gal of fuel }}{G s}\right](\text { Distance Traveled })
$$

Where $\mathrm{gC} / \mathrm{gal}$ of fuel is the carbon weight fraction of the test fuel.

\subsubsection{Data Acquisition System}

The WVU Translab data acquisition system consisted of a main computer, reduction computer, vehicle operator video monitor, control and data acquisition hardware, and signal controlling devices. The main computer was used to control all 
aspects of test execution, from the pre-test calibration of the analyzers and instrumentation to the collection of data recorded during a test cycle. This computer was pre-programmed with various driving schedules, which are discussed later in this thesis, which the vehicle operator followed during a test. The vehicle operator monitor was connected to the main computer and displayed all information that the field engineer monitored from inside the analytical trailer, including a real time trace of vehicle speed versus time that the driver was to follow.

The control and data acquisition system hardware included two digital dynamometer controllers, two signal-processing boards, and numerous signalconditioning modules. The digital dynamometer controllers were Dyne Systems Co. Dyn-Loc IV units and were connected to the main computer in a closed loop system. The main computer sent signals to the dynamometer controllers responsible for applying load on the dynamometers, thus simulating road drag and aerodynamic losses.

All output signals from the analyzers and transducers were fed through the RTI815 signal processing boards and Analog Devices 3B signal conditioning modules. The signal conditioning modules were used in the calibration process of the analyzers. The RTI- 815 boards converted the output signals from the analyzers and transducers into ADC codes, which were recorded on the main computer and then sent to the reduction computer.

The reduction computer was used to perform all post-test analysis of the raw experimental data, which included data conversion from ADC codes to engineering units, continuous integration of the results, and graphical analysis of the test results. (Hall, 2002) 


\subsection{Special Equipment}

During the data collection portion of this thesis, some special equipment was used. This equipment included a TEOM, Tapered Element Oscillating Microbalance, and a smoke opacity meter.

\subsubsection{TEOM}

The TEOM, Tapered Element Oscillating Microbalance, is a system that provides real-time data about the particulate mass concentrations in the diluted diesel exhaust. The TEOM system operates by passing exhaust gas through a hollow glass tube, which is allowed to oscillate at its natural frequency, and through a small filter element, which traps the PM from the exhaust gas. As the PM is deposited on the filter, the natural frequency of the system, hollow tube and filter assembly, changes. A computer records this frequency and changes it into a mass calculation using the formula found in equation 3.9 .

$$
\mathrm{M}=\mathrm{K}_{0}\left(\mathrm{~F}_{1}^{-2}-\mathrm{F}_{0}^{-2}\right)
$$

where $\mathrm{M}$ is the resultant mass in grams, $\mathrm{F}_{1}$ is the current frequency, $\mathrm{F}_{0}$ is the initial frequency, and $\mathrm{K}_{0}$ is the calibration constant for tapered element (Okrent, 1998). The computer logged data as often as every 0.21 seconds. These data were computed and

reported from the computer as mass concentration $\left(\mathrm{mg} / \mathrm{m}^{3}\right)$, total mass (grams), and mass rate $(\mathrm{g} / \mathrm{s})$.

These data were of most concern relative to this thesis for the cold start test runs. These data were used to determine the cold start efficiencies of the DPFs for trapping particulate matter and, if possible, to determine the temperature at which the DPFs activate and begin to oxidize the PM. 


\subsubsection{TEOM Limitations}

As the TEOM system is a very sensitive piece of equipment, there are certain limitations involved with its use. Sample flow rate, sample temperature, moisture content, and filter age all have significant effects on the confidence of the TEOM data.

The flow rate of the sample exhaust gas through the filter affects the agreement with conventional gravimetric particulate sampling measurements. As the flow rate is increased, the residence time for ultrafine PM and volatiles to become attached to the filter surfaces decreases due to the increased velocity. However as the flow rate is decreased, the positive-to-negative mass ratio decreased, lowering the accuracy or realtime particulate measurement. Through experimentation, a flow rate of 2 liters per minute was found to best compromise between conventional filtration agreement and real-time characteristics (Gilbert, 2002).

Lower sampling temperatures have proven to allow more volatile organic compounds to be trapped by the filter element, however increased temperatures have shown higher moisture rejection characteristics. A $40^{\circ} \mathrm{C}$ sampling temperature has shown to provide the optimum compromise between VOC and moisture rejection (Gilbert, 2002).

Moisture content can greatly affect the TEOM system data by giving an instantaneous false reading of particulate mass collected by the filter element. As the sampling mass is reported continuously, the filters cannot be post-conditioned, as are traditional particulate filters, to lesson the effects of moisture content.

It has been shown that aged filters more efficiently trap particulate matter than do new filters. New filters collect $40 \%$ less mass on the first test than on the third test. 
When the first test with a new filter is disregarded, the $99 \%$ confidence in the TEOM data was $\pm 4.3 \%$. For comparison, conventional gravimetric mass measurement has a $99 \%$ confidence of 1.7\% for PM data (Gilbert, 2002).

\subsubsection{Smoke Opacity Meter}

Another piece of special equipment that was used for a portion of the data collection stage of this thesis was a Telonic Berkeley Inc. Model 107 smoke opacity meter. The smoke opacity meter was used to measure the opacity of the exhaust gas and particulate mixture as well as determine the exhaust, or smoke, density. The smoke opacity meter measured contributions of particulate matter as well as contributions of white smoke to the opacity value. These data were used in evaluating the cold start performance of the DPF systems.

The smoke opacity meter functioned on the principle of attenuation of the intensity of a light beam by smoke aerosol absorption and scattering. The light beam utilized by the meter was generated by a green light emitting diode (LED) and a condensing lens. The light beam was projected through the center of the exhaust stream and detected by a photodiode. The output signals from the LED and the photodiode were sent through the ADC controllers and recorded by the main lab computer. The smoke opacity and smoke density were then determined from the light intensity reduction expressed in equation 3.10 .

$$
\frac{l}{l_{0}}=e^{-n \overline{a Q} L}
$$

where $1_{0}$ is the light intensity emitted by the LED, 1 is the light intensity detected by the

photodiode, $\mathrm{n}$ is the number density of smoke particles, $\overline{\mathrm{a}}$ is the average particle 
projected area, $\overline{\mathrm{Q}}$ is the average particle extinction coefficient, and $\mathrm{L}$ is the light beam path length within the smoke (the diameter of the exhaust pipe). The smoke opacity, N, is shown in equation 3.11 as a function of the light intensity reduction, and the smoke density, $\mathrm{K}$, is shown in equation 3.12 as a function of the smoke opacity (Telonic Berkeley, 1999).

$$
\begin{gathered}
N=\left(1-\frac{l}{l_{0}}\right) * 100=\operatorname{opacity}(\%) \\
K=\left(-\frac{1}{L}\right) * \ln \left(1-\frac{N}{100}\right)=\operatorname{SmokeDensity~}\left(m^{-1}\right)
\end{gathered}
$$




\section{Chapter 4 - Test Vehicles, Driving Cycles, and Results}

\subsection{Cold Start DPF Performance}

\subsubsection{Test Vehicles}

Seven vehicles were tested for cold start DPF performance evaluation. Table 4.1.1 summarizes the vehicles tested in this program. Six of these vehicles were 1999 Orion II transit buses taken from the Washington Metropolitan Area Transit Authority (WMATA) fleet. All of these vehicles were equipped with Cummins 6BT5.9 engines rated at $175 \mathrm{hp}$ and were tested at 18,975 pounds. Of these six buses, two were equipped with oxidation catalysts and used as a baseline for DPF performance. The remaining four buses were equipped with DPFs, two with Engelhard DPXs and two with JohnsonMatthey CRTs.

The seventh vehicle in this study was a 1995 Mack tractor truck owned by West Virginia University. This truck was equipped with a Mack E7-400 V-MAC II sixcylinder engine rated at $400 \mathrm{hp}$. It was tested at a weight of 42,000 pounds using a standard muffler in place and then retested with an Engelhard DPX. It is noted that the Engelhard DPX utilized on the WVU Mack was not optimized for this application. It was a unit intended for a $435 \mathrm{hp}$ Detroit Diesel Corporation engine, however the Mack engine was of similar displacement.

The WMATA buses were chosen for warm weather-cold start performance evaluation, while the WVU Mack tractor truck was chosen for cold weather-cold start evaluation. The average ambient temperatures during cold start test runs were $76^{\circ} \mathrm{F}$ and $34^{\circ} \mathrm{F}$ respectively. 
Table 4.1.1: Vehicles Tested for Cold Start DPF Performance Evaluation.

\begin{tabular}{|c|c|c|c|c|c|}
\hline fleet & number & vehicle & engine & aftertreatment & fuel \\
\hline WMATA & 3722 & Orion II Transit Bus & Cummins 6BT5.9 & Oxidation Catalyst & D1 \\
\hline WMATA & 3723 & Orion II Transit Bus & Cummins 6BT5.9 & Oxidation Catalyst & D1 \\
\hline WMATA & 3724 & Orion II Transit Bus & Cummins 6BT5.9 & Engelhard DPX & ULSD1 \\
\hline WMATA & 3725 & Orion II Transit Bus & Cummins 6BT5.9 & Engelhard DPX & ULSD1 \\
\hline WMATA & 3726 & Orion II Transit Bus & Cummins 6BT5.9 & Johnson Matthey CRT & ULSD1 \\
\hline WMATA & 3727 & Orion II Transit Bus & Cummins 6BT5.9 & Johnson Matthey CRT & ULSD1 \\
\hline \multirow{2}{*}{ WVU } & \multirow{2}{*}{21017} & \multirow{2}{*}{ Mack Tractor Truck } & \multirow{2}{*}{$\begin{array}{c}\text { Mack E7-400 } \\
\text { V-MAC II }\end{array}$} & Engelhard DPX & ECD1 \\
\hline & & & & standard muffler & ECD1 \\
\hline
\end{tabular}

\subsubsection{Driving Schedules}

All WMATA buses were tested using variations of the Central Business District cycle (CBD) found in the Society of Automotive Engineers Standards J1376: Fuel Economy Measurement Test (Engineering Type) for Trucks and Buses (SAE, 1997). The CBD cycle consisted of fourteen acceleration ramps each followed by brief steady state periods of $8.94 \mathrm{~m} / \mathrm{s}(20 \mathrm{mph})$. Each steady state portion was followed by a deceleration ramp with approximately twice the slope as the previous acceleration ramp and a short idle period, resulting in a total test time of 900 seconds.

Each bus was subjected to a single cold start test run followed by at least three hot start runs. The cold start tests were performed using the ColdCBD test cycle. This test cycle was a continual loop of CBD cycles. The cold start tests were concluded when the field engineer determined that the exhaust temperature, carbon monoxide, and hydrocarbon emissions had sufficiently stabilized.

The hot start test runs were performed using the $3 \mathrm{CBD}$ driving cycle. This test cycle consisted of three CBD cycles run back-to-back, with the first sequence being a warm-up with no data collection. Due to the effectiveness of the DPFs, the CBD cycle length was tripled to increase the amount of PM collected on the filters to facilitate accurate gravimetric measurement. The $3 \mathrm{CBD}$ driving cycle is shown in Figure 4.1.1 as 
driven during testing. Note that this figure shows only the portions of the cycle in which data are collected, there are an additional fourteen ramps at the beginning of the cycle, which are not shown, that comprise the warm-up sequence of the 3CBD driving cycle.

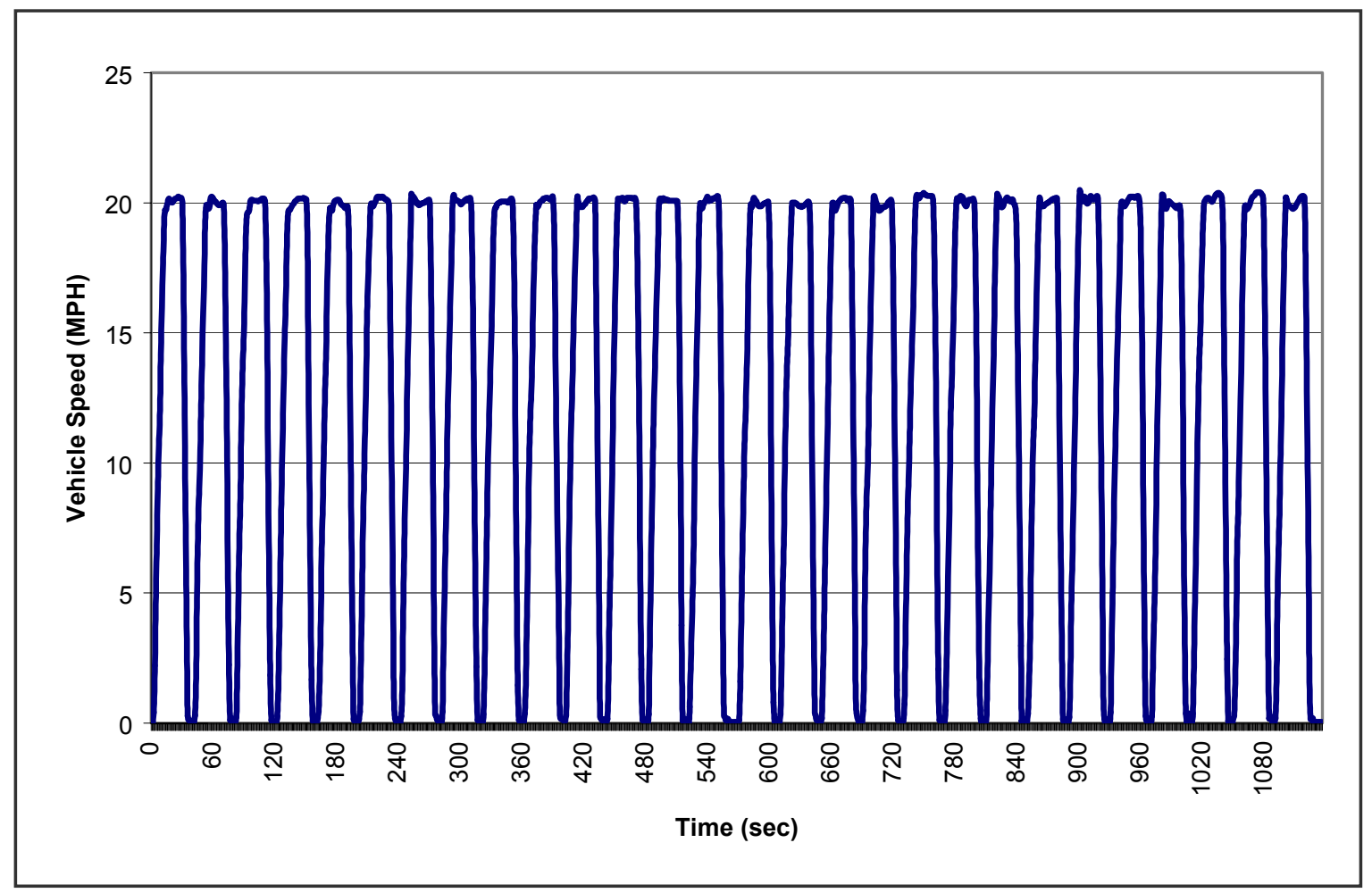

Figure 4.1.1: The 3CBD driving cycle utilized for hot start testing with WMATA transit buses as driven by WMATA bus 3722 .

The WVU Mack tractor truck was tested with two separate driving schedules developed by West Virginia University, the WVU one peak cycle (denoted as WVU-1P) and the WVU 5 Mile truck route (denoted as 5miles). The main difference between a driving cycle and a driving route was the respective definition of test length. A cycle was a speed versus time schedule where the test concluded at a given time (in seconds) without regard to total distance traveled, whereas a route was a speed versus distance schedule that ended when a specified total distance was reached without regard to elapsed time. 
A variation of the WVU 5 Mile route was used for all hot start test runs. The WVU 5 Mile route was developed to simulate both transient and steady state vehicle operations of a class 8 truck. It consisted of five acceleration ramps, each to a steady state speed of $8.94,11.18,13.41,15.64$, and $17.88 \mathrm{~m} / \mathrm{s}(20,25,30,35$, and $40 \mathrm{mph})$ respectively. Each steady state period was followed by a deceleration and an idle period. The total distance covered in a single WVU 5 Mile test run was five miles (Clark, et al., 1994).

The variation of the WVU 5 Mile route that was used for hot start test runs was denoted as 2-5miles. This cycle repeated the WVU 5 Mile route two times continuously for a total distance traveled of 10 miles. This double schedule was utilized to ensure sufficient loading of the PM filters to facilitate accurate measurement. Figure 4.1.2 shows the vehicle speed versus time plot for a hot test run using the $2-5$ miles route.

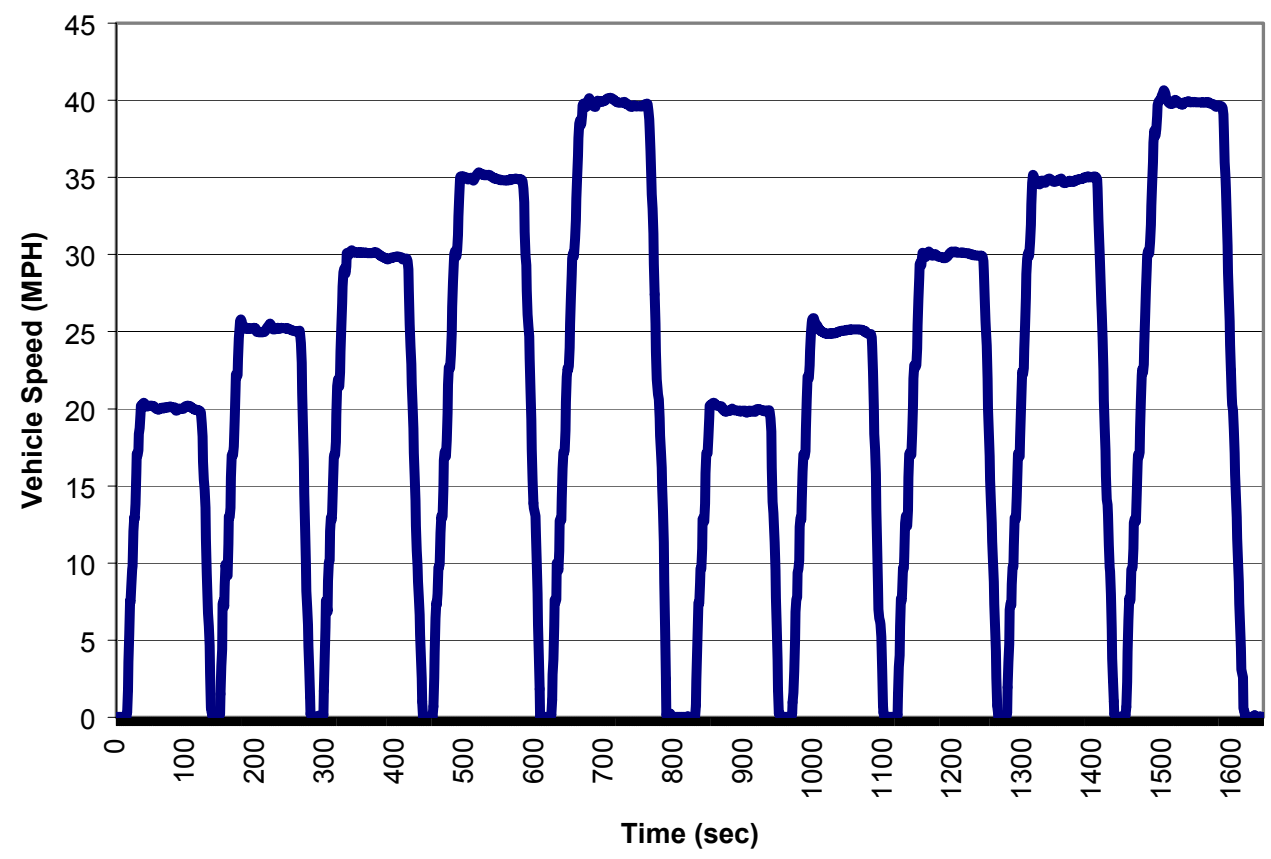

Figure 4.1.2: The 2-5miles driving route developed by West Virginia University as driven by the WVU Mack. 
The WVU one-peak cycle was used for cold start test runs with the WVU Mack tractor truck. The WVU one-peak cycle utilized the first acceleration ramp and steady state speed of the 5-peak cycle in a repeated fashion much like the CBD cycle. The CBD cycle was determined to be inappropriate for large class 8 vehicles, such as the Mack tractor truck, due to their inability to meet the steep accelerations under heavy load conditions. The WVU one-peak offers much more realistic accelerations for these types of vehicles. Much like the ColdCBD cycle, the WVU one-peak repeated indefinitely until stopped by the field engineer when the exhaust temperature, carbon monoxide, and hydrocarbon emissions stabilized. Figure 4.1.3 shows a plot of the vehicle speed versus time for the WVU one-peak as driven during a cold start test run of the WVU Mack tractor truck.

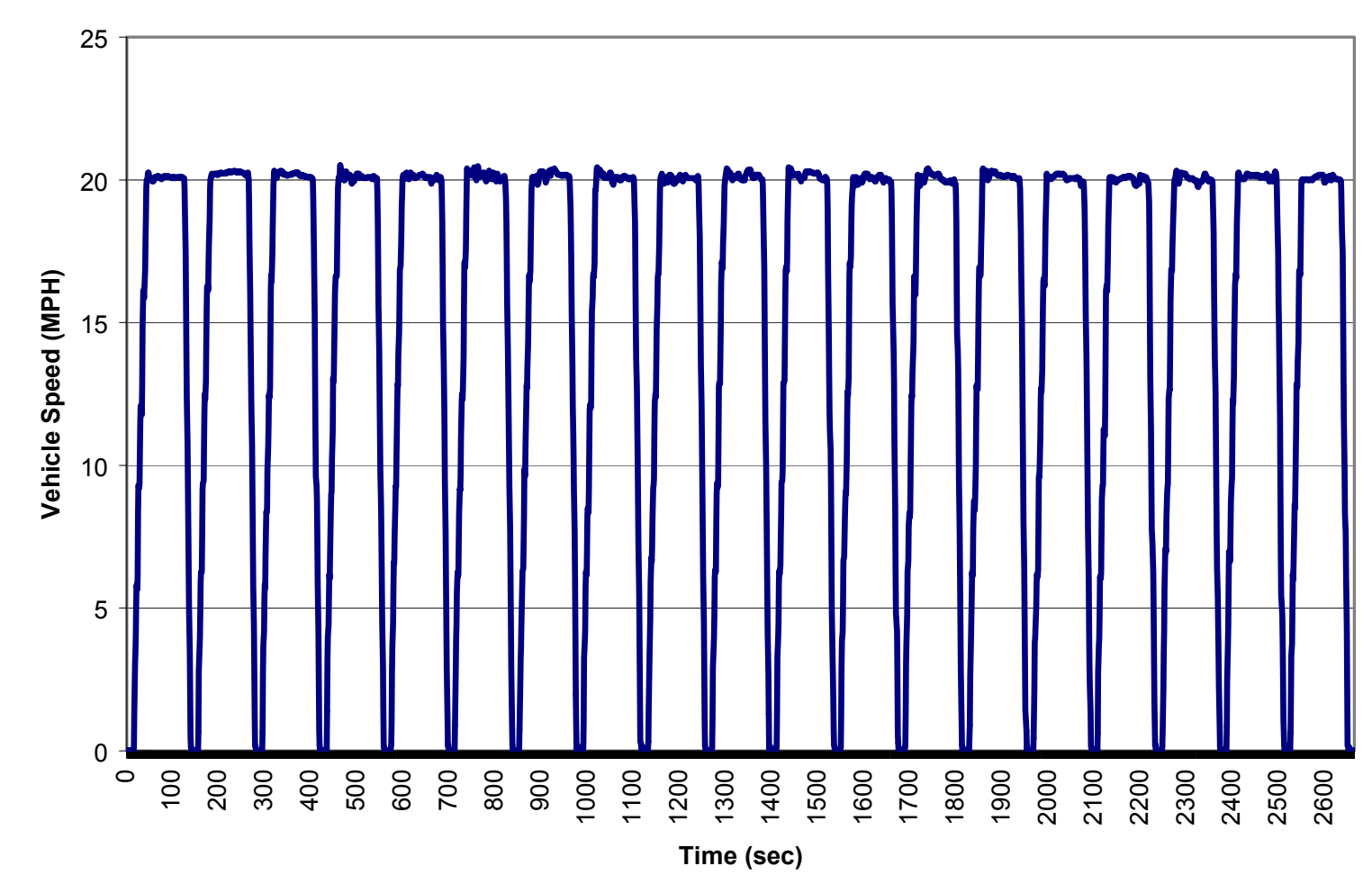

Figure 4.1.3: The WVU one-peak (WVU-1P) driving cycles as used for cold start testing on the Mack Tractor Truck. 


\subsubsection{Results}

There were two areas of concern for the cold start DPF performance evaluation: general operational efficiency of the DPF under cold start conditions and determination of an approximate light-off temperature at which the emissions stabilize. In this section, continuous data, integrated data, and general observations are presented.

\subsubsection{CO Emissions}

Carbon monoxide emissions from the WMATA Orion II transit buses equipped with either the Engelhard DPX or the Johnson-Matthey CRT were reduced by $72.7 \%$ and $76.9 \%$, respectively, when compared to the oxidation catalyst equipped vehicles. Figure 4.1.4 graphically demonstrates this reduction in a grams per mile basis (g/mile). In this figure, each bar represents the average of the integrated emissions data for each type of after-treatment device, with error bars showing the maximum and minimum values recorded.

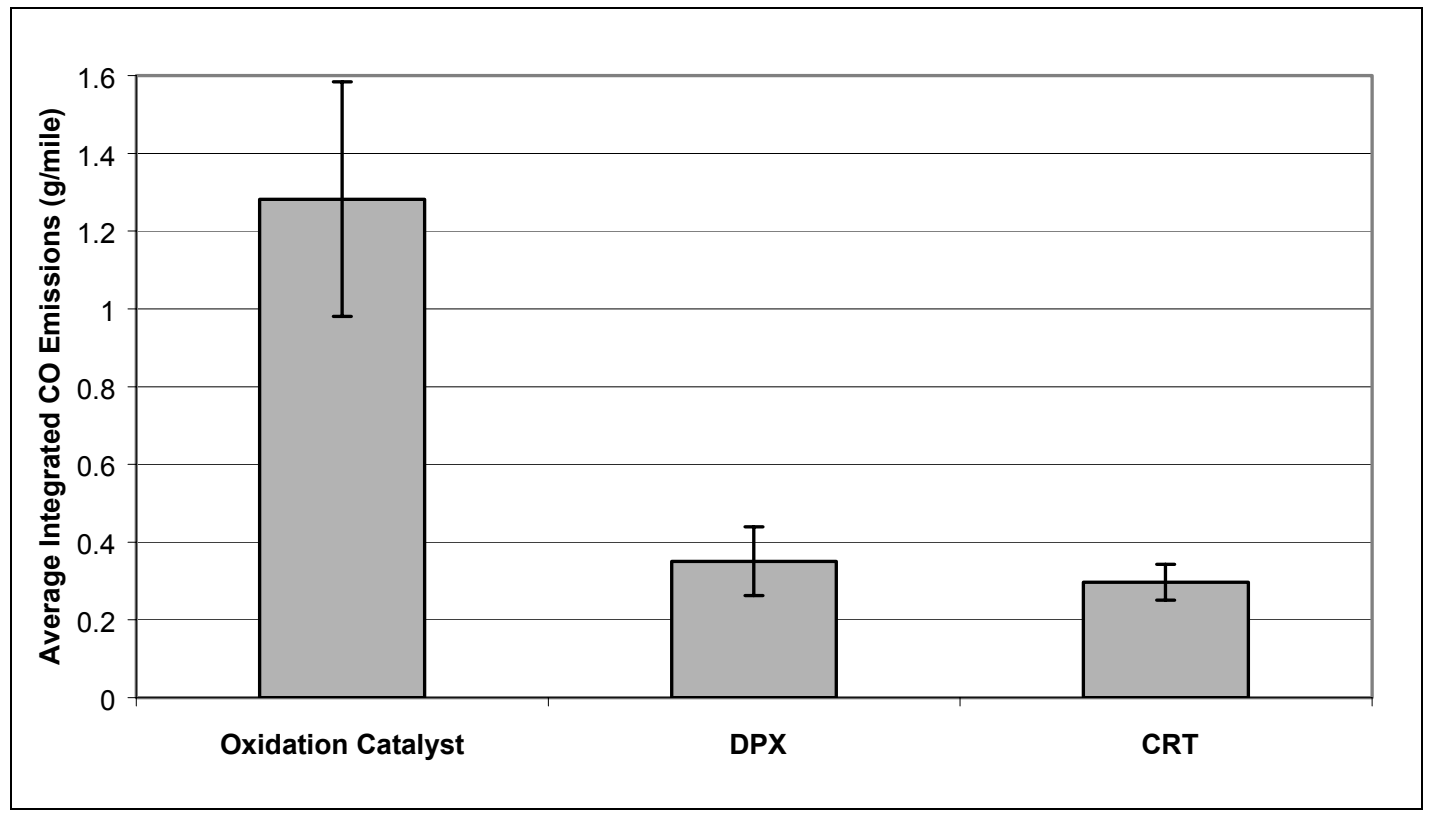

Figure 4.1.4: Average CO emissions recorded during cold start test runs from WMATA Orion II transit buses, with maximum and minimum values shown as error bars. 
Figure 4.1.5 shows the continuous $\mathrm{CO}$ data collected from three of the six WMATA buses, one from each type of after-treatment tested. The plot was limited to three samples for clarity, however it should be noted that the other three vehicles tested produced similar results. Additionally, only the first one thousand seconds of each test run is shown to compensate for the varying test length and for additional clarity. From this figure, it can be seen that the particulate filter equipped vehicles released less $\mathrm{CO}$ and the emission concentration stabilized much faster.

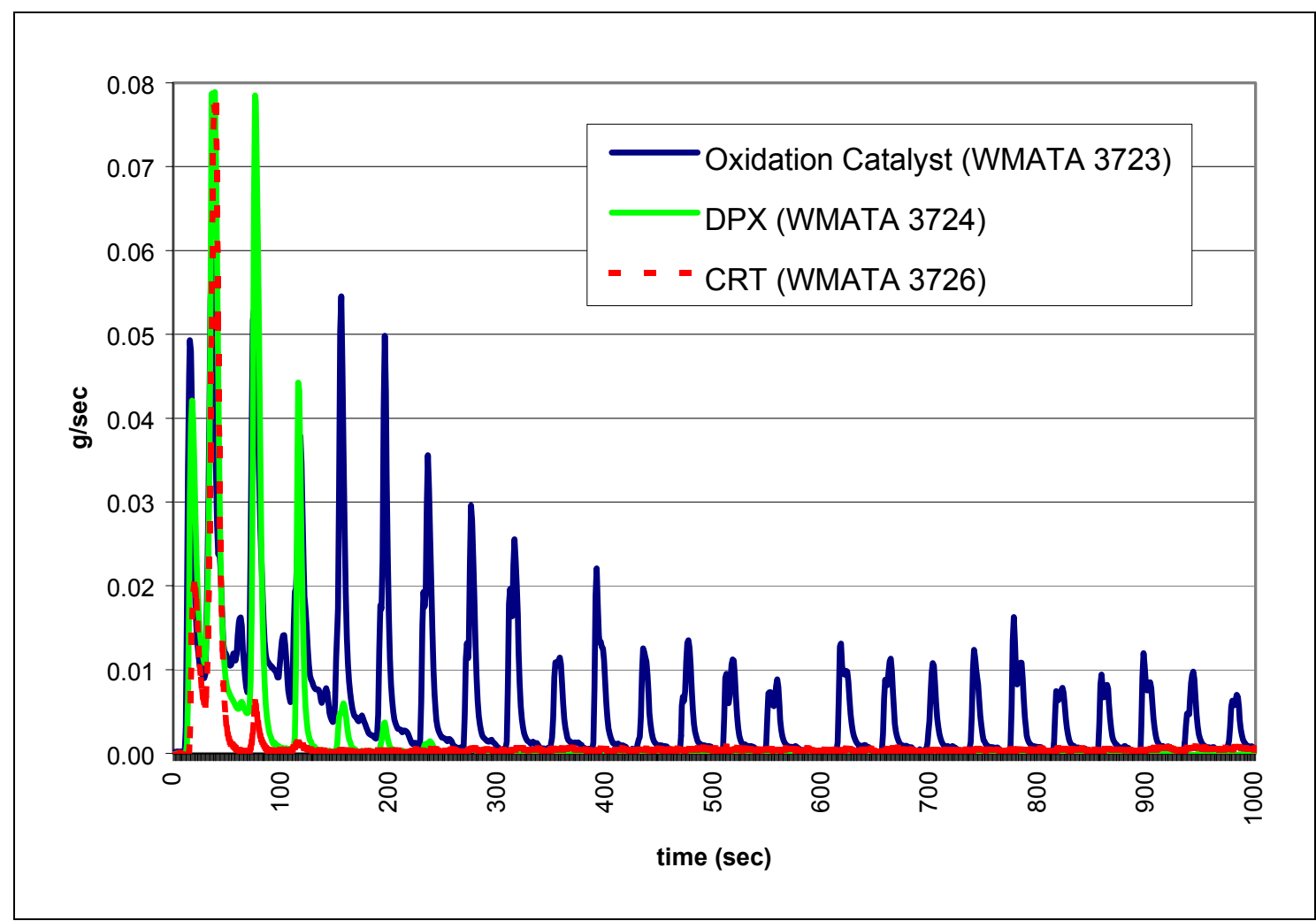

Figure 4.1.5: Continuous CO emissions data from three WMATA transit buses

The WVU Mack tractor truck experienced a 53\% reduction in CO emissions when using the Engelhard DPX particulate filter. Similar to the WMATA vehicles, CO emissions, in addition to being lower in concentration, also stabilized much faster. Figure 4.1.6 demonstrates this phenomenon by showing the continuous $\mathrm{CO}$ emissions in units of parts per million (ppm) versus time for DPF equipped and non-equipped runs. Also 
shown in this figure is the exhaust temperature, which was use in determination of DPF light-off temperature discussed in Chapter 5 - Conclusions.

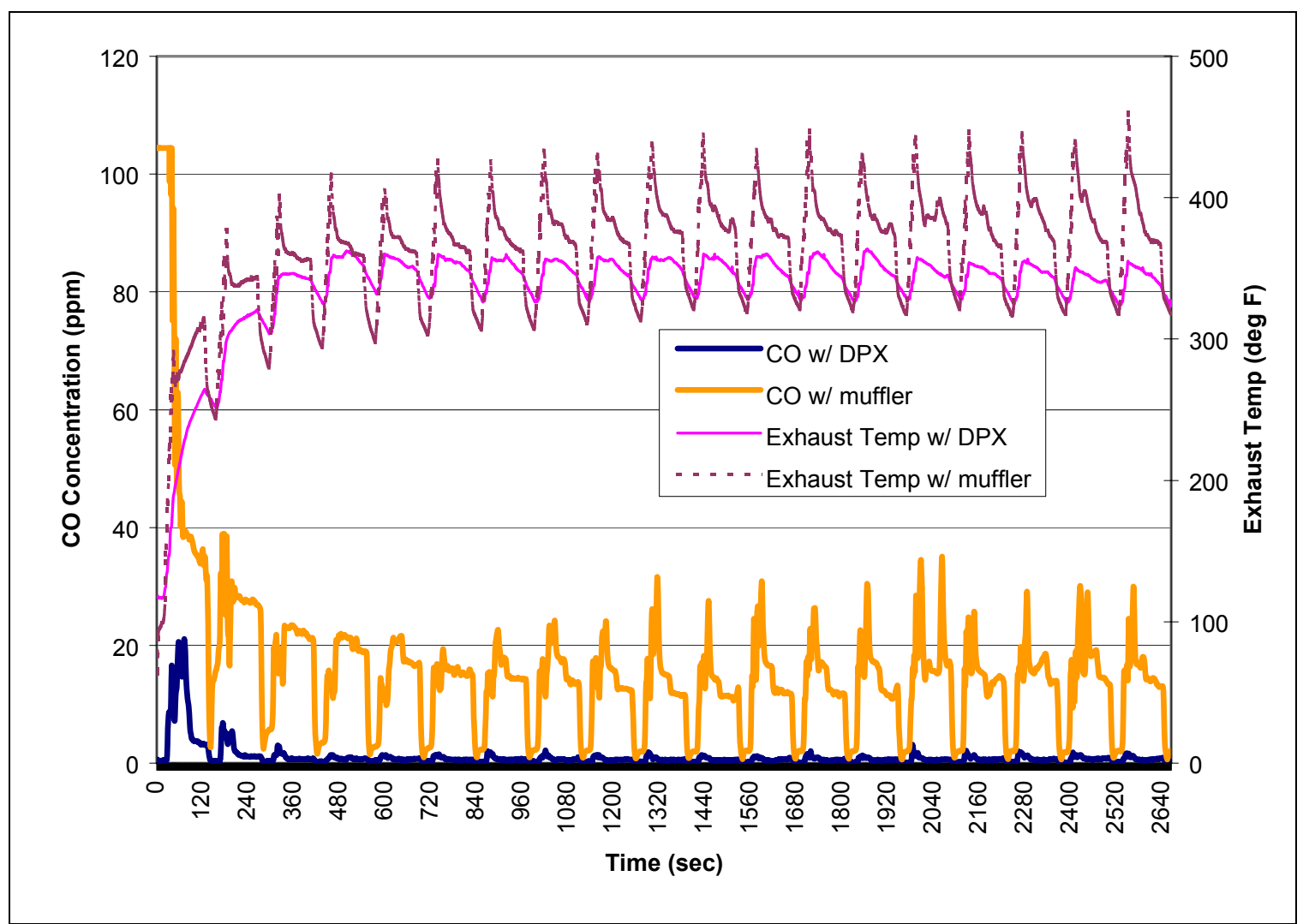

\section{Figure 4.1.6: Continuous $\mathrm{CO}$ emissions taken from the WVU Mack tractor truck during cold-weather cold start testing.}

\subsubsection{HC Emissions}

Hydrocarbon emissions from the WMATA transit buses equipped with DPFs were $83 \%$ and $86 \%$ lower for the Engelhard DPX and Johnson-Matthey CRT respectively when compared to the oxidation catalyst equipped vehicles. Figure 4.1 .7 shows the average integrated $\mathrm{HC}$ emissions concentrations collected during warm-weather cold start test runs in units of grams/mile. Each bar in this figure represents the average $\mathrm{HC}$ emission levels recorded for each after-treatment device, with error bars showing the maximum and minimum values recorded. As the data from WMATA 3725 was below 
detectable limits, no error bar is shown for the DPX column as only one value was available.

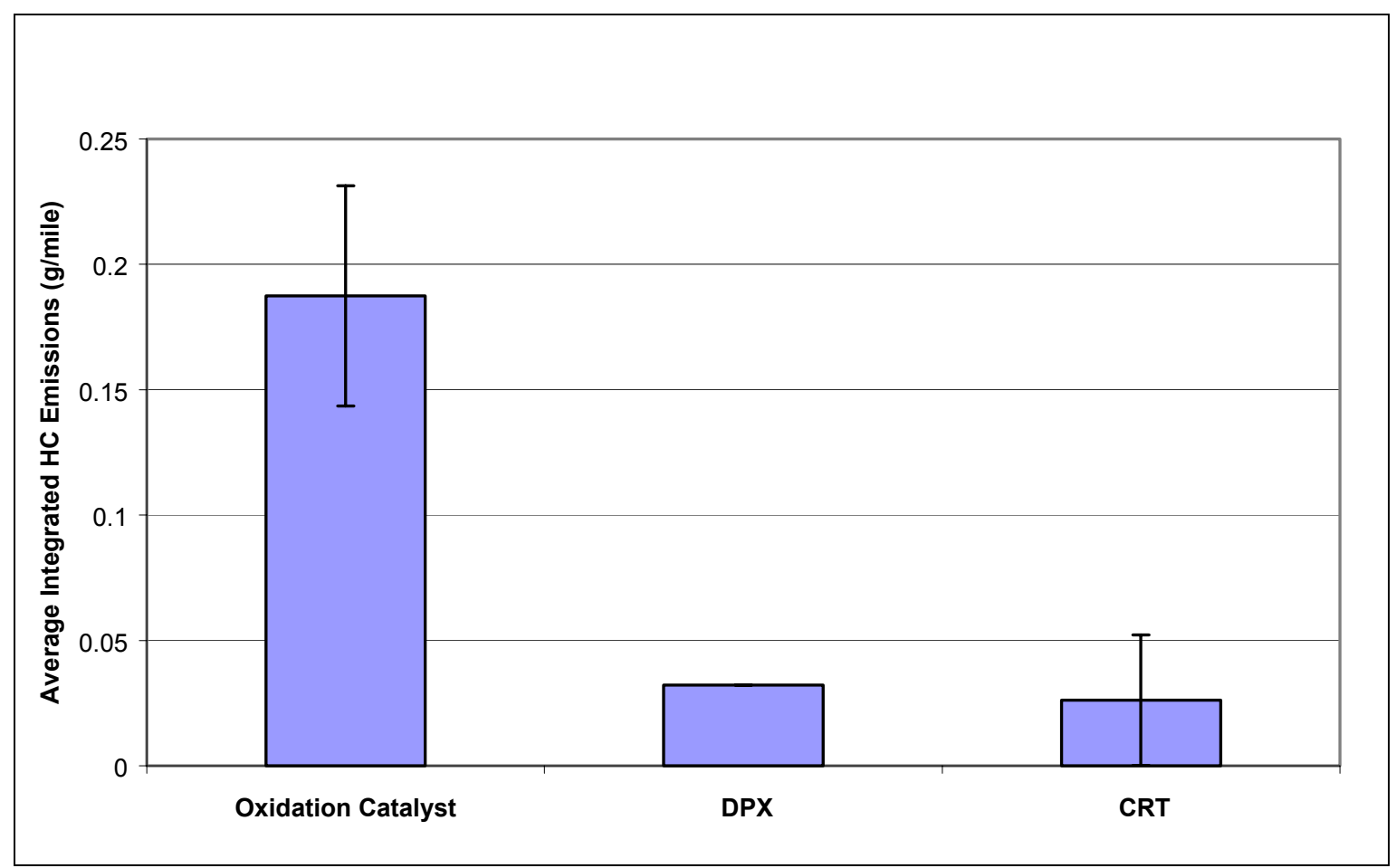

Figure 4.1.7: Average HC emissions collected during cold start testing of the WMATA transit buses.

Figure 4.1.8 shows the first one-thousand seconds of continuous HC data collected from three of the WMATA Orion II transit buses tested. This plot shows rapid decrease in $\mathrm{HC}$ emissions to near undetectable limits experienced in the particulate filter equipped vehicles. After approximately 400 seconds, the $\mathrm{HC}$ emissions dropped into the noise levels of the HC analyzer for both the DPX and CRT particulate filters.

The WVU Mack tractor truck experienced a 78\% reduction in HC emissions when equipped with the Engelhard DPX particulate filter. This reduction is represented in Figure 4.1.9. This figure shows the continuous $\mathrm{HC}$ emissions and exhaust temperature for two cold start test runs, one run using the DPF and one using a standard muffler. From this plot, it can be seen that the DPX begins greatly reducing HC emissions at a 
relatively low exhaust temperature, and emission levels stabilize after approximately 400 seconds.

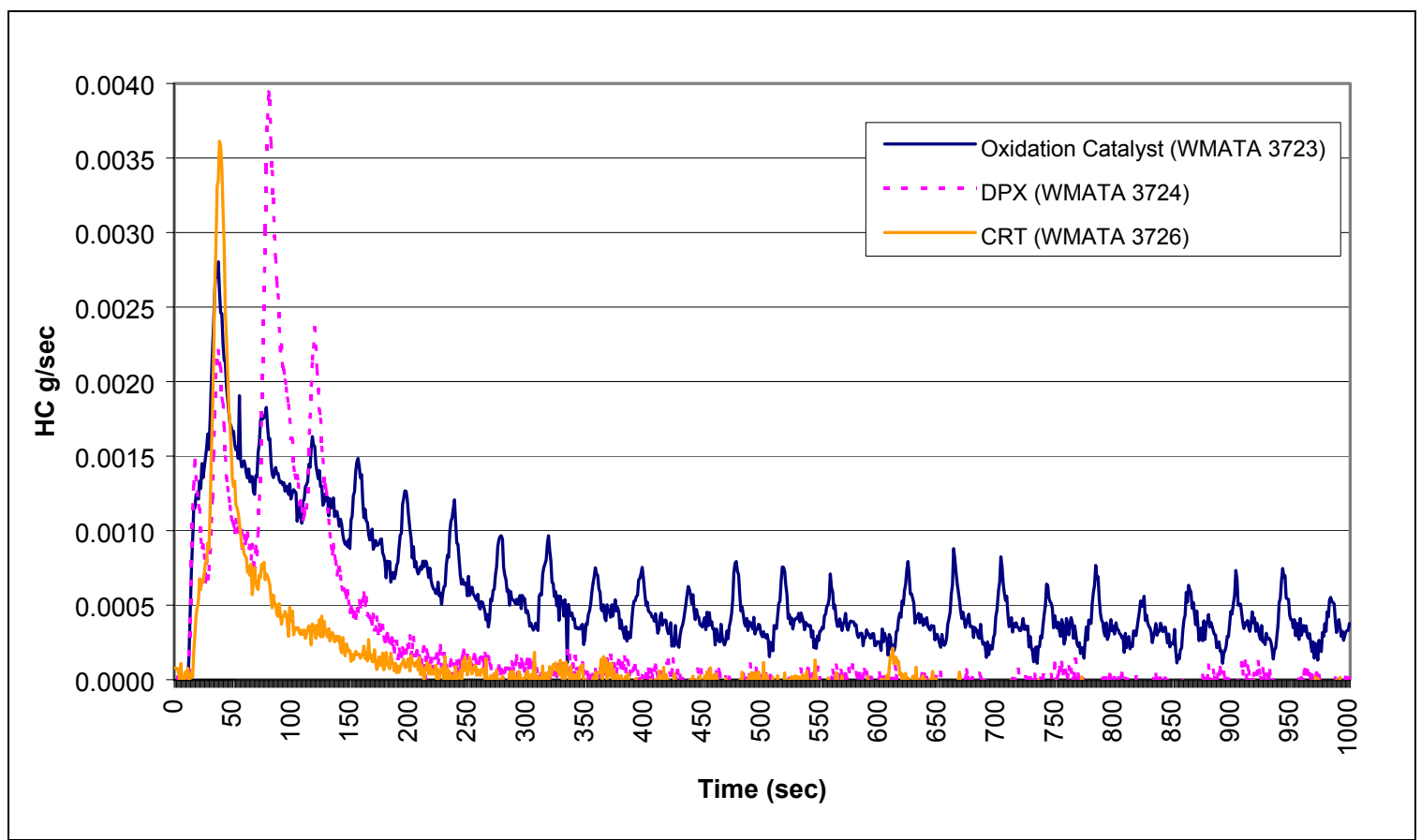

Figure 4.1.8: HC emissions from cold start testing of WMATA transit buses.

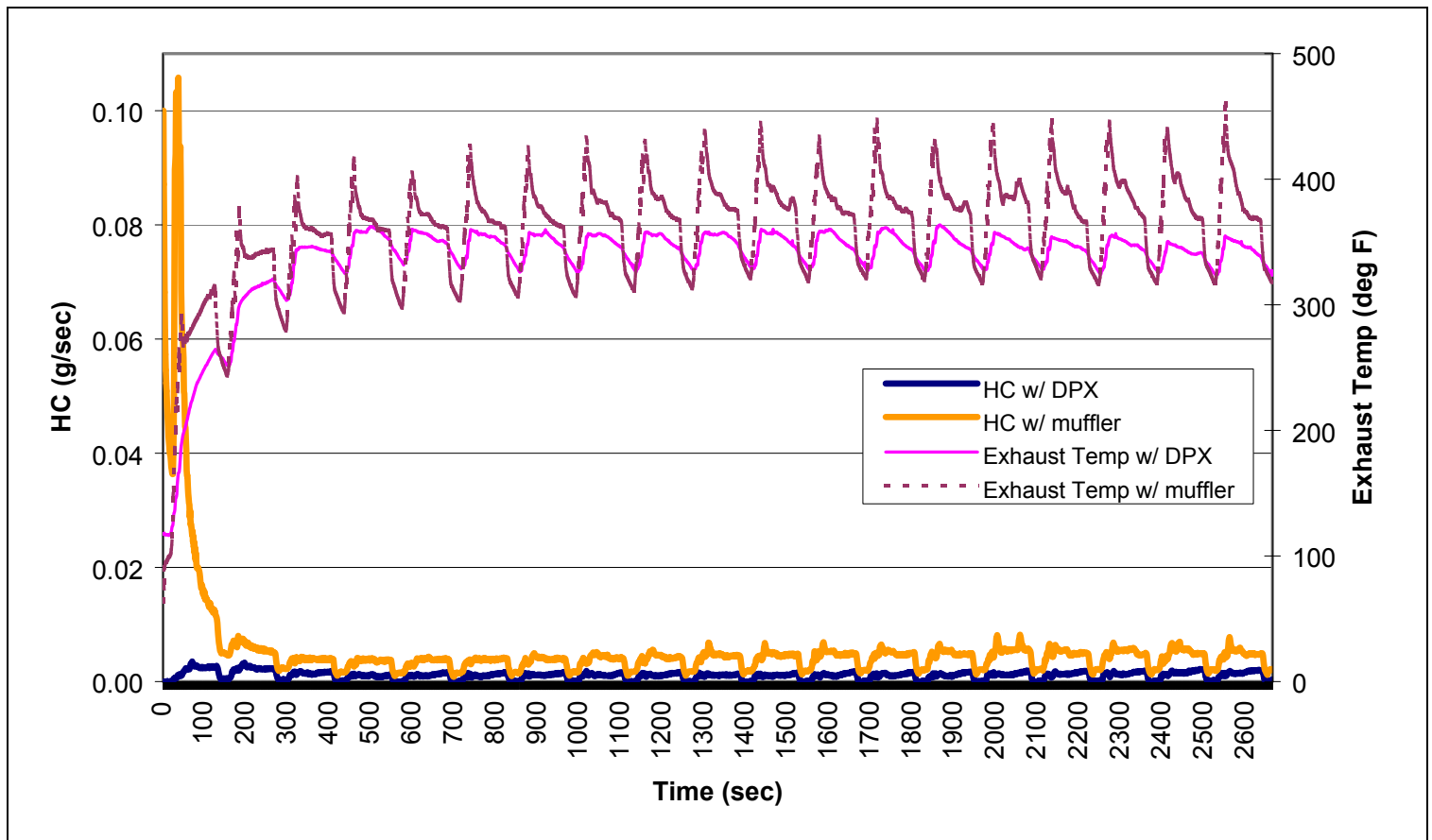

Figure 4.1.9: HC emissions from cold start testing of the WVU Mack tractor truck. 


\subsubsection{3 $\mathrm{NO}_{\mathrm{X}}$ Emissions}

As expected, no significant $\mathrm{NO}_{\mathrm{X}}$ reductions were recorded in any of the seven vehicles tested in this program. However, NO emissions were reduced through conversion to $\mathrm{NO}_{2}$ by the DPFs. On average, these reductions were $30 \%$ and $46 \%$ with the Engelhard DPX and Johnson-Matthey CRT, respectively. Figure 4.1.10 shows the average integrated $\mathrm{NO}_{\mathrm{X}}$ and $\mathrm{NO}$ emissions measured from the WMATA buses. It should be noted that only total $\mathrm{NO}_{\mathrm{X}}$ emissions were measured from the WVU Mack, thus it was not considered in determining $\mathrm{NO} / \mathrm{NO}_{\mathrm{X}}$ split characteristics. It was determined that $\mathrm{NO}-$ $\mathrm{NO}_{2}$ conversion increased proportionally with the exhaust temperature until the particulate filter light-off temperature was reached and engine-out emissions production stabilized. An example of this phenomenon is shown in Figure 4.1.11. In this figure, the $\mathrm{NO}$ and $\mathrm{NO}_{\mathrm{X}}$ emissions are shown from WMATA bus 3724 equipped with an Engelhard DPX relative to the post-filter exhaust temperature. Note that forth order trend lines were added to the raw data for clarity due to the overlap of the $\mathrm{NO}$ and $\mathrm{NO}_{\mathrm{X}}$ data sets. Additionally, it was determined that engine-out emissions stabilized at approximately 500 seconds. 


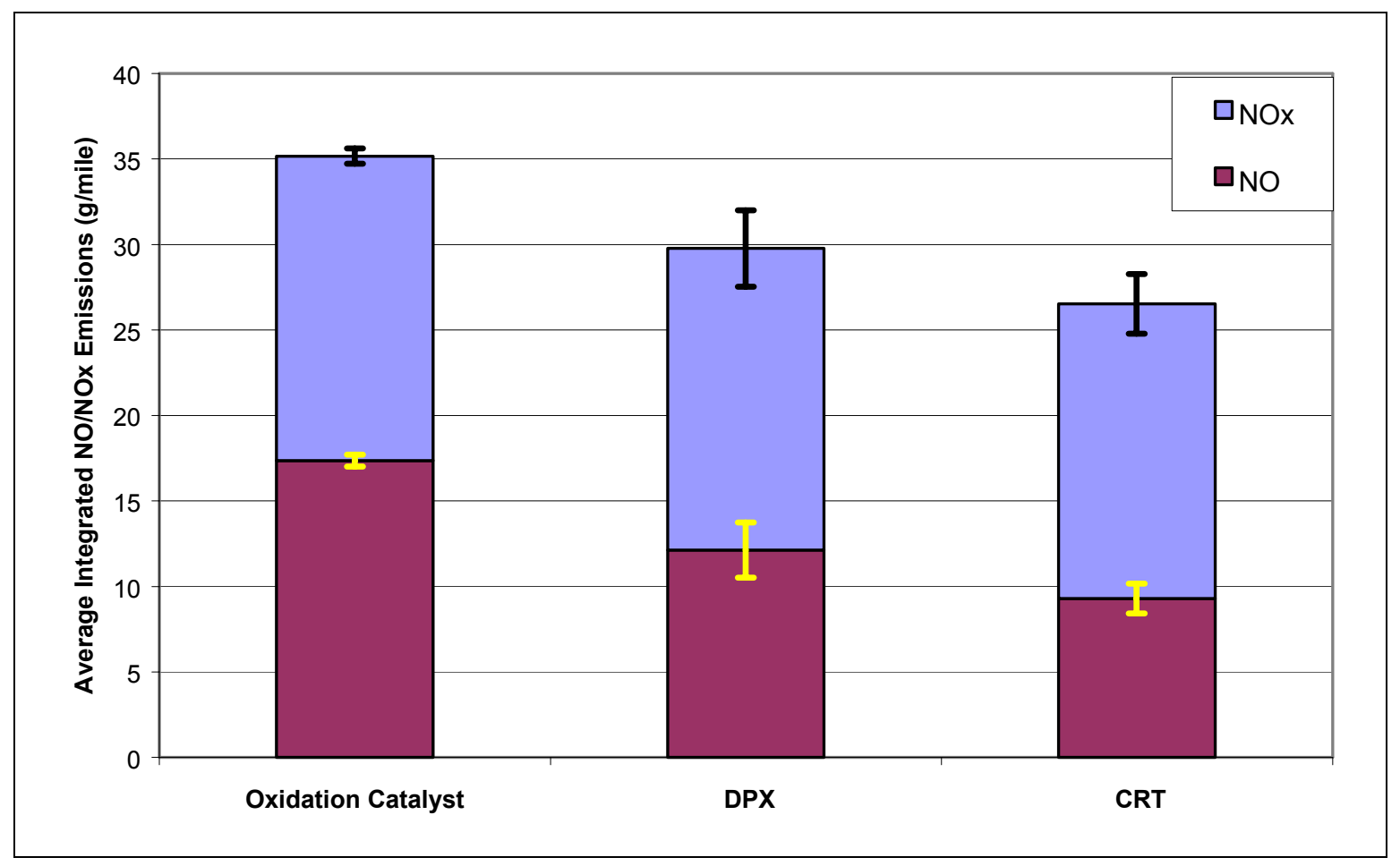

Figure 4.1.10: Average integrated $\mathrm{NO}$ and $\mathrm{NO}_{\mathrm{X}}$ emissions in grams per mile collected from cold start testing of WMATA buses

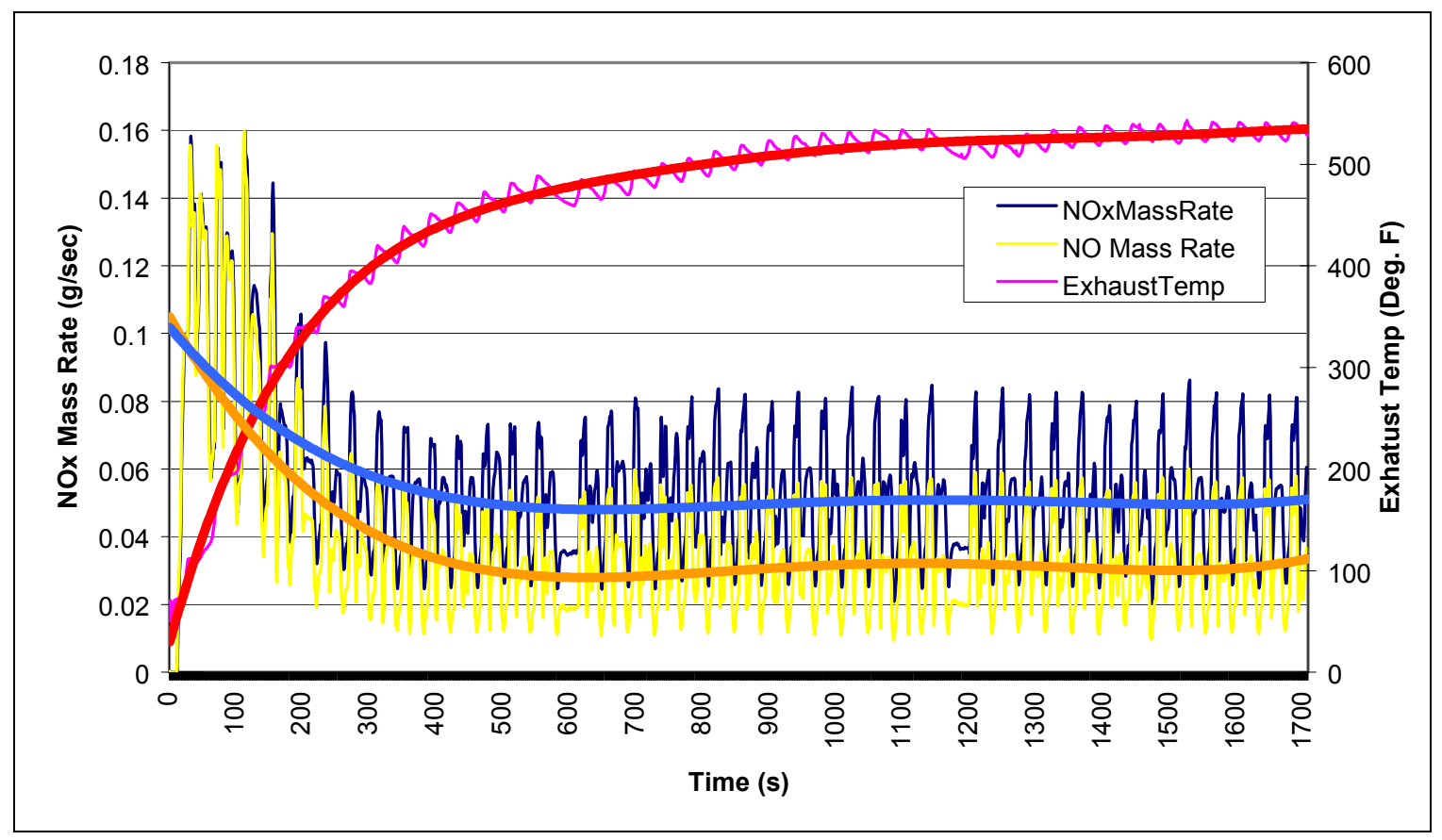

Figure 4.1.11: NO/NO ${ }_{X}$ split shown from WMATA bus 3724 using an Engelhard DPX 


\subsubsection{4 $\mathrm{CO}_{2}$ Emissions / Fuel Economy}

No significant changes were noticed in $\mathrm{CO}_{2}$ emissions from any of the seven vehicles tested. Additionally, fuel economy was not significantly affected by the particulate filter retrofit. A maximum fuel economy increase of approximately seven percent was recorded from the WMATA fleet vehicles, however this was a vehicle-tovehicle comparison and not a pre-to-post retrofit comparison, thus the fuel economy variation was attributed to other circumstances, such as possible variations in engine timing or air filter quality, and consequently disregarded. A fuel economy penalty is possible with the retrofitting of DPFs to existing vehicles as the exhaust backpressure may increase due to flow restrictions across the filter.

\subsubsection{PM Emissions}

The greatest emission reductions were witnessed in the particulate matter data where an order of magnitude reduction occurred for all vehicles in the program. PM concentrations from the WMATA buses went from an average of $0.052 \mathrm{~g} / \mathrm{mile}$ with the oxidation catalysts to $0.0052 \mathrm{~g} / \mathrm{mile}$ and $0.0037 \mathrm{~g} /$ mile with the Engelhard DPX and Johnson-Matthey CRT respectively. This figured to a $90 \%$ and $93 \%$ reduction, respectively. The WVU Mack data showed a reduction from $0.24 \mathrm{~g} /$ mile with the muffler to $0.021 \mathrm{~g}$ /mile with the DPF. This was a reduction of greater than $99 \%$.

TEOM data for all vehicles showed a cycle-wide reduction in mass concentration, however the most important observation from this data was the lack of a spike in the data at engine start-up. This correlates to filter efficiency at low, or ambient, temperatures, i.e. the filters collect PM before reaching the particulate filter light-off temperature. Figure 
4.1.12 shows the TEOM data for two cold-weather cold-start test runs using the WVU Mack, one with the DPF installed and one with a muffler in place.

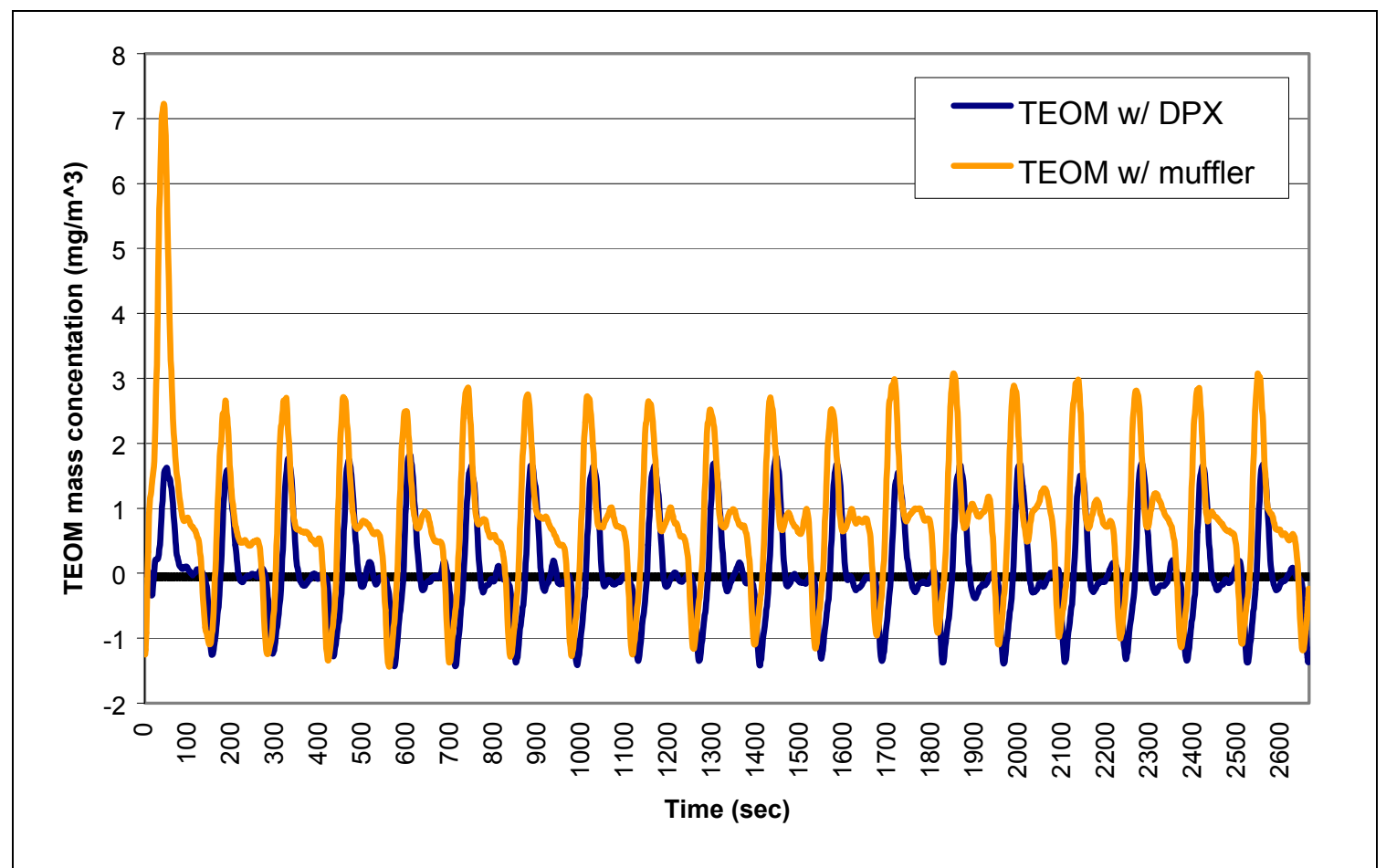

Figure 4.1.12: TEOM data from the WVU Mack tractor truck from coldweather cold-start testing.

\subsubsection{White Smoke Emissions}

The particulate filters had little affect on reducing white smoke emissions. The continuous data showed a large "puff" of smoke emitted at initial engine start up on each cold start run, thus suggesting the particulate filters do not filter the white smoke constituents. However, it should be noted that inconsistencies, including electrical noise and analyzer drift, were found in the smoke opacity data for several test runs, thus voiding the opacity data collected from these runs. Additionally, opacity measurements were not taken during the testing of the WVU Mack tractor truck. Figure 4.1.13 shows the continuous data collected from a sample cold start test run from vehicle WMATA 3724. Shown on this figure are the smoke opacity, smoke density, and exhaust 
temperature data from this run. The white smoke puff emitted at engine start up is visible as a spike in opacity seen on the left of the figure.

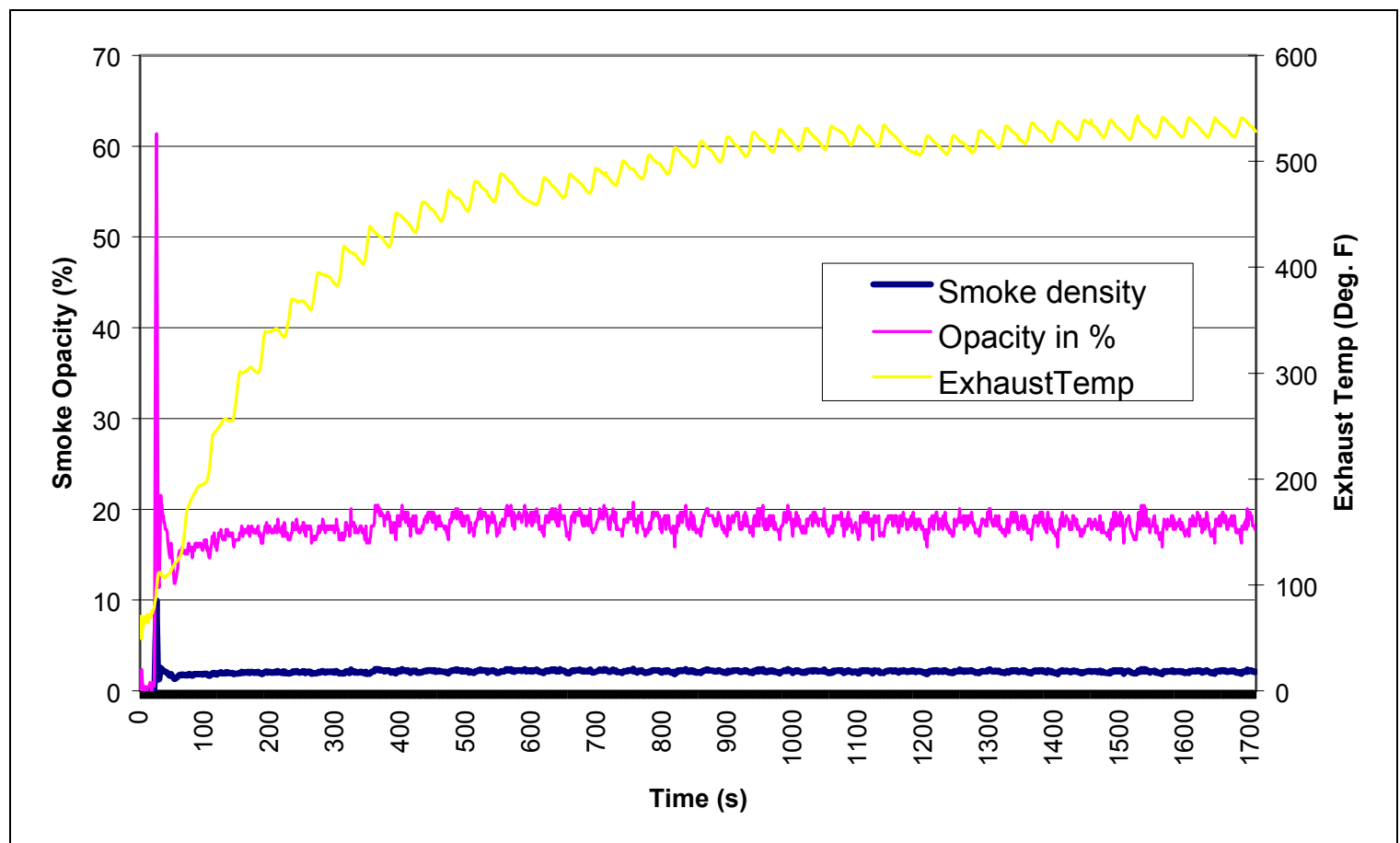

Figure 4.1.13: Smoke opacity, smoke density, and exhaust temperature data from WMATA bus 3724.

\subsection{Long-Term Durability Evaluation of Ralph's Grocery Fleet Vehicles}

To determine the aging characteristics and durability of the diesel particulate filters, a three-year, three-round study was performed in Riverside, California using trucks from the Ralph's Grocery Fleet based out of Riverside, California. The selected vehicles were originally tested in the spring and summer of 2000. The same vehicles were retested for round two in the spring of 2001. The final tests were performed in the spring of 2002.

\subsubsection{Test Vehicles}

Four vehicles were chosen for the long-term DPF durability evaluation. These vehicles were 1998 Sterling Class 8 tractor trucks taken from the Ralph's Grocery Fleet 
in Riverside, California. Two vehicles were equipped with Engelhard DPXs and two with Johnson-Matthey CRTs. Each vehicle was equipped with a 12.7 liter Detroit Diesel Corporation Series 60 six-cylinder engine and a 10-speed manual transmission. Each truck had a gross vehicle weight of 80,000 pounds and was tested at 42,000 pounds.

It was predicted that the diesel particulate filter performance would degrade proportionally with the mileage accumulated between testing rounds. The mileage of each vehicle at the time of testing for each round is shown in Figure 4.2.1.

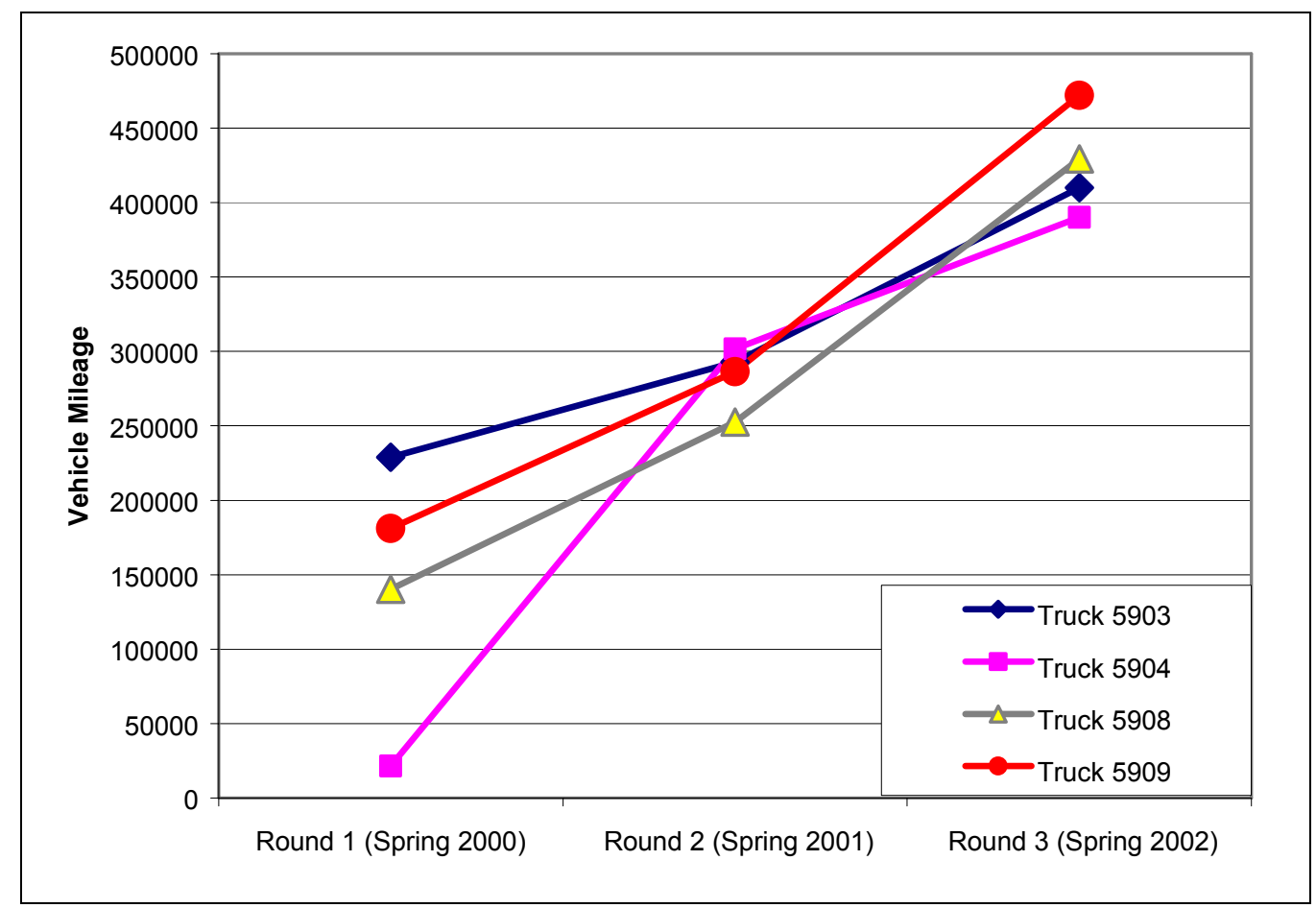

Figure 4.2.1: Vehicle mileage for durability study

\subsubsection{Vehicle Fuels}

As set forth in the original test matrix by Keith Vertin of NREL, National Renewable Energy Laboratory, three fuels were utilized during the course of this durability study. They included CARB Diesel, Emission Control Diesel (ECD), and Emission Control Diesel-1 (ECD1). Table 4.2.1 shows the test vehicles, DPFs, and the fuels utilized in 
each round. It should be noted that in Table 4.2.1, CRT and DPX refer to the JohnsonMatthey CRT and Engelhard DPX respectively.

Table 4.2.1: Vehicle Test Matrix for Durability Study

\begin{tabular}{|c|c|c|c|c|c|c|}
\hline & \multicolumn{2}{|c|}{ Round 1} & \multicolumn{2}{|c|}{ Round 2} & \multicolumn{2}{|c|}{ Round 3} \\
\hline $\begin{array}{c}\text { Vehicle ID } \\
\text { Number }\end{array}$ & DPF & Fuel & DPF & Fuel & DPF & Fuel \\
\hline \multirow{5}{*}{5903} & & & CRT & ECD & & \\
\hline & CRT & ECD & NONE & ECD & CRT & ECD1 \\
\hline & NONE & ECD & CRT & ECD1 & NONE & CARB \\
\hline & NONE & CARB & NONE & ECD1 & & \\
\hline & & & NONE & CARB & & \\
\hline & & & & & & \\
\hline \multirow{4}{*}{5904} & CRT & ECD & CRT & ECD & CRT & ECD1 \\
\hline & NONE & ECD & CRT & ECD1 & NONE & CARB \\
\hline & NONE & CARB & NONE & ECD1 & & \\
\hline & & & NONE & CARB & & \\
\hline & & & & & & \\
\hline \multirow{2}{*}{5908} & DPX & ECD & DPX & ECD & DPX & ECD1 \\
\hline & & & DPX & ECD1 & NONE & CARB \\
\hline \multirow{2}{*}{5909} & DPX & ECD & DPX & ECD & DPX & ECD1 \\
\hline & & & & & DPX & CARB \\
\hline
\end{tabular}

Table 4.2.2 shows the fuel characteristics for each of the fuels utilized in this study as reported by the US Department of Energy, Office of Transportable Technologies (USDOE, 2002). It has been shown that the use of ultra-low sulfur fuels, particularly ECD, can reduce all regulated engine out emissions when compared to engine out emissions produced from CARB fueled engines. In previous emission testing performed by West Virginia University for NREL, emissions reductions for regulated emissions ranged from a low of three percent for $\mathrm{NO}_{\mathrm{X}}$ emissions to a maximum of thirteen percent for PM and HC emissions (LeTavec, et al., 2000). This is important to note, as CARB fuel was the only fuel used consistently in each round of testing for this evaluation. 
Table 4.2.2: Fuel Properties for CARB, ECD, and ECD1 Diesel as Reported by the US Department of Energy Office of Transportable Technologies (USDOE, 2002)

\begin{tabular}{|l|c|c|c|c|}
\hline Property & SI Units & CARB & ECD & ECD1 \\
\hline Density & $\mathrm{kg} / \mathrm{m}^{\wedge} 3$ & 844.5 & 811.9 & 828.5 \\
\hline Distillation (Initial Boiling Point) & Deg. C & 177.6 & 211.6 & 168.9 \\
\hline Cetane Number & unitless & 54.1 & 64.7 & 51.3 \\
\hline Cetane Index & unitless & 50.6 & 67.2 & 49.8 \\
\hline Carbon & mass \% & 85.8 & 84.7 & 87.01 \\
\hline Hydrogen & mass \% & 13.44 & 14.44 & 13.82 \\
\hline Sulfur & ppm & 121.1 & 7.4 & 13.1 \\
\hline Olefins & volume \% & 3.4 & 2.5 & 3 \\
\hline Saturates & volume \% & 72.8 & 88 & 75.9 \\
\hline Total Aromatics & mass \% & 22.5 & 10.9 & 22.8 \\
\hline Ash & mass \% & $<0.001$ & $<0.001$ & $<0.001$ \\
\hline Heat of Combustion, gross (HHV) & MJ/kg & 45.74 & 46.42 & 45.96 \\
\hline Heat of Combustion, net (LHV) & MJ/kg & 42.89 & 43.36 & 43.02 \\
\hline Flash Point & Deg. C & 71.7 & 87.2 & 58.3 \\
\hline Cloud Point & Deg. C & -9 & -3 & -11 \\
\hline
\end{tabular}

\subsubsection{Driving Schedules}

For consistency of test results between testing rounds, the same driving schedule was used for all testing throughout the study. The driving schedule utilized was the CitySuburban Heavy Vehicle Route, or CSHVR. This route was developed by West Virginia University in 1999 as a useful and realistic test schedule for truck emissions characterization. It has proved to be relatively insensitive to vehicle test weight, as it demands full power operation of the vehicle during acceleration ramps without regard to test weight (Clark, et al., 1999).

The CSHVR was developed from data logged from vehicles performing local deliveries in Akron, $\mathrm{OH}$ and Richmond, VA. This data was used to develop three speed versus time driving cycles, a Yard cycle, a Freeway cycle, and a City-Suburban cycle. The City-Suburban cycle was converted to a speed versus distance route, the CSHVR, in which the test vehicle performed numerous maximum accelerations throughout the test schedule. The resultant route covered a distance of 6.68 miles with a maximum speed of 
43.8 mph (Clark, et al., 1999). Figure 4.2.2 shows the trace of the CSHVR route as driven by a test vehicle.

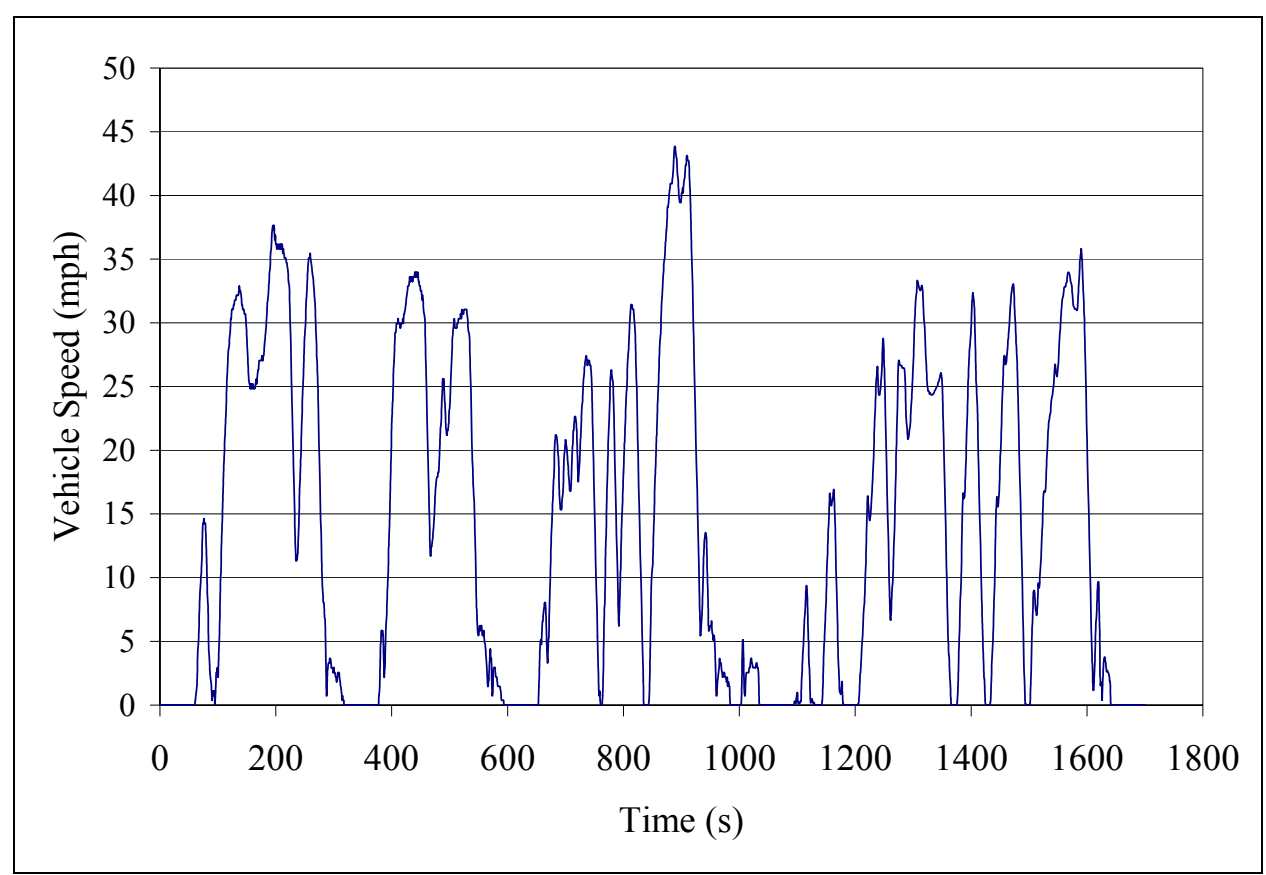

Figure 4.2.2: Scheduled speed vs. time for the CSHVR as driven by a test vehicle.

The CSHVR was used for all test runs performed in this study without DPFs installed, however, in order to facilitate sufficient particulate filter loading when using a DPF, the route distance was doubled to 13.4 miles by repeating the route sequence. This double length route was denoted as $2 \mathrm{cshvr}$.

\subsubsection{Results}

The purpose of this evaluation was to determine the life cycle and durability of a diesel particulate filter. The data collected for this study is presented in this section in units of grams per mile $(\mathrm{g} / \mathrm{mile})$. The data is organized into three sets: emissions with DPFs installed, engine-out emissions using standard CARB fuel, and engine-out emissions using ultra-low sulfur fuels (ECD and ECD1). The engine-out emissions are presented in order to determine any existing trends or fluctuations in the round-to-round 
data which may skew the approximation of DPF durability. The existence and possible causes of these fluctuations are discussed in a subsequent section of this thesis.

\subsubsection{CO Emissions}

$\mathrm{CO}$ emissions from test runs using the DPFs are shown in Figure 4.2.3. CO emissions were consistent for all vehicles in round one, however the Engelhard DPX equipped vehicles showed a significant increase in $\mathrm{CO}$ concentrations in rounds two and three compared to the Johnson-Matthey CRT equipped vehicles. Note that, as specified in the original test matrix, truck 5903 was not tested with ECD1 fuel in round 2.

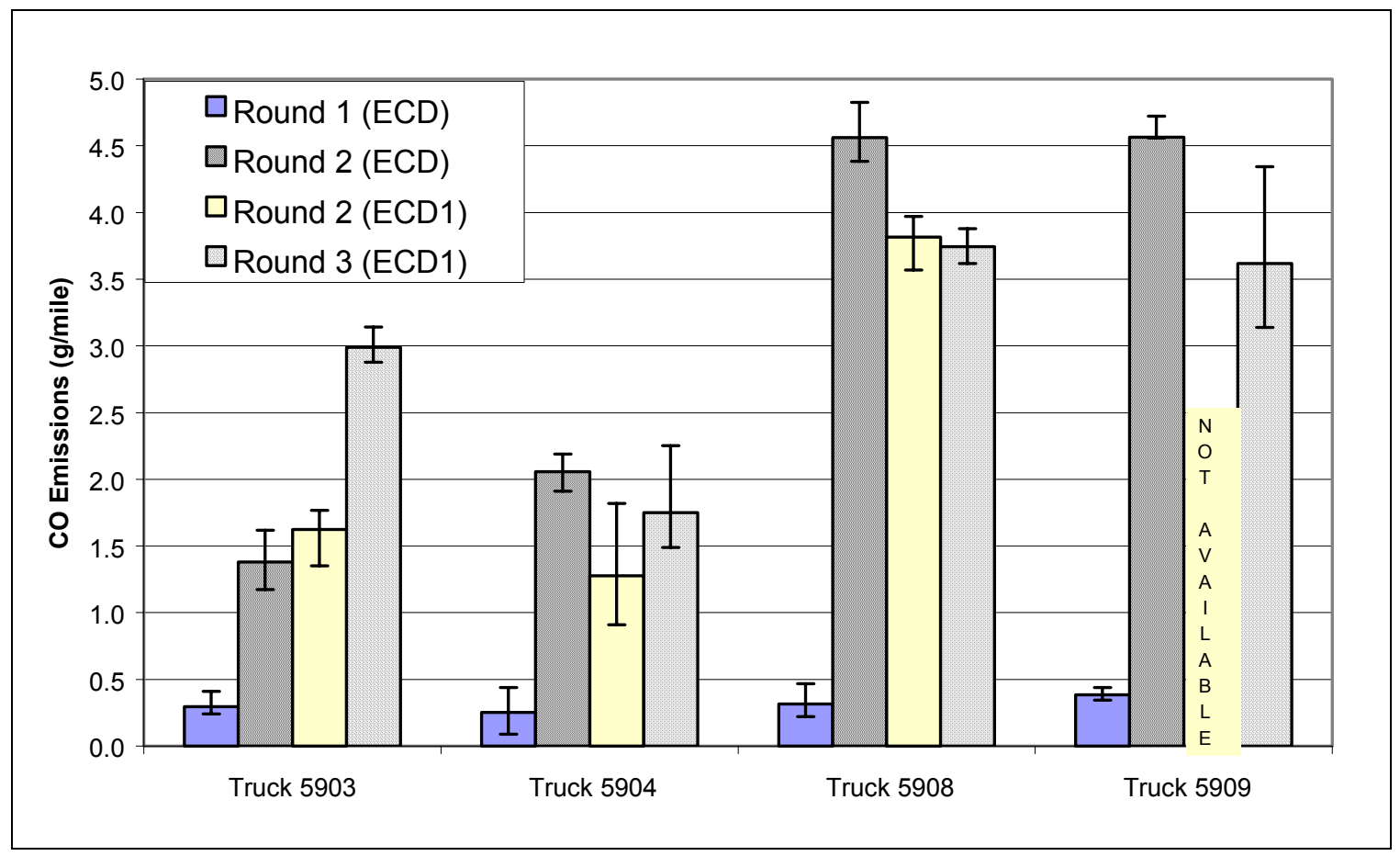

Figure 4.2.3: CO emissions from test runs using DPFs

$\mathrm{CO}$ emissions from test runs without DPFs installed are shown in Figures 4.2.4 and 4.2.5. Only trucks 5903 and 5904 were tested without particulate filters in each round of this study, additionally truck 5904 was only tested with ECD1 fuel in round 2 without a particulate filter. In round three, no vehicles were tested without a particulate filter running on ultra-low sulfur fuel. Trucks 5908 and 5909 were tested with CARB 
fuel without a particulate filter installed in round three, however this data is not shown as there is no data to compare it to in the previous rounds of testing.

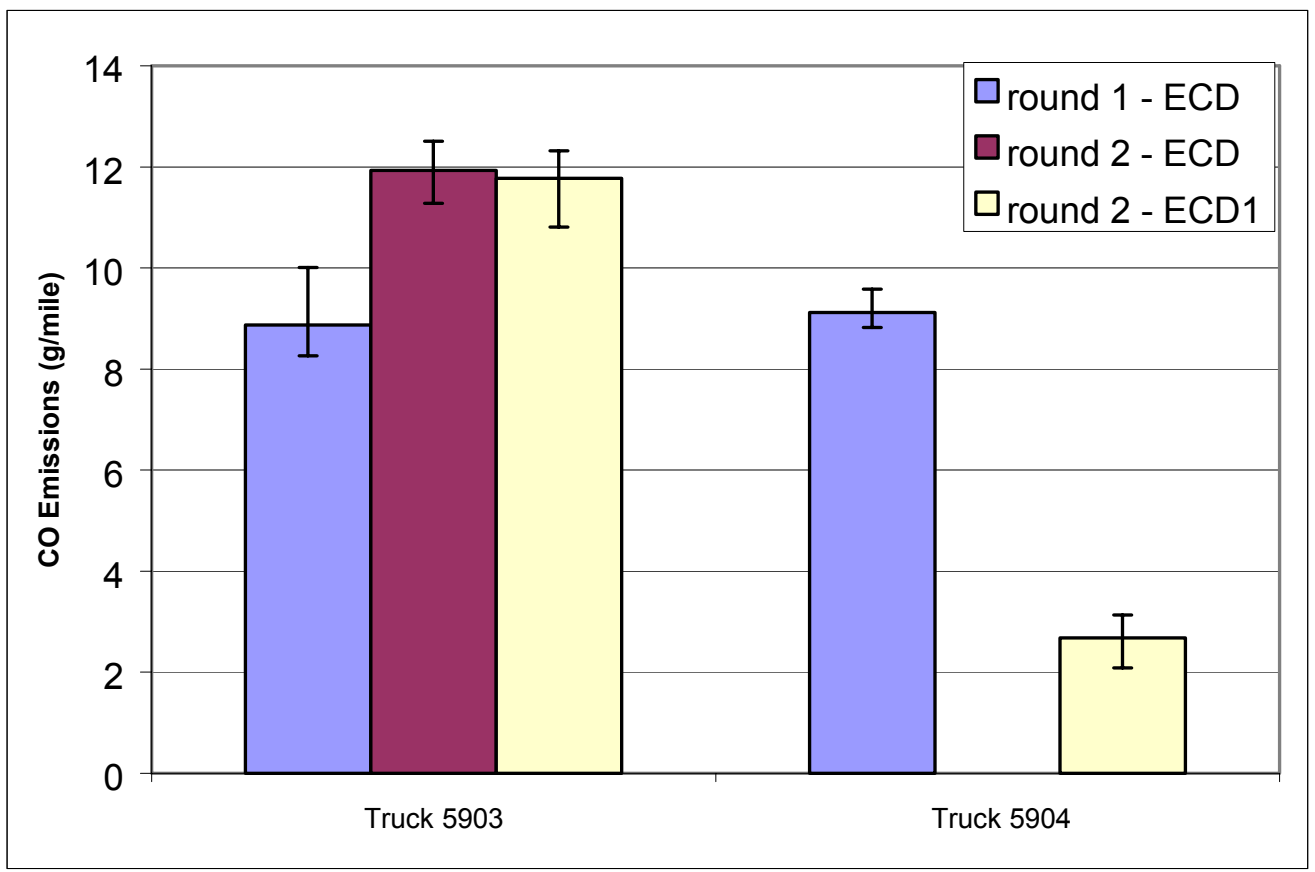

Figure 4.2.4: $C O$ emissions from trucks 5903 and 5904 running on ultra-low sulfur fuel without the DPFs.

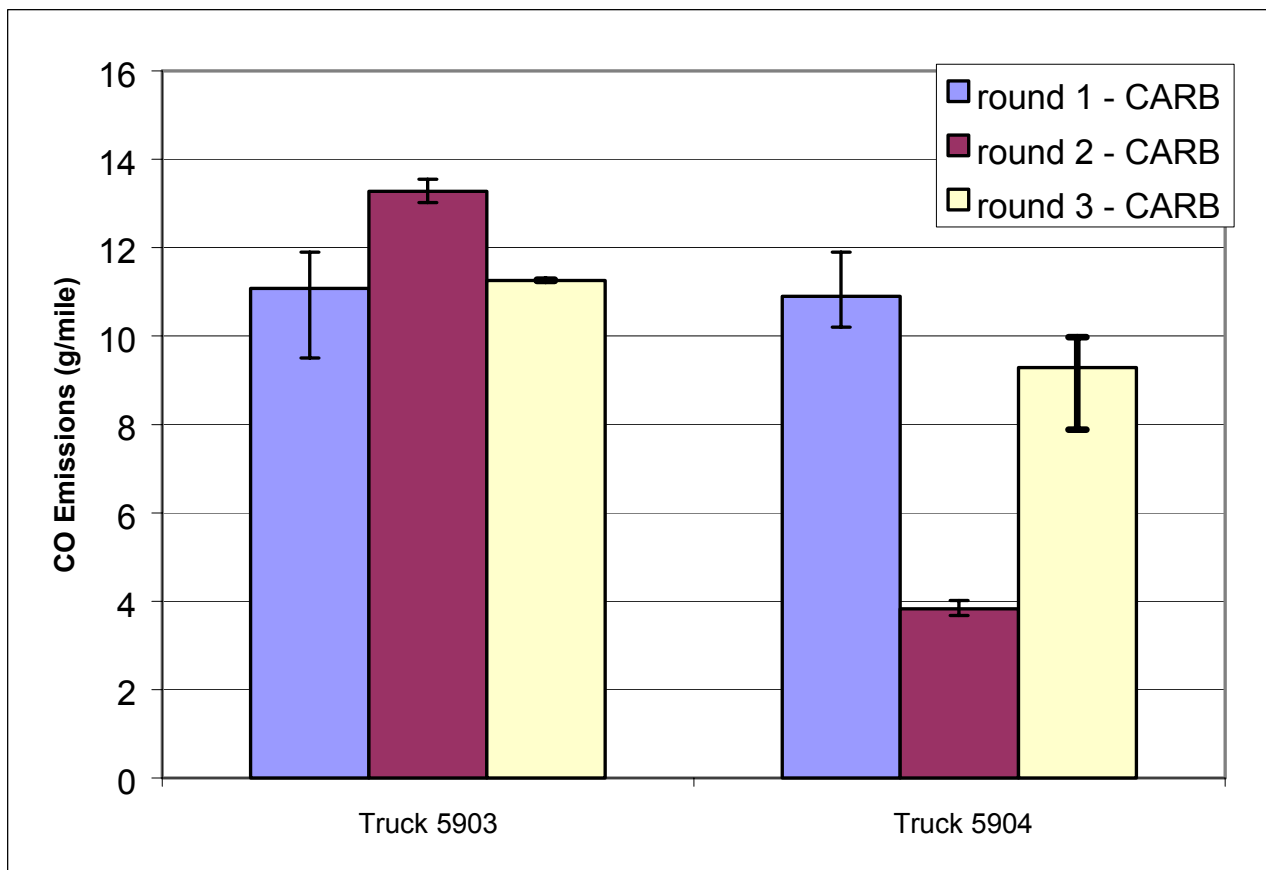

Figure 4.2.5: CO emissions from trucks 5903 and 5904 running on CARB fuel without the DPFs. 
Round one yielded $\mathrm{CO}$ emissions reductions of greater than 90 percent for both DPF types. In round two, $\mathrm{CO}$ emissions reductions dropped to approximately 85 percent for the CRT and 62 percent for the DPX while the vehicles were fueled with ECD. While fueled with ECD1, reductions were 81 percent and 52 percent for the CRT and DPX respectively. Round three data showed reductions of approximately 74 percent and 57 percent for the CRT and DPX respectively, however these reductions were recorded with the filter equipped vehicles running on ECD1 fuel and the non-filter equipped vehicles using CARB fuel.

\subsubsection{HC Emissions}

HC emissions from test runs utilizing the DPFs are shown in Figure 4.2.6. HC emissions from round one were below detectable limits for all of the trucks tested. Additionally, truck 5903 equipped with a Johnson-Matthey CRT released below detectable limits of HC throughout all rounds of testing. Round three data for truck 5908 was declared "not reportable" due to inconsistencies within that data. 


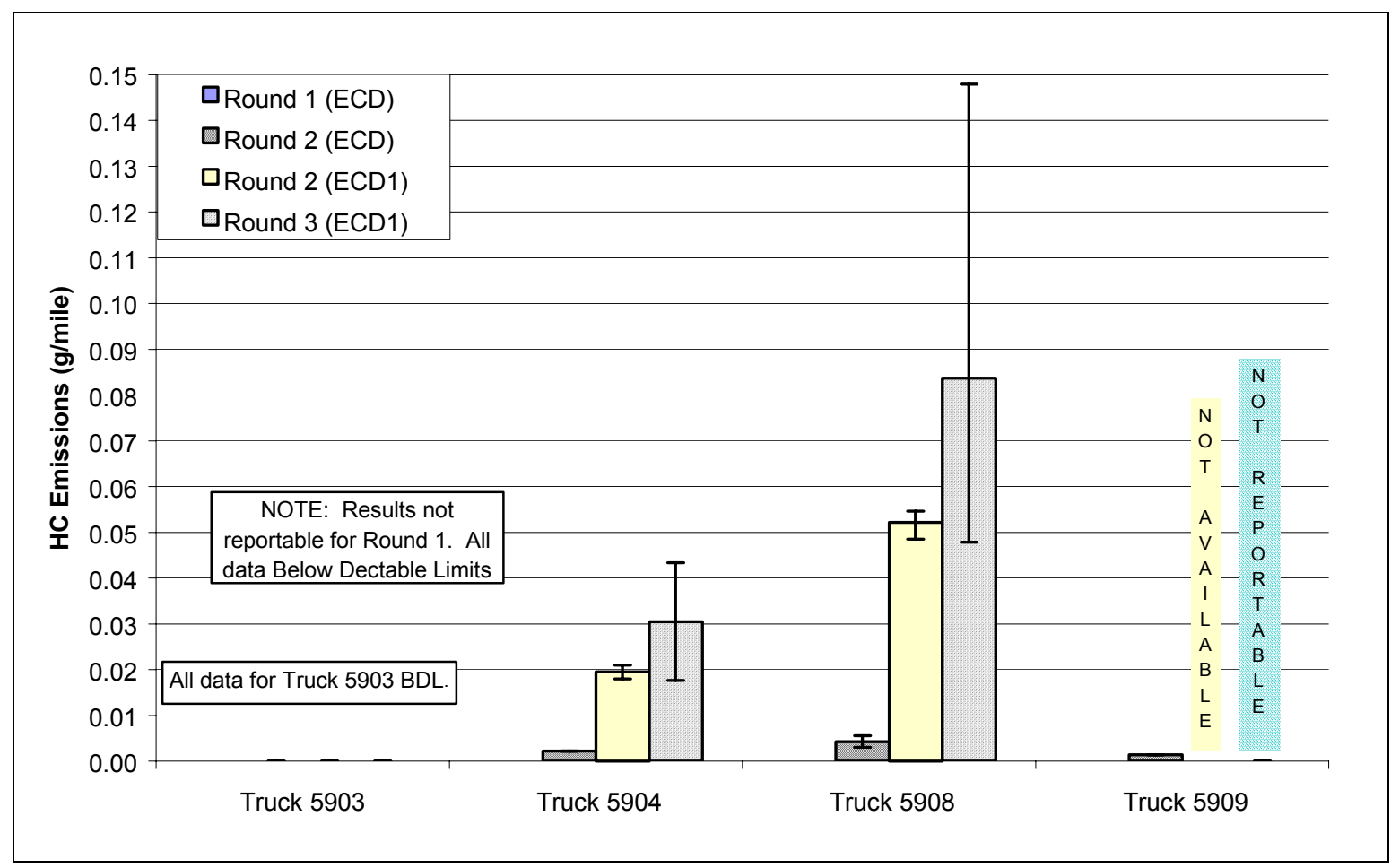

Figure 4.2.6: HC emissions from test runs utilizing the DPFs.

Figure 4.2.7 shows the engine-out emissions of Trucks 5903 and 5904 when fueled with ECD and ECD1 fuels. Engine out emissions of the same trucks when fueled with CARB fuel are shown in Figure 4.2.8. 


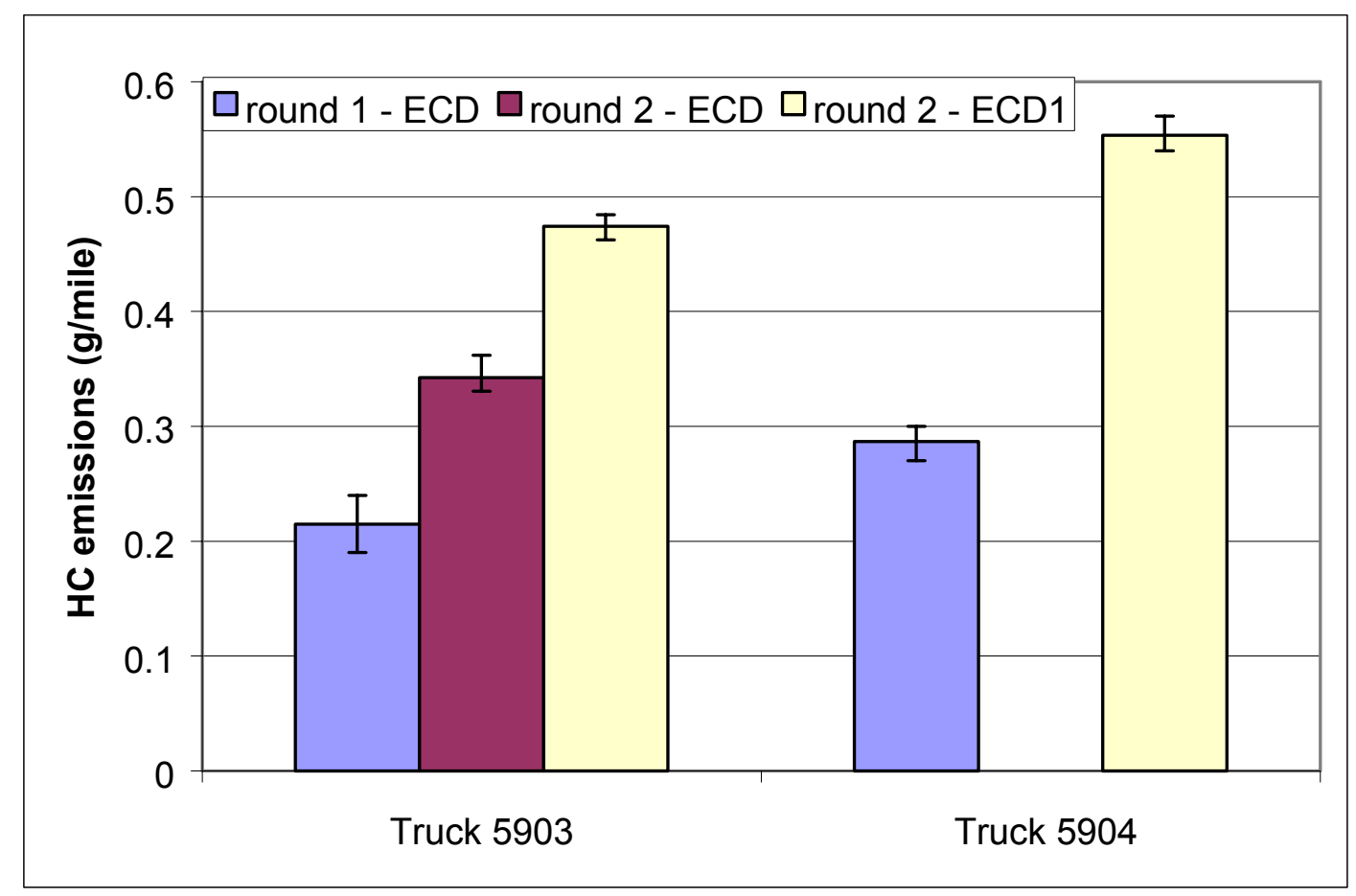

Figure 4.2.7: HC emissions from trucks 5903 and 5904 running on ultra-low sulfur fuel without the DPFs.

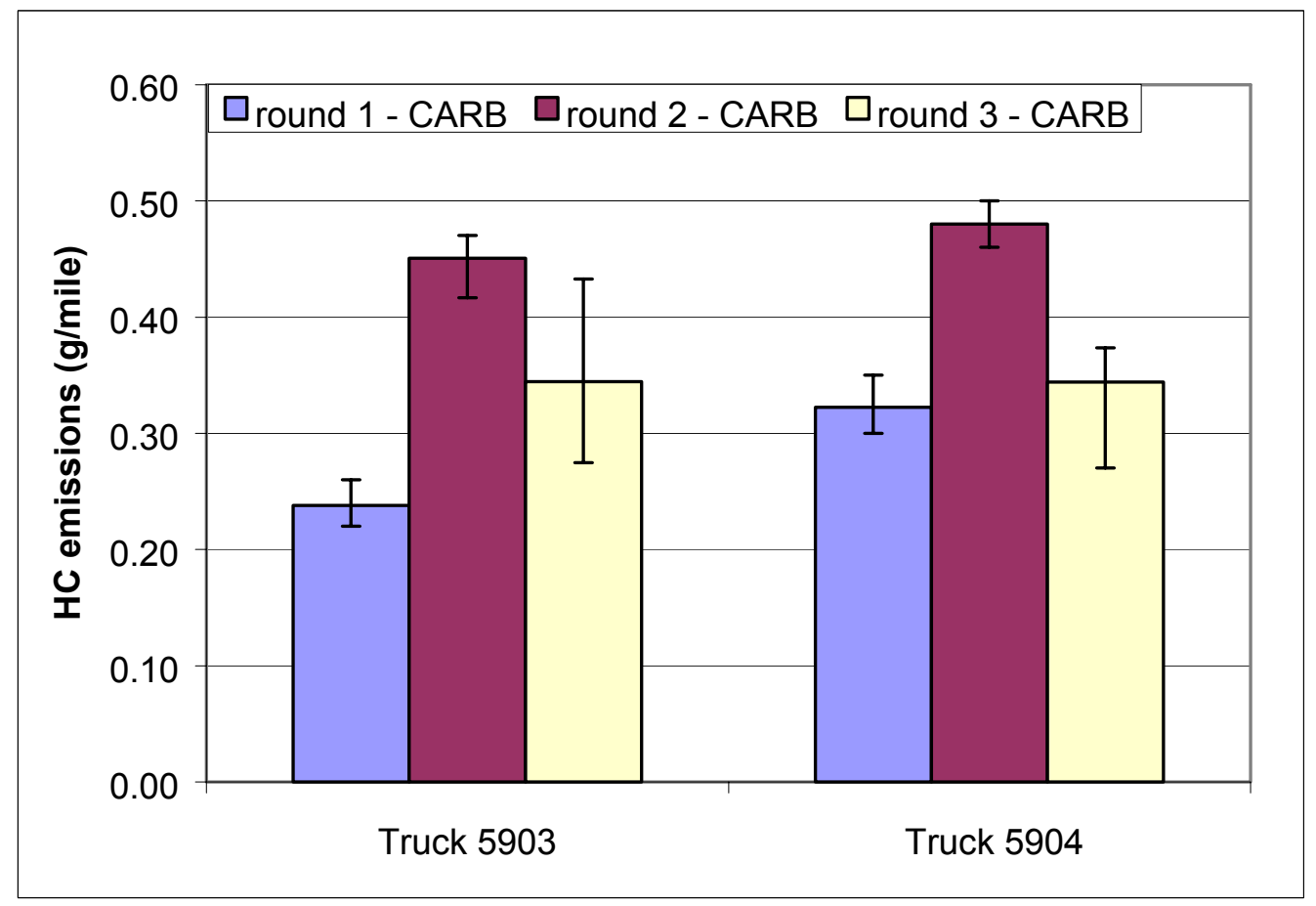

Figure 4.2.8: HC emissions from trucks 5903 and 5904 running on CARB fuel without DPFs. 
Round one test data yielded $\mathrm{HC}$ emission reductions greater than 99 percent for all vehicles tested. While testing with ECD fuel in round two, reduction levels remained approximately 99 percent for both DPF types, however with the ECD1 fuel, reduction levels dropped to 98 percent and 89 percent for the CRT and DPX respectively. Round three $\mathrm{HC}$ emission reductions were approximately 95 percent and 75 percent for the CRT and DPX respectively, however these reductions were achieved with respect to engineout emissions data from CARB fuel rather than ECD1.

\subsubsection{NOx Emissions}

NOx emissions from round one tests using DPFs are shown in Figure 4.2.9. Only NOx data was recorded in this round of testing, thus a determination of the NO/NOx split could not be made. Figures 4.2.10 and 4.2.11 show the NO/NOx emissions from DPF equipped test runs from round two and round three respectively. Round two

demonstrated an approximate 27 percent average conversion rate from $\mathrm{NO}$ to $\mathrm{NO}_{2}$, while round three showed only a 24 percent conversion rate. 


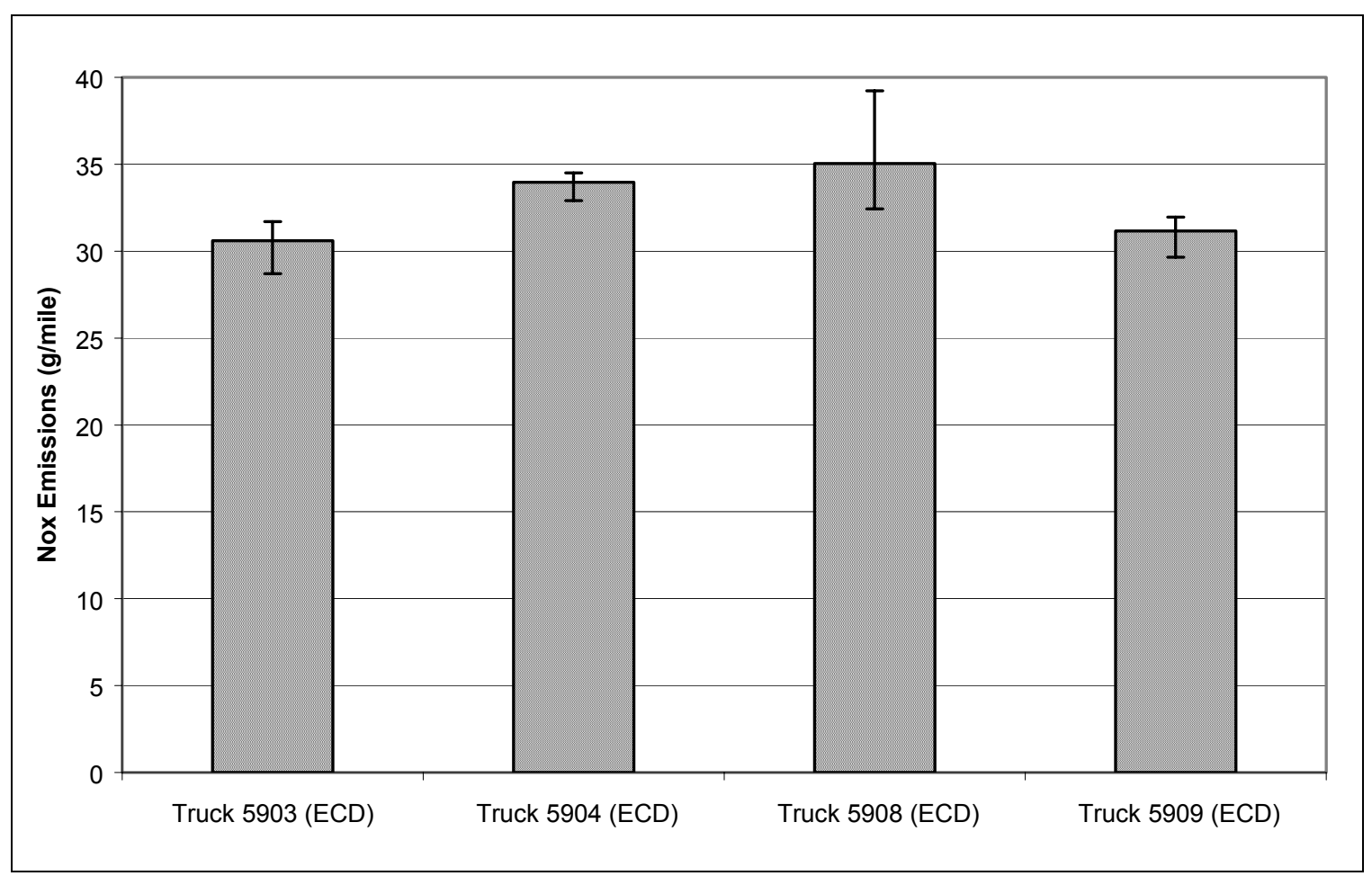

Figure 4.2.9: Round one NOx emissions using particulate filters.

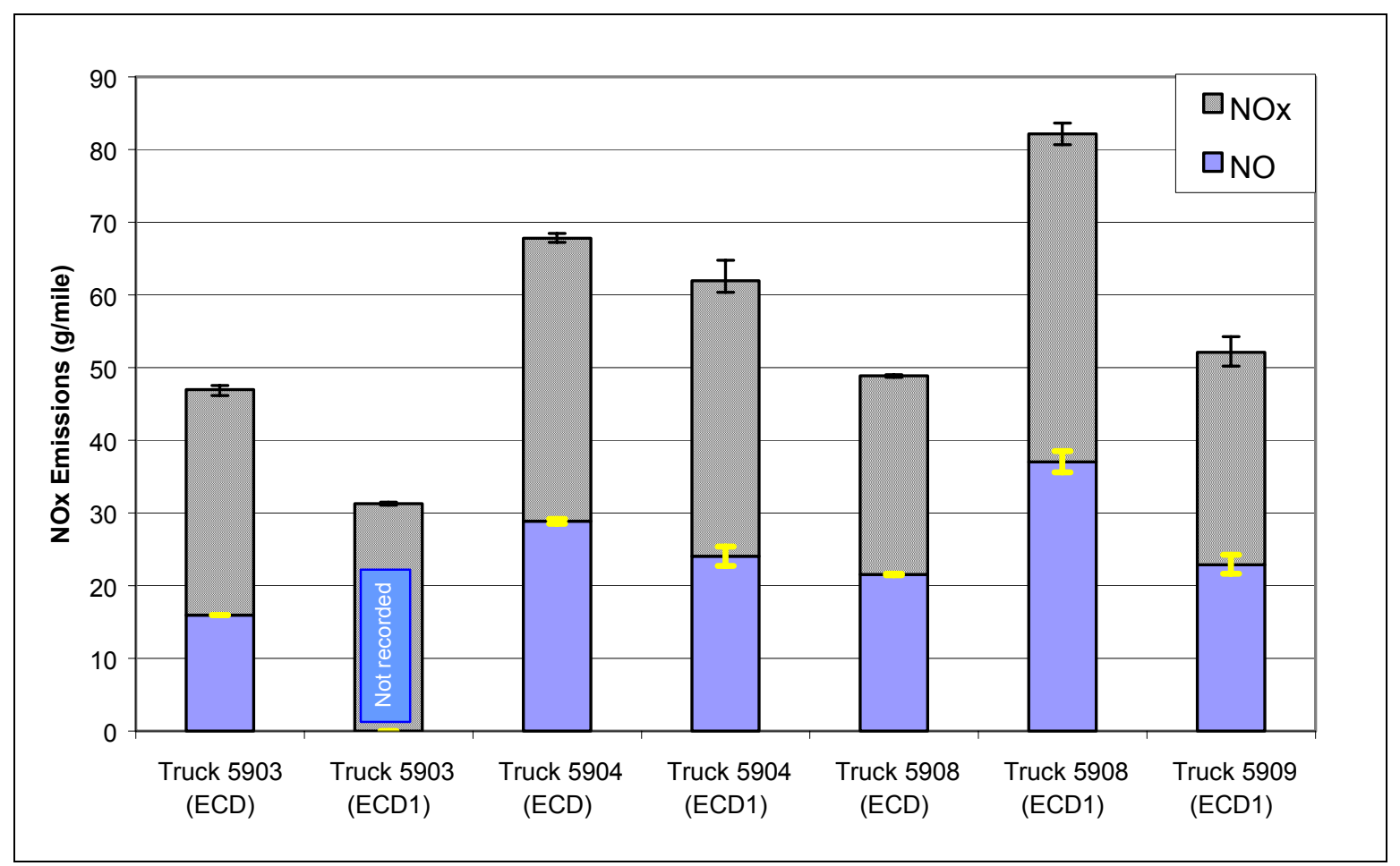

Figure 4.2.10: Round two NO and NOx emissions using particulate filters. 


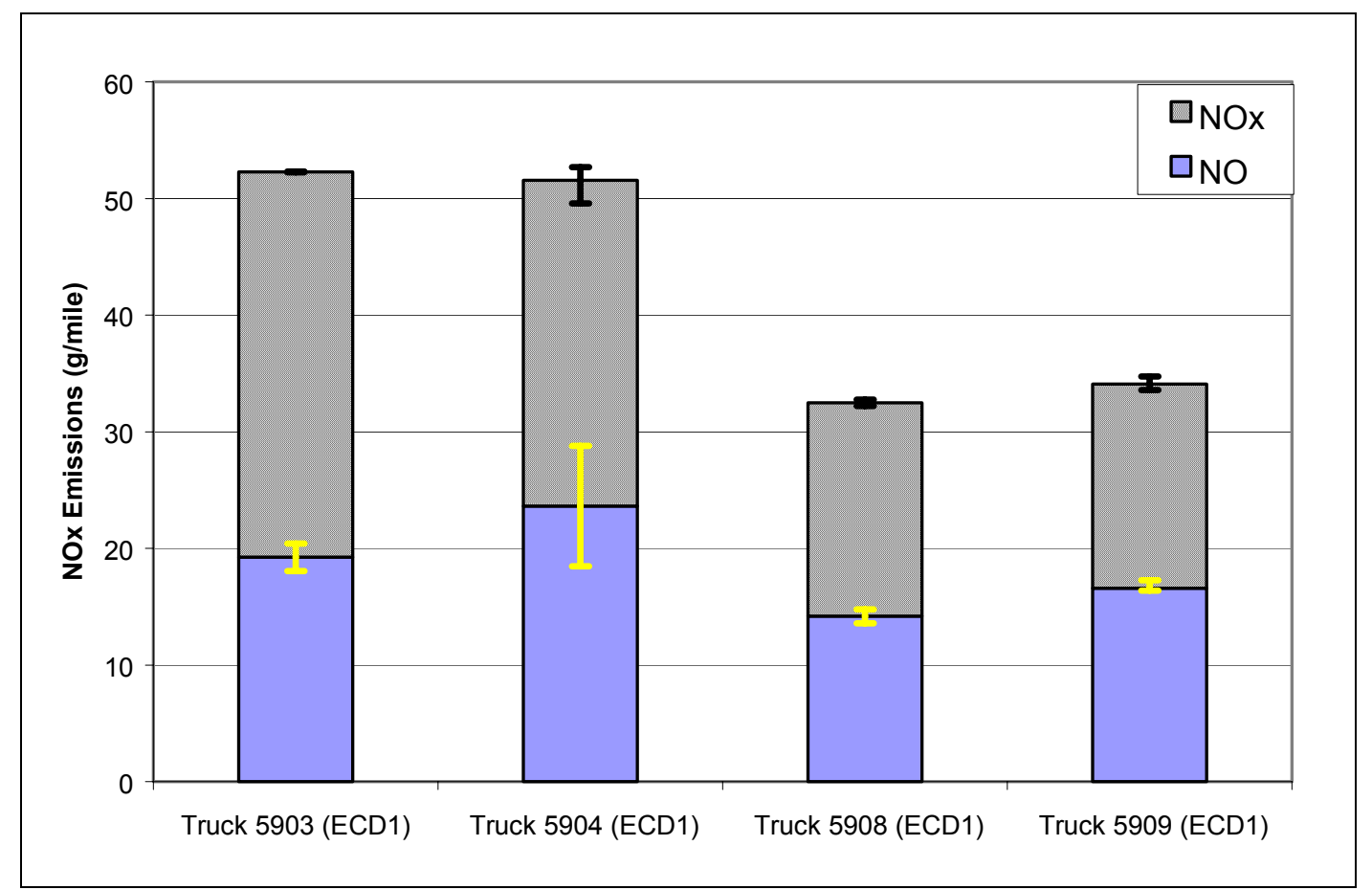

Figure 4.2.11: Round three NO and NOx emissions using particulate filters.

NOx emissions from test runs not using DPFs are shown in Figures 4.2.12 and 4.2.13 for $\mathrm{ECD} / \mathrm{ECD} 1$ fueled runs and $\mathrm{CARB}$ fueled runs respectively. As NO is not converted to $\mathrm{NO}_{2}$ without the presence of a catalyst, $\mathrm{NO}$ emissions were not reported for these runs in any round of testing.

As expected, there were no significant reductions in NOx concentrations in any of the rounds of testing. However, NO concentrations were lowered by approximately 27 percent and 24 percent, in rounds two and three, respectively. 


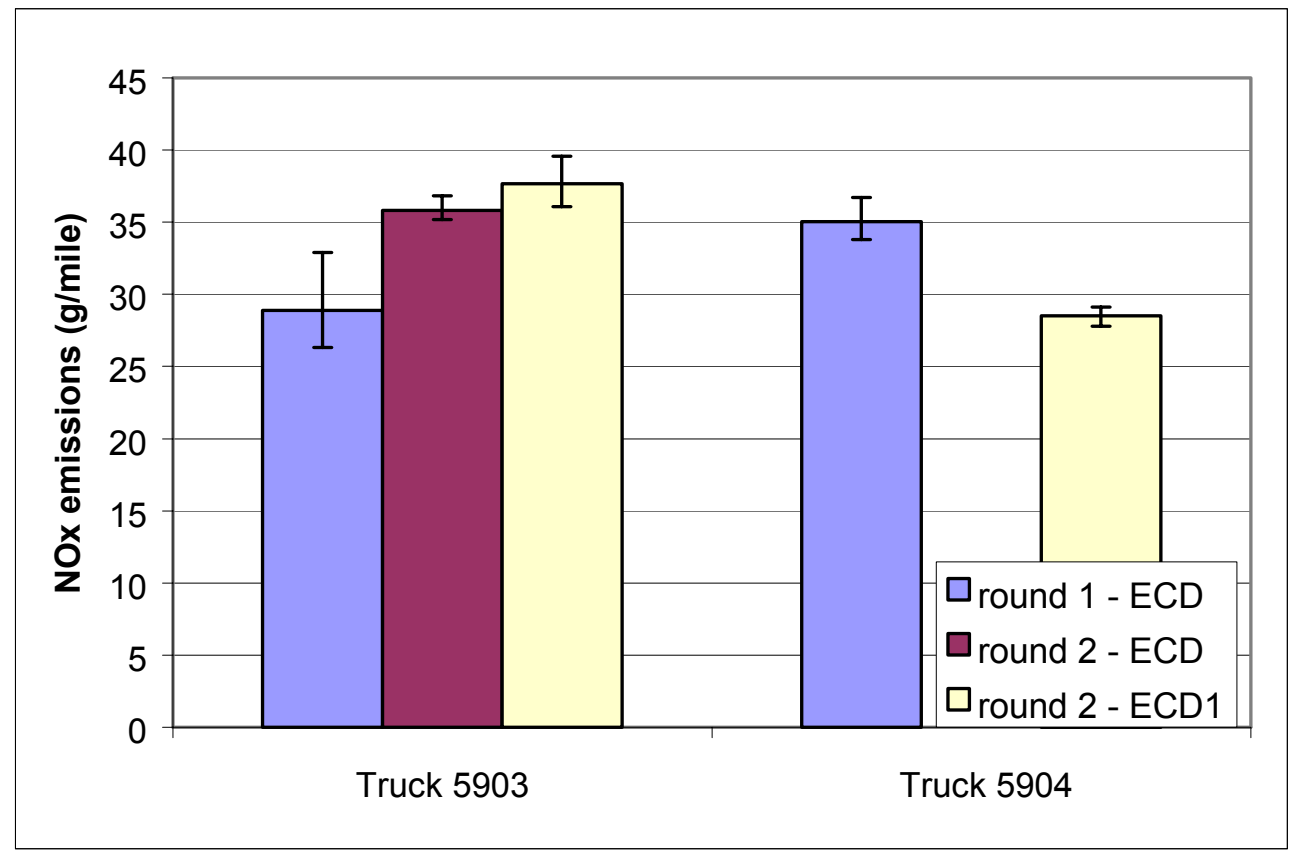

Figure 4.2.12: Total NOx emissions from ECD/ECD1 fueled test runs without DPFs.

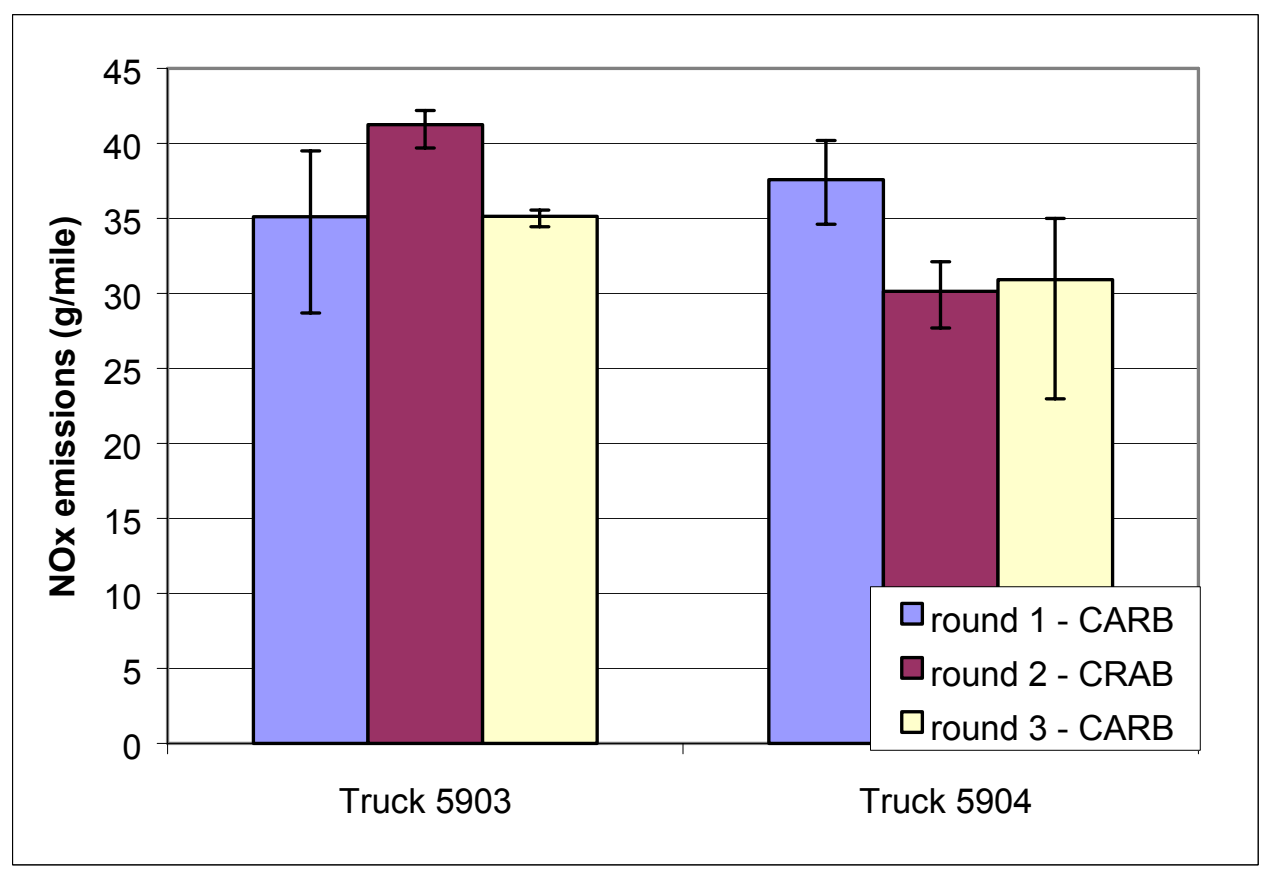

Figure 4.2.13: Total NOx emissions from CARB fueled test runs without DPFs. 


\subsubsection{4 $\mathrm{CO}_{2}$ Emissions / Fuel Economy}

Figure 4.2.14 shows the $\mathrm{CO}_{2}$ emissions released during testing with DPFs

installed. The calculated values for the fuel economy for these tests are shown in Figure 4.2.15 in units of miles per gallon (MPG). Variations in the fuel economy from round to round were generally slight, with truck 5908 seeing the largest variation between rounds one and two, a twelve percent decrease.

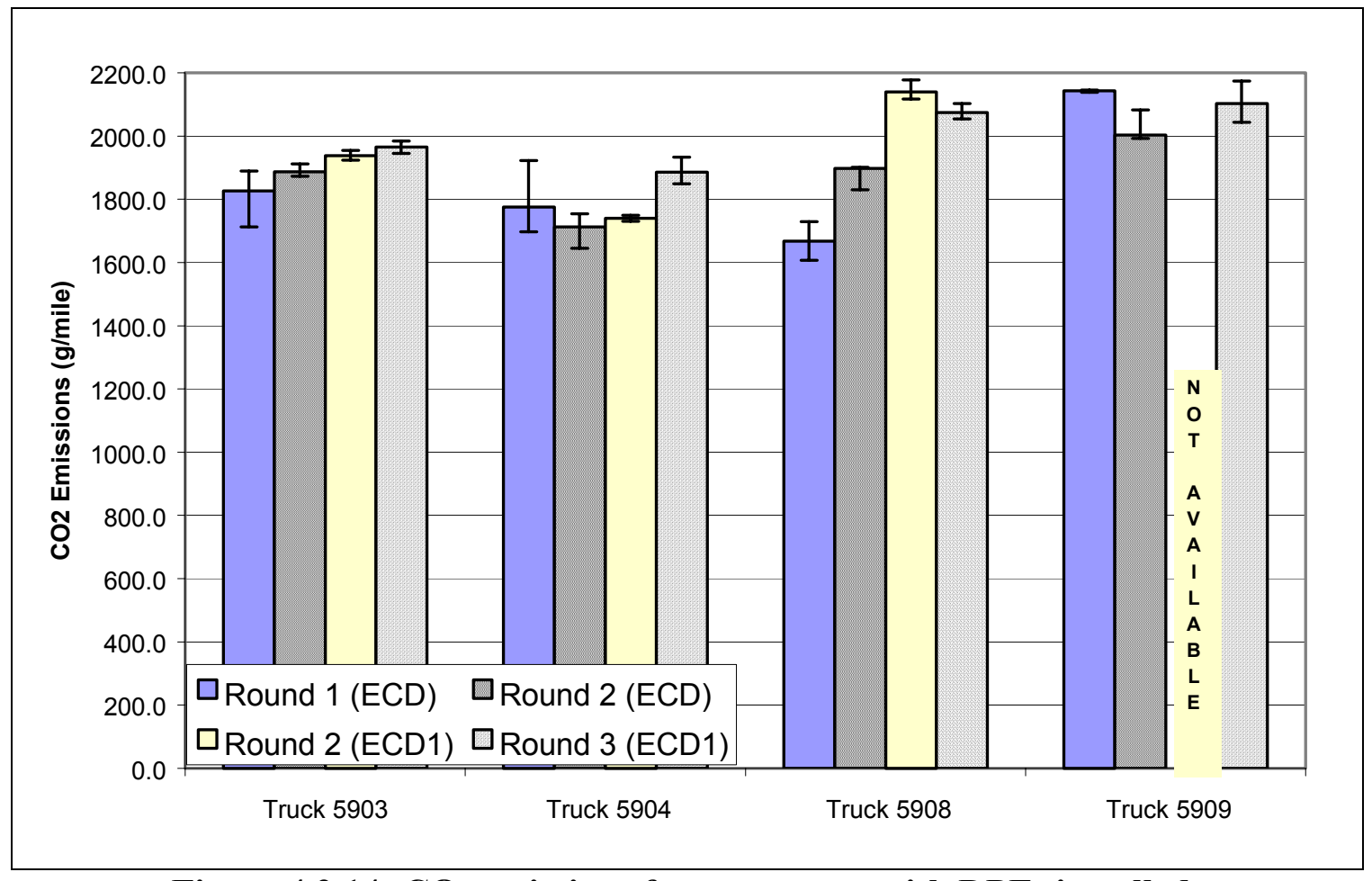

Figure 4.2.14: $\mathrm{CO}_{2}$ emissions from test runs with DPFs installed. 


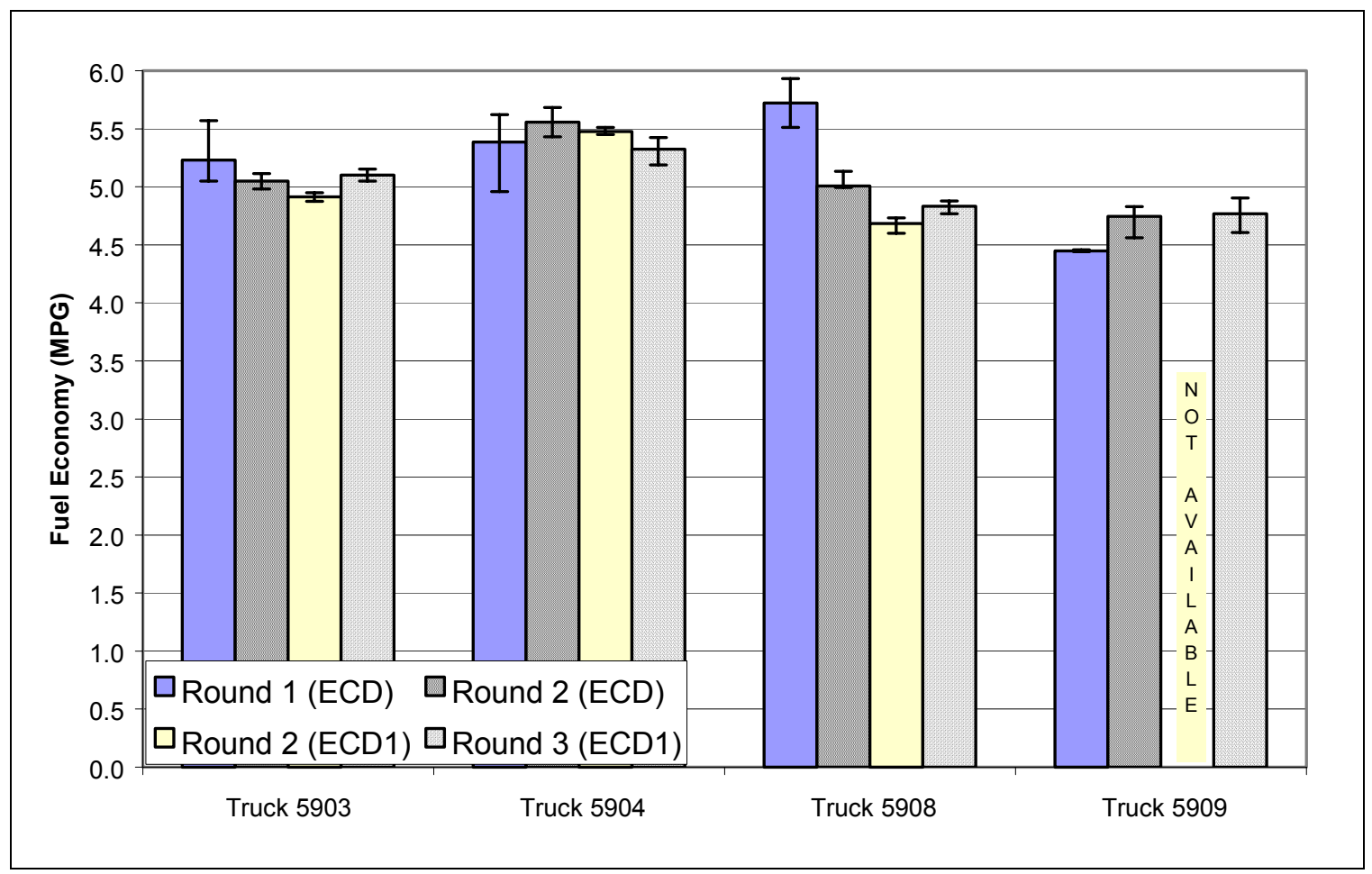

Figure 4.2.15: Fuel economy from test runs with DPFs installed.

$\mathrm{CO}_{2}$ emissions and fuel economy values for non-DPF equipped runs using ECD and ECD1 fuel are shown in Figure 4.2.16. Figure 4.2.17 shows similar plots of data collected for non-DPF runs using CARB fuel.
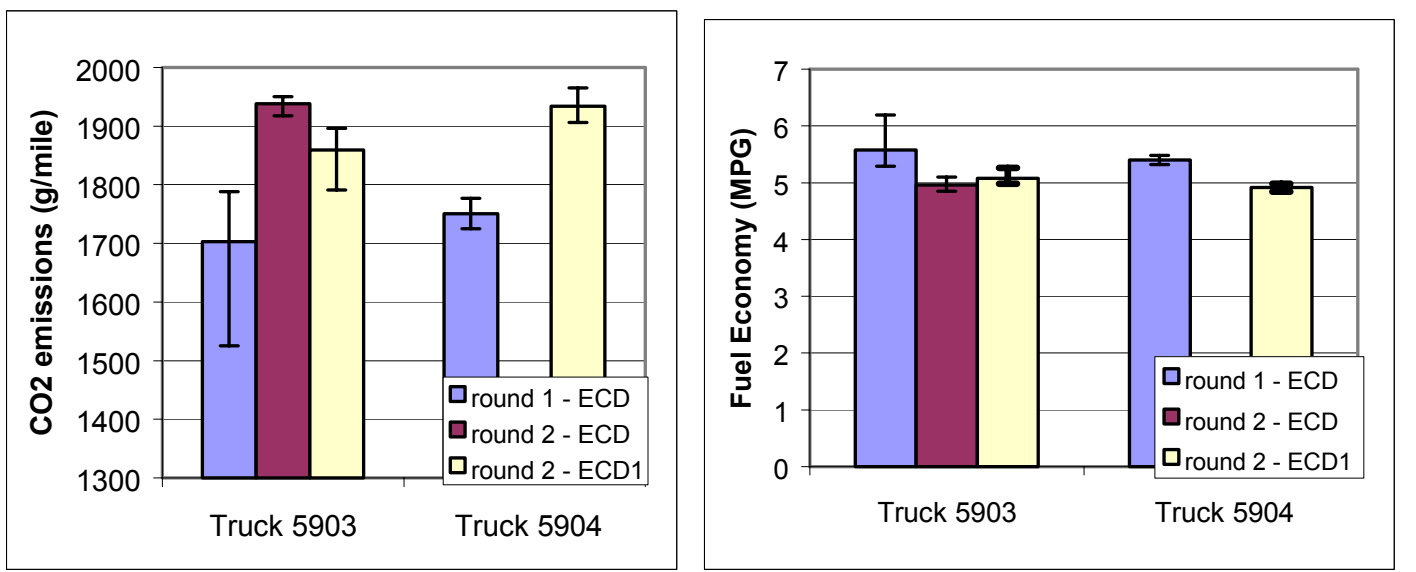

Figure 4.2.16: $\mathrm{CO}_{2}$ emissions (left) and fuel economy (right) for non-DPF test runs using ECD/ECD1 fuel. 

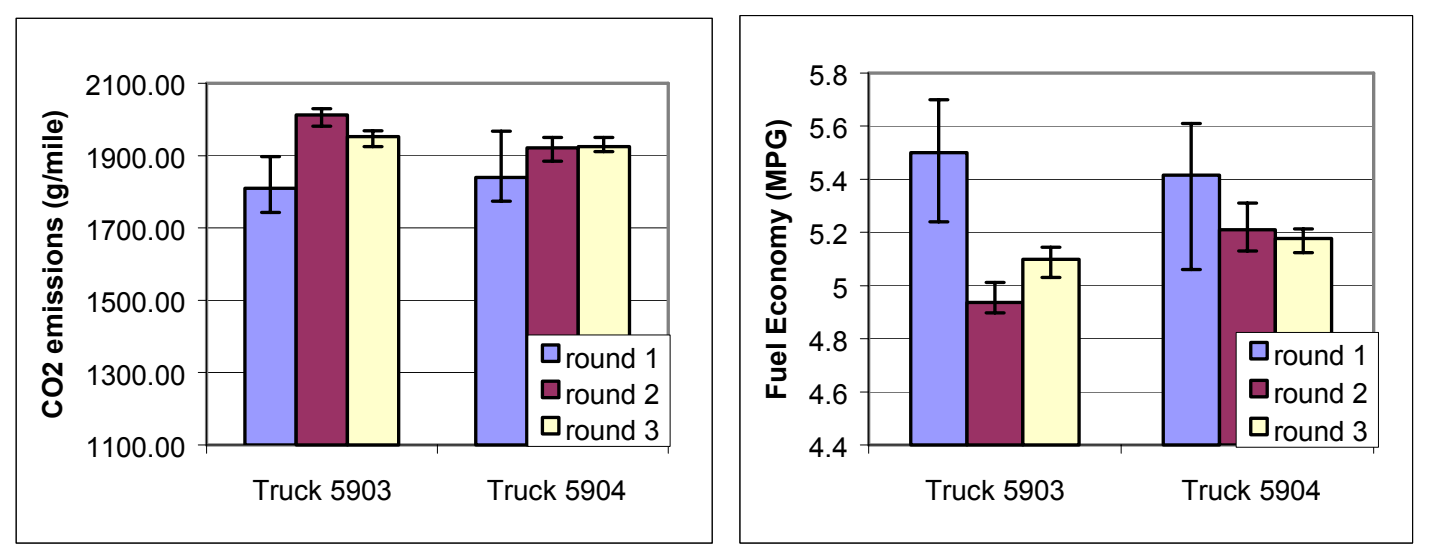

Figure 4.2.17: $\mathrm{CO}_{2}$ emissions (left) and fuel economy (right) for non-DPF test runs using CARB fuel.

No significant changes in $\mathrm{CO}_{2}$ emissions were recorded in this evaluation. With the exception of the CRT equipped vehicles tested in round two, all $\mathrm{CO}_{2}$ data was slightly higher for DPF equipped test runs, averaging five percent, with an extreme outlier of 10.8 percent recorded from DPX equipped vehicles in round three. This is attributed to the increased exhaust backpressure typically caused by particulate filters. CRT equipped vehicles demonstrated a slight reduction, less than seven percent, in $\mathrm{CO}_{2}$ emissions in round two. This suggests a vehicle and/or DPF maintenance issue which will be discussed in a subsequent section of this chapter.

As expected, fuel economy fluctuated only a few percent between testing rounds. In most cases, the fuel economy fluctuated less than 0.3-MPG between testing rounds. The exception to this, however, was truck 5908, which showed a $0.7-\mathrm{MPG}$ reduction in fuel economy between rounds one and two. This non-typical fluctuation suggests a buildup of ash on the filter surface within the DPF, the significance of which is discussed a later portion of this chapter. 


\subsubsection{PM Emissions}

Figure 4.2.18 shows the PM emissions from particulate filter equipped test runs. In round one, filter efficiencies were so high that neither truck 5903 or 5908 released a detectable amount of particulate matter. This continued for truck 5903 in round two when fueled with ECD fuel. PM emissions increased for all vehicles when fueled with ECD1 fuel in round two. This increase was attributed to the higher quantities of sulfur and total aromatics in the ECD1 fuel compared to the ECD fuel as shown in Table 4.2.2. Note that, as stated in the original test matrix, truck 5909 was not tested in round two with ECD1 fuel.

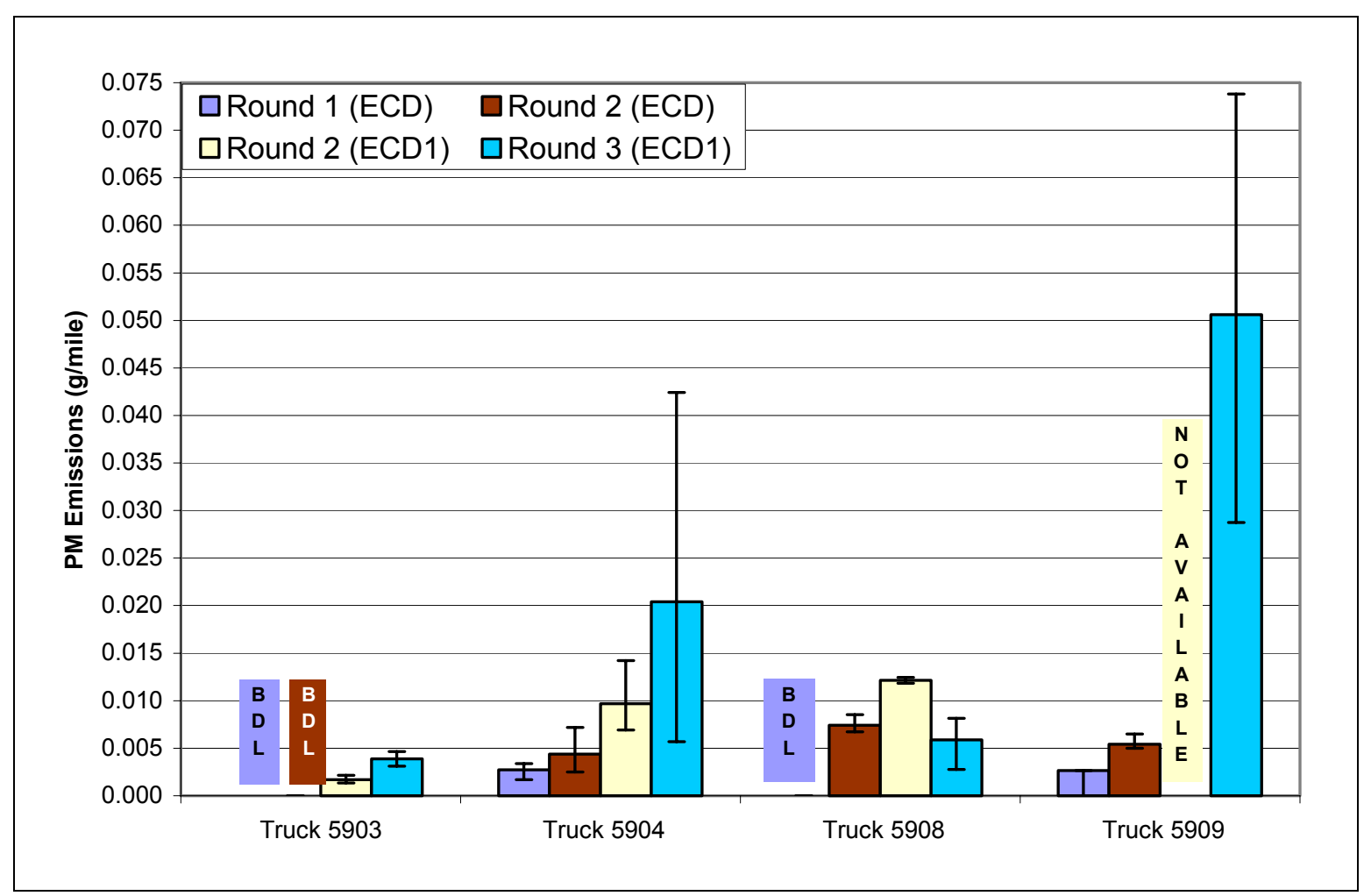

Figure 4.2.18: PM emissions from DPF-equipped test runs.

Figures 4.2.19 and 4.2.20 show the engine-out PM emissions from non-DPF test runs fueled with ECD/ECD1 fuel and CARB fuel respectively. As stated earlier, truck 
5904 was not tested in round two with ECD fuel, and only CARB fuel was used in round three when testing without DPFs installed.

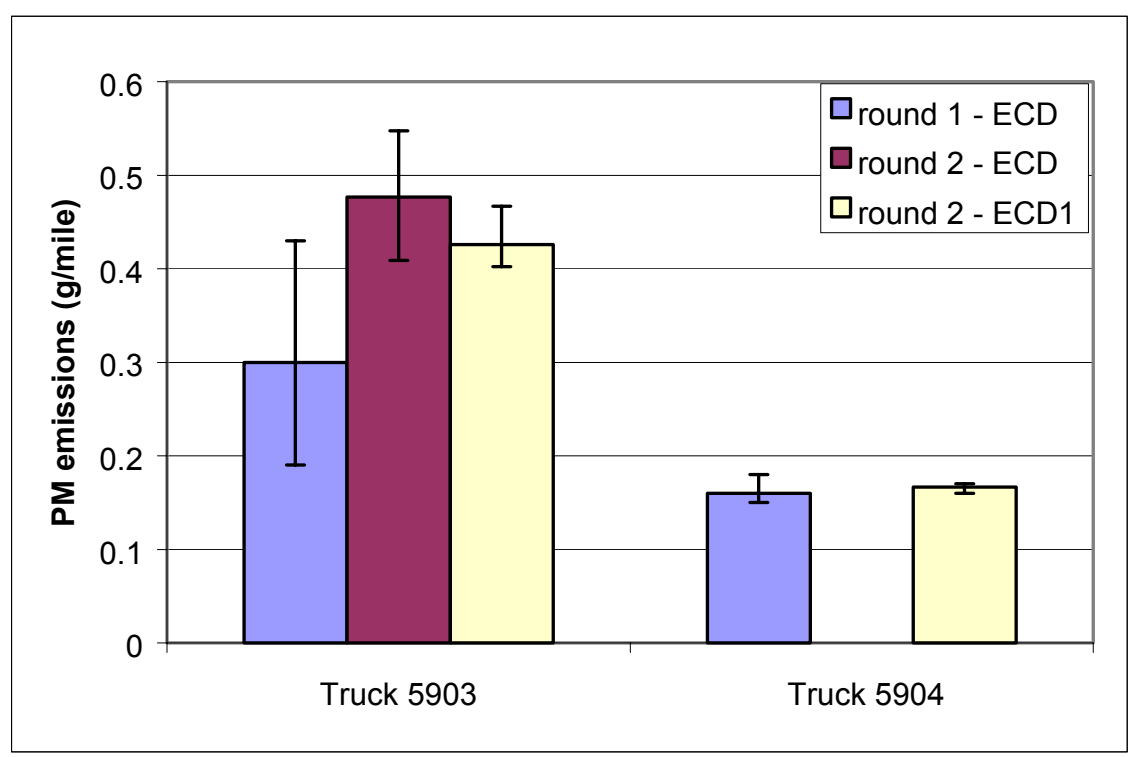

Figure 4.2.19: Engine-out PM emissions from non-DPF test runs using ECD/ECD1 fuel.

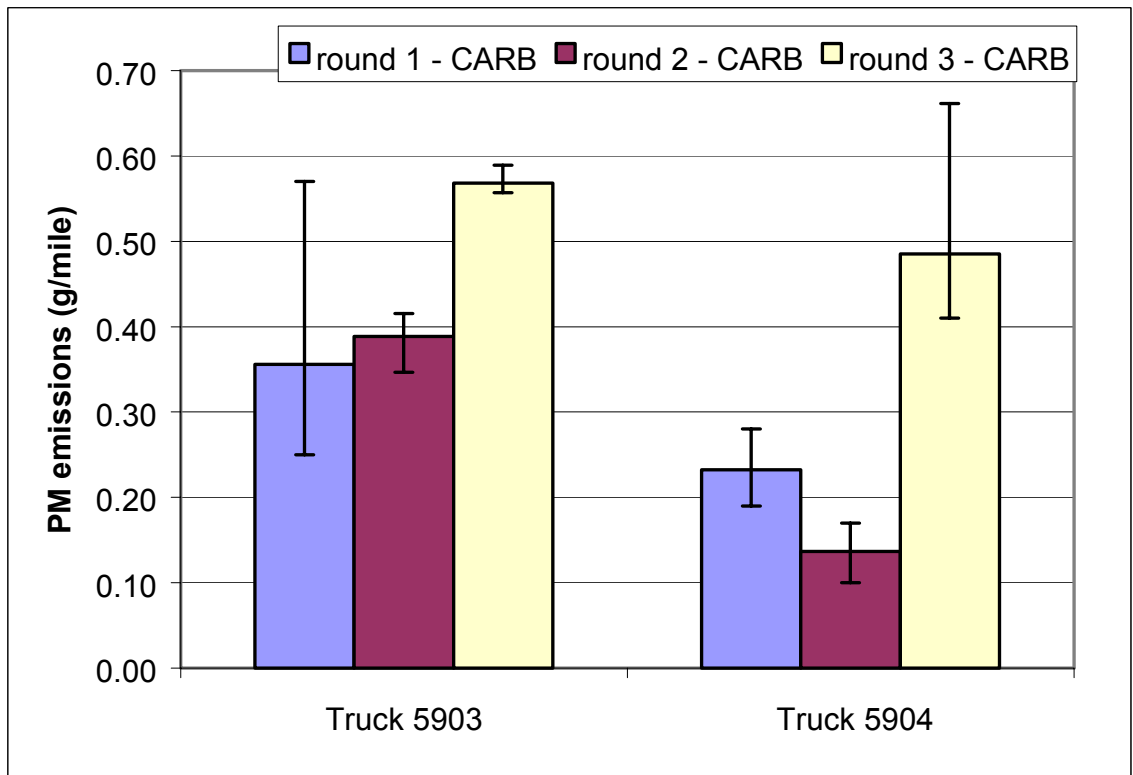

Figure 4.2.20: Engine-out PM emissions from non-DPF test runs using CARB fuel.

As predicted, particulate matter emissions were greatly reduced through out all rounds of testing. Round one showed reductions greater than 99 percent for both DPF 
types tested. Results were similar in round two when testing with ECD fuel, however reductions dropped slightly to 98 percent and 96 percent for the CRT and DPX respectively when testing with ECD1 fuel; again this was attributed to the higher concentrations of sulfur and total aromatics in this fuel. Round three tests produced reductions of 97 percent and 95 percent for the CRT and DPX respectively, however the round three calculations were performed using engine-out PM levels from CARB fuel and filtered PM levels from ECD1 fuel.

\subsubsection{Limitations of Study}

As with any experimentally acquired data, both human and mechanical errors can skew or corrupt the data. Accordingly, there are three pertinent issues that affect the validity of this study: the vehicle and DPF maintenance, number of vehicles tested, and a lack of consistency in vehicle configuration between rounds.

\subsubsection{Vehicle and DPF Maintenance}

During any type of long-term study, all possible sources of variance need to be monitored. At times, this can be a very daunting task, especially when some of these sources are out of the control of the researchers. Such was the case with vehicle and particulate filter maintenance. The vehicle maintenance records were not made available to the researchers at the time of the study. Vehicle maintenance, especially engine modifications, tuning, and controls, can have a large effect on engine-out emissions. Without access to these records, the emissions data cannot be normalized to account for possible fluctuations caused by maintenance operations performed on the test vehicles.

Similarly, DPF maintenance can affect emissions concentrations. Although the DPFs studied in this evaluation were passive regeneration units, maintenance was still 
required at periodic intervals. Most significant to the scope of this study was the active removal of ash from the filter surfaces inside the particulate filter. Ash does not react with the catalysts within the filters and thus may build up within the filter causing diminished flow and increased exhaust backpressure. The increased exhaust backpressure has a detrimental effect to $\mathrm{CO}_{2}$ emissions and consequently a similar effect on fuel economy. Maintenance records showed the removal of ash from the particulate filters just prior to the round three testing, however ash was not removed prior to the first two rounds of testing, making round to round comparisons more difficult.

\subsubsection{Test Vehicles}

Although four test vehicles are adequate for most studies, such a limited number of vehicles may have a negative effect on the results of a long-term study of this nature. By limiting the number of vehicles in such a fashion, the demands on the testing facility become much greater. Fluctuations in data become more apparent and have an increased effect on the results as the data is averaged over a small number of vehicles. Even relatively minor fluctuations, such as driver variance, can have a dramatic effect on the outcome of the test results.

\subsubsection{Test Consistency}

A large problem with the data presented was the lack of consistent information between testing rounds. Although the original test matrix was followed, multi-variable changes occurred at numerous points in the study. The most prominent of these changes was the fuel change / DPF removal in round three. By only testing the vehicles with a different fuel when the DPF was removed, namely CARB fuel rather than ECD or ECD1 as in the previous rounds, there was no consistent baseline from which to compare the 
three rounds. An attempt to estimate the engine-out emissions from ECD or ECD1 fuel for round three proved to be infeasible due to fluctuations and inconsistencies in the data, as described above.

\subsection{General Performance Evaluation and Manufacturer Comparison}

The objective of this study was to determine and compare the general performance characteristics of two styles of diesel particulate filter, the Johnson-Matthey CRT and the Engelhard DPX. All vehicles in this study were tested using driving schedules representative of the actual duty of the vehicle. Additionally, all vehicles were tested solely on ultra-low sulfur diesel fuels used by the respective fleets.

\subsubsection{Test Vehicles}

For the general performance evaluation and product comparison ten, vehicles were chosen from three fleets, including the Westchester County Transit Authority (WCTA), Washington Metropolitan Area Transit Authority (WMATA), and the New York City Department of Sanitation (NYCDOS).

\subsubsection{Westchester County Transit Authority (WCTA)}

Two transit buses were selected from the WCTA fleet. They included a 1996 Orion

bus with an 8.5L six cylinder Detroit Diesel Series 50 engine rated at 272 horsepower and a Neoplan articulated transit bus with a 12.7L six cylinder Detroit Diesel Series 60 engine rated at 450 horsepower.

Test weights were determined by adding one half of the passenger load (assuming 150 pounds per passenger plus 150 pounds for the driver) to the vehicle curb weight. The 
Orion bus was tested at 29,650 pounds, while the Neoplan bus was tested at 55,700 pounds.

Each bus from this fleet was tested with the Engelhard DPX, Johnson-Matthey CRT, and a standard muffler.

\subsubsection{Washington Metropolitan Area Transit Authority (WMATA)}

Four transit buses were tested from the WMATA fleet for general performance evaluation and product comparison. Two 1995 Ikarus buses equipped with 11L Cummins M11-330E engines rated at 330 horsepower were tested. Bus number 5203 was equipped with a Johnson-Matthey CRT, while bus number 5229 was equipped with an Engelhard DPX.

The other two buses from this fleet were Orion Transit buses equipped with 5.9L Cummins 6BT5.9 engines rated at 175 horsepower. Bus number 3724 was equipped with an Engelhard DPX, and bus number 3726 was equipped with a Johnson-Matthey CRT.

The Ikarus buses were tested at 51,900 pounds, while the Orion buses were tested at 18,975 pounds. The test weights were obtained in the same fashion as with the WCTA buses.

\subsubsection{New York City Department of Sanitation (NYCDOS)}

The New York City Department of Sanitation supplied four vehicles for evaluation. They were all 1997 Heil Crane Carrier Corporation refuse trucks equipped with 10.8L Cummins M11 engines rated at 280 horsepower. Trucks 25CF042 and 25CF043 were equipped with Johnson-Matthey CRT particulate filters, while trucks 25CF044 and 25CF045 were equipped with Engelhard DPX units. 
The trucks were tested at approximately 65 percent of their gross vehicle weight of 65,098 pounds. The resulting test weight was 42,000 pounds.

Each vehicle in this evaluation was tested while running on ultra-low sulfur diesel fuel already in service at the respective fleets. Table 4.3.1 summarizes the vehicle information pertinent to this evaluation.

Table 4.3.1: Vehicle Information from General Performance Evaluation

\begin{tabular}{|c|c|c|c|c|c|c|c|}
\hline Fleet & Number & Vehicle Type & $\begin{array}{c}\text { Engine } \\
\text { Manufacturer }\end{array}$ & $\begin{array}{l}\text { Engine } \\
\text { Model }\end{array}$ & $\begin{array}{c}\text { Test } \\
\text { Weight }\end{array}$ & Aftertreatment & Test Cycle \\
\hline \multirow{3}{*}{ WCTA } & \multirow{3}{*}{479} & \multirow{3}{*}{ Orion Transit Bus } & \multirow{3}{*}{ Detroit Diesel } & \multirow{3}{*}{ Series 50} & \multirow{3}{*}{34675} & Engelhard & 2BEELINE \\
\hline & & & & & & Johnson-Matthey & 2BEELINE \\
\hline & & & & & & standard Muffler & BEELINE \\
\hline \multirow{3}{*}{ WCTA } & \multirow{3}{*}{568} & \multirow{3}{*}{$\begin{array}{l}\text { Neoplan Art. } \\
\text { Transit Bus }\end{array}$} & \multirow{3}{*}{ Detroit Diesel } & \multirow{3}{*}{ Series 60} & \multirow{3}{*}{55700} & Engelhard & 2BEELINE \\
\hline & & & & & & Johnson-Matthey & 2BEELINE \\
\hline & & & & & & standard Muffler & BEELINE \\
\hline \multirow{2}{*}{ WMATA } & \multirow{2}{*}{5203} & \multirow{2}{*}{ Ikarus Transit Bus } & \multirow{2}{*}{ Cummins } & \multirow{2}{*}{ M11-E330E } & \multirow{2}{*}{51900} & Johnson-Matthey & 2WMATA \\
\hline & & & & & & standa & WMATA \\
\hline \multirow{2}{*}{ WMATA } & \multirow{2}{*}{5229} & \multirow{2}{*}{ Ikarus Transit Bus } & \multirow{2}{*}{ Cummins } & \multirow{2}{*}{ M11-E330E } & \multirow{2}{*}{51900} & Engelhard & 2WMATA \\
\hline & & & & & & standard Muffler & WMATA \\
\hline \multirow{2}{*}{ WMATA } & \multirow{2}{*}{3724} & \multirow{2}{*}{ Orion Transit Bus } & \multirow{2}{*}{ Cummins } & \multirow{2}{*}{ 6BT5.9 } & \multirow{2}{*}{18975} & Engelhard & 2WMATA \\
\hline & & & & & & standard Muffler & WMATA \\
\hline \multirow{2}{*}{ WMATA } & \multirow{2}{*}{3726} & \multirow{2}{*}{ Orion Transit Bus } & \multirow{2}{*}{ Cummins } & 6BT5 9 & 18975 & Johnson-Matthey & 2WMATA \\
\hline & & & & $6 B 15.9$ & 10915 & standard Muffler & WMATA \\
\hline NYCDOS & 25CF042 & Refuse Truck & Cummins & M11 & 42000 & Johnson-Matthey & NYGTC3X \\
\hline INYCDUS & $25 C F 042$ & Reruse Iruck & cummins & MIIT & $4 \angle 000$ & standard Muffler & NYGTC3X \\
\hline DOS & 25CF043 & k & is & 111 & 42000 & Johnson-Matthey & OCRTC2X \\
\hline & & & & דו & $4 \angle 000$ & standard Muffler & OCRTC2X \\
\hline Dos & 25 & $R_{2}>$ & & & 42 & Engelhard & OCRTC2X \\
\hline & 24 & & 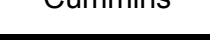 & & & standard Muffler & OCRTC2X \\
\hline NYCDOS & 25CF045 & Refuse Truck & Cummins & M11 & 42000 & Engelhard & NYGTC3X \\
\hline INYCDUS & 2501045 & Reruse Iruck & cummins & IVITT & $4 \angle 000$ & standard Muffler & NYGTC3X \\
\hline
\end{tabular}

\subsubsection{Driving Schedules}

As shown in Table 4.3.1, six driving schedules were used in this test matrix. Of these six driving schedules, four were unique cycles and two were extended length cycles. The unique driving cycles were BEELINE, WMATA, NYGTC3X, and OCRTC2X. The two extended length cycles were 2BEELINE and 2WMATA. Each cycle was developed by WVU in order to simulate the specific use of each vehicle being tested. 


\subsubsection{BEELINE / 2BEELINE Cycle}

The BEELINE Cycle was developed specifically for the Westchester County Transit Authority. The 2BEELINE Cycle is a double length BEELINE cycle developed to facilitate sufficient particulate filter loading for microbalance measurement when testing with a diesel particulate filter.

The cycle was developed from data logged from continuous operation over an eight-day period of two buses in Westchester County, NY. Both Engine Control Module (ECM) and global positioning system (GPS) data were logged, however only ECM data was used in the development of the driving cycle. The continuous data was divided into "microtrips" on a speed basis. A microtrip is defined as a period of vehicle operation, beginning when vehicle speed exceeds $0.5 \mathrm{mph}$ and ending when vehicle speed returns to less than $0.5 \mathrm{mph}$, with an included period of idle at the conclusion of vehicle motion.

A total of 2,257 microtrips resulted from the continuous data. Using a random number generator, microtrips were selected and joined in a string as a possible driving cycle with greater than 1,700 seconds. Using this process, 120,000 candidate strings were developed. The root mean square (RMS) was calculated for each string using equation (4.3.1), and the string with the lowest RMS, excluding any string with discontinuities in the microtrip data or excessively steep acceleration or deceleration ramps, was selected as the driving cycle (Wayne, 2002).

$$
R M S=\sqrt{\left[\left(\frac{A-A^{\prime}}{A}\right)^{2}+\left(\frac{B-B^{\prime}}{B}\right)^{2}+\left(\frac{C-C^{\prime}}{C}\right)^{2}+\left(\frac{D-D^{\prime}}{D}\right)^{2}+\left(\frac{E-E^{\prime}}{E}\right)^{2}\right]}
$$

A - Kinetic Energy No Idle $\left(\mathrm{mph}^{2}\right)$ for database

$\mathrm{A}^{\prime}$ - Kinetic Energy No Idle $\left(\mathrm{mph}^{2}\right)$ for candidate cycle

B - Average Vehicle Speed No Idle (mph) for database

$\mathrm{B}^{\prime}$ - Average Vehicle Speed No Idle (mph) for candidate cycle 
$\mathrm{C}$ - Standard Deviation of Speed No Idle (mph) for database

$\mathrm{C}^{\prime}$ - Standard Deviation of Speed No Idle (mph) for candidate cycle

$\mathrm{D}$ - Average Vehicle Speed with Idle ( $\mathrm{mph}$ ) for database

$\mathrm{D}^{\prime}$ - Average Vehicle Speed with Idle (mph) for candidate cycle

E - Percentage Time Idle (\%) for database

$\mathrm{E}^{\prime}$ - Percentage Time Idle (\%) for candidate cycle

The resulting BEELINE Cycle has an RMS value of $0.49 \%$, a total time of 1701 seconds, and a distance of 6.81 miles. Figure 4.3.1 shows the BEELINE cycle trace.

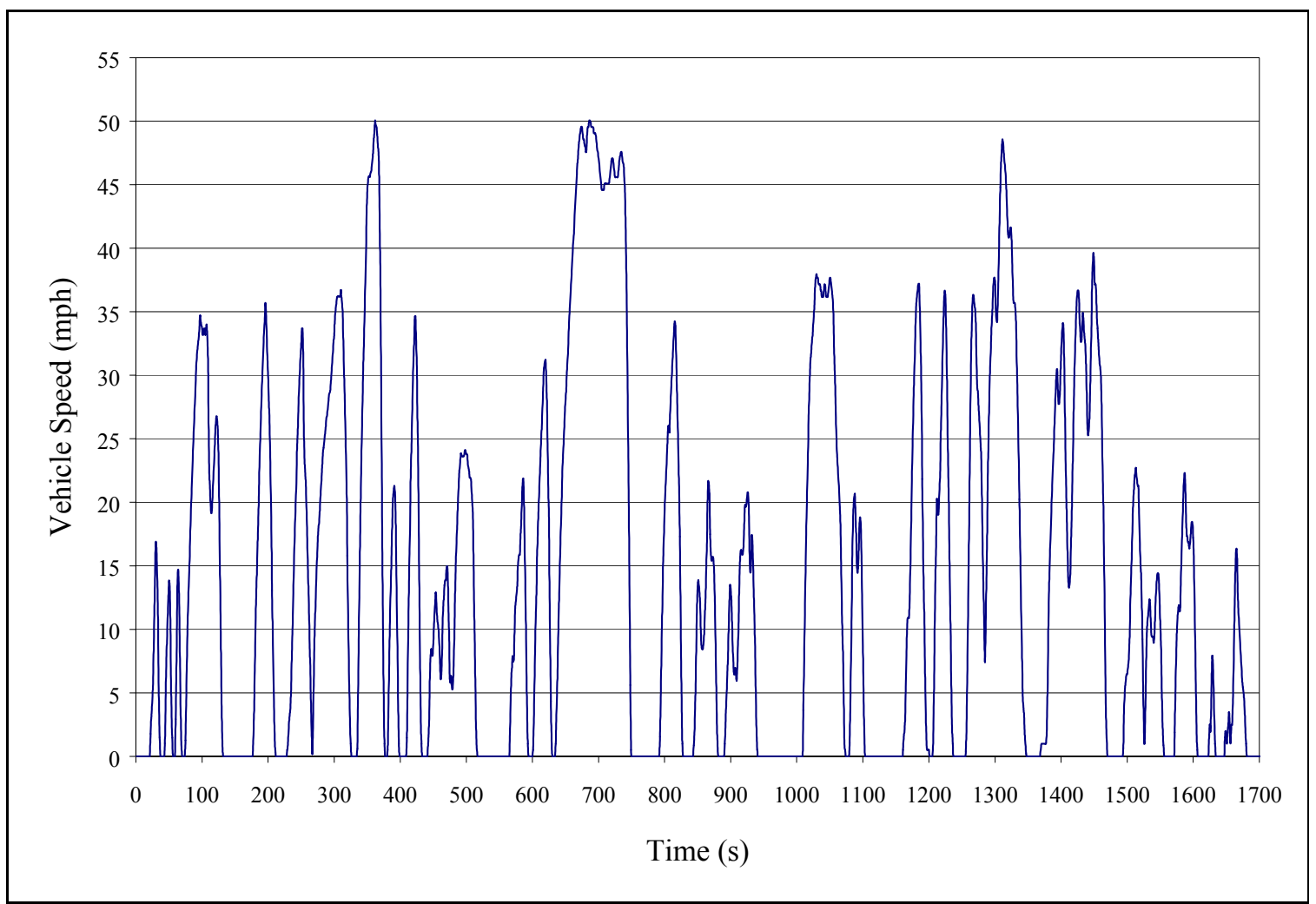

Figure 4.3.1: BEELINE cycle driving cycle developed for WCTA.

\subsubsection{WMATA / 2WMATA Cycle}

The WMATA cycle was developed specifically for the Washington Metropolitan Transit Authority. The 2WMATA cycle is a double length cycle developed to facilitate sufficient particulate filter loading for microbalance measurement when testing with a diesel particulate filter. 
The WMATA cycle was developed in a similar fashion to the BEELINE cycle. Vehicle speed data was logged via a GPS from several transit buses in and around the Washington D.C. area. This data was divided into microtrips, randomly selected into candidate strings, and the resulting RMS values calculated using the same criteria used for the BEELINE cycle. The selected candidate string had an RMS value of 0.8896 .

The selected candidate string was converted into a cycle through the addition of idle periods at the beginning and end of the cycle as well as between the microtrips comprising the candidate string. The idle operation within the cycle represented the percentage of idle operation within the database. The included idle times at the beginning and end of the cycle were set at 20 seconds each in order to allow for equipment response and measurement of all emissions from the driving cycle. The WMATA cycle is shown in Figure 4.3.2.

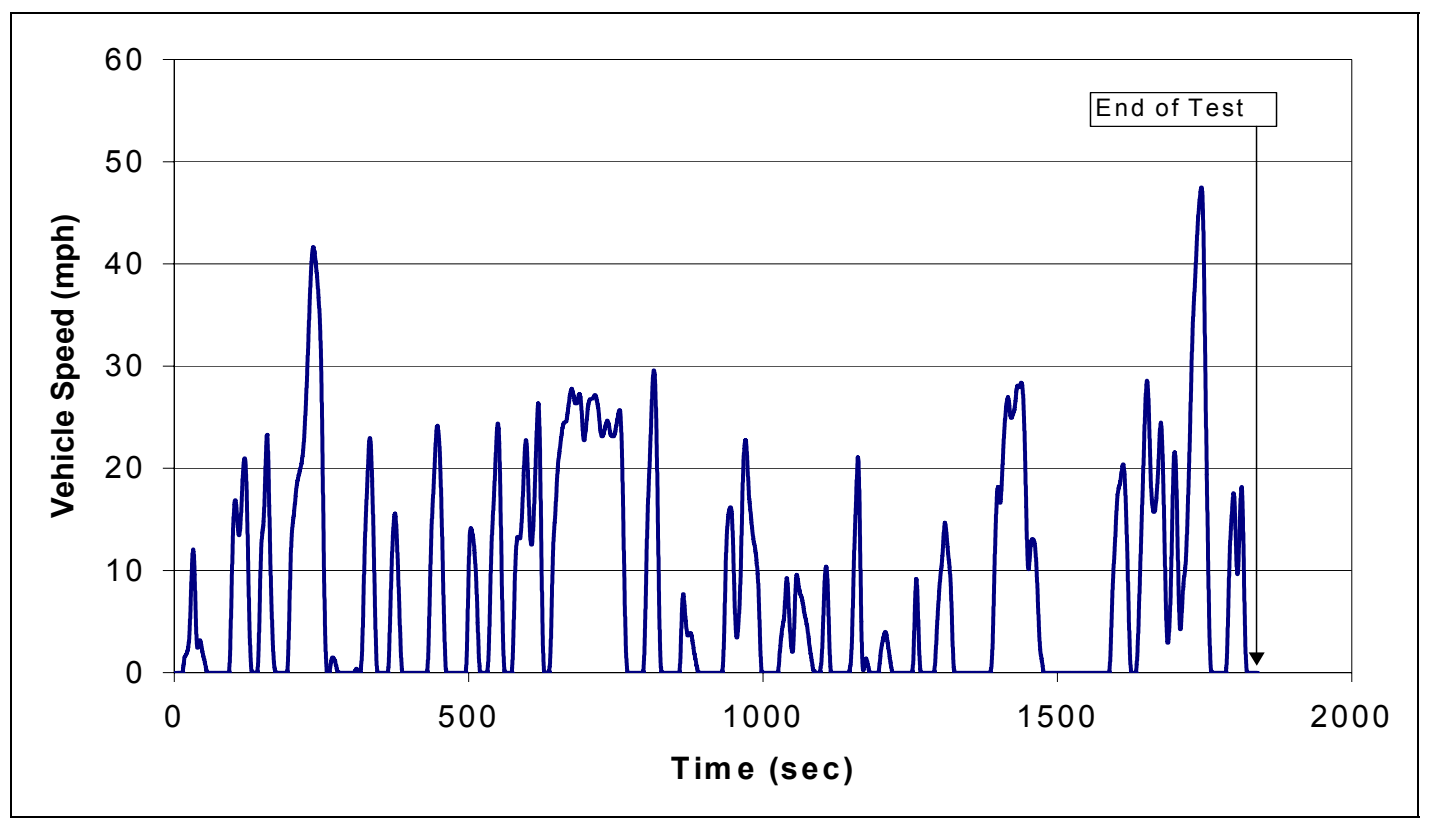

Figure 4.3.2: WMATA cycle developed for the Washington Metropolitan Area Transit Authority. 


\subsubsection{NYGTC3X Cycle}

The NYGTC3X cycle is a derivative of the NYGTC cycle that was developed for the New York Department of Sanitation. Data was acquired by following refuse haulers in Morgantown, WV and New York City. Additionally, some supplementary data was acquired from a Detroit Diesel powered truck in New York City using a vehicle speed and pedal position data logger. Using this data it was determined that drivers seldom use full power when traveling form pickup point to pickup point, the average vehicle speed and distances traveled are low, and compaction cycles should be included in the cycle. The resulting driving cycle incorporated three compactions, one acceleration to $20 \mathrm{mph}$, three accelerations to $12.5 \mathrm{mph}$, and four accelerations to $5.5 \mathrm{mph}$. The distance traveled was 0.38 miles with a majority of time spent idling. Three warm-up ramps were included at the beginning of the cycle in order to insure the aftertreatment devices had sufficiently reached operating temperature prior to data collection (Wayne, 2002).

The NYGTC3X cycle was developed to facilitate sufficient particulate filter loading for microbalance measurement when testing with a diesel particulate filter. This modified cycle used three NYGTC cycles repeated sequentially. The cycle possessed three sets of three compactions, for a total of nine. The warm-up ramps were only included at the beginning of the first NYGTC cycle, and the total distance traveled was 1.14 miles. Figure 4.3.3 shows the NYGTC3X cycle as driven on the test bed. Note, the warm-up ramps were not shown on this figure as no data was recorded during that time. 


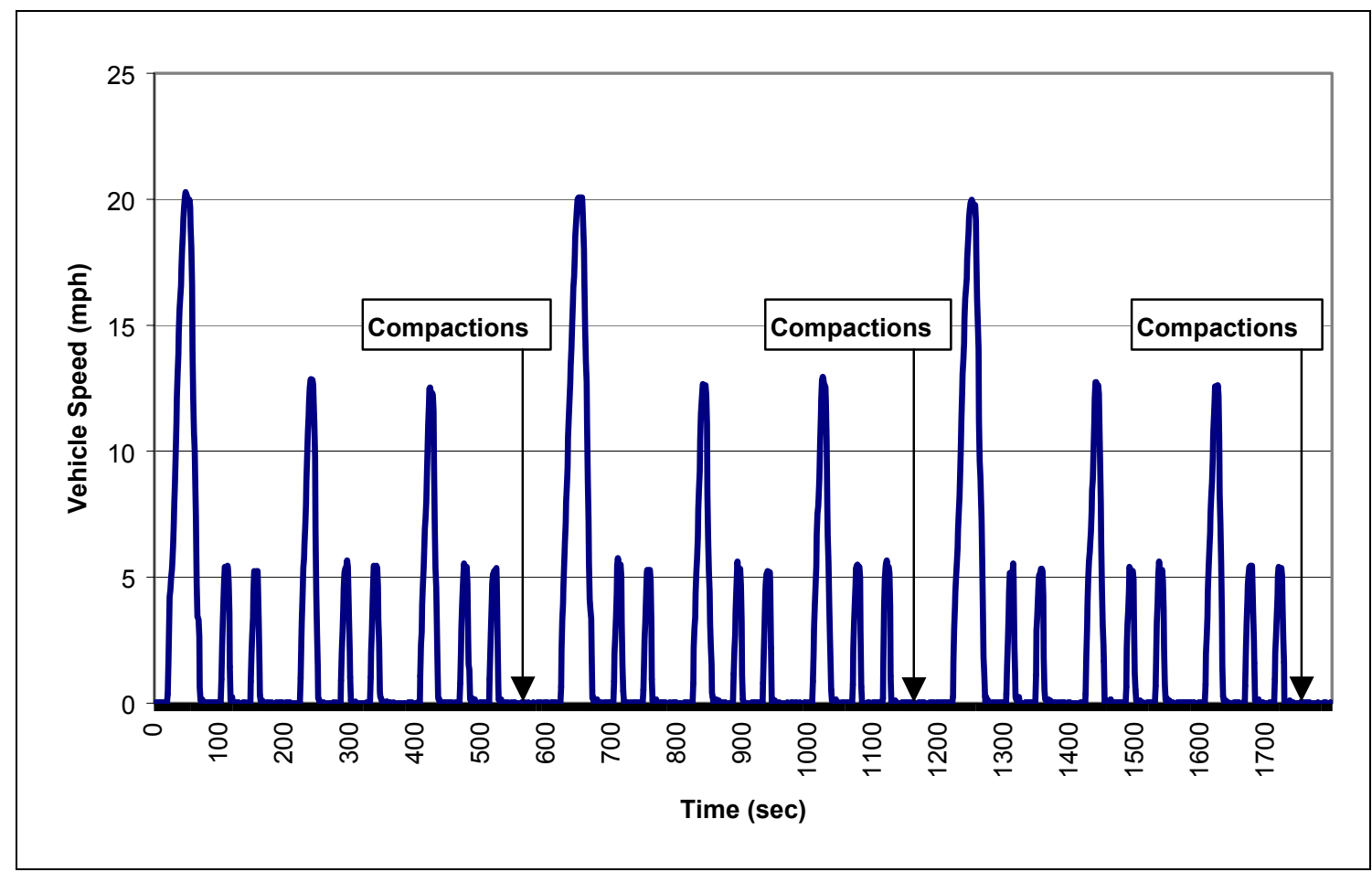

Figure 4.3.3: NYGTC3X cycle developed for the NY Department of Sanitation.

\subsubsection{OCRTC2X Cycle}

The OCRTC2X cycle was a derivative of the OCRTC cycle, which represents sanitation truck operation in Orange County, CA, however it was applied to the NYCDOS vehicles for sake of comparison. The OCRTC cycle, Orange County Refuse Truck Cycle, was developed from GPS data collected in February 2000. The continuous data was divided into microtrips, randomly selected into candidate strings, and the RMS values calculated as they were with the BEELINE and WMATA cycles.

The resulting cycle contained less overall idle time and higher maximum speeds than the NYGTC cycle. No warm-up ramps were included in this cycle.

The OCRTC2X cycle was developed to facilitate sufficient particulate filter loading for microbalance measurement when testing with a diesel particulate filter. It was composed of two OCRTC cycles run continually with an overall distance of 5.2 miles. 
Four compaction cycles were included at 300 seconds, 1050 seconds, 1460 seconds, and 2200 seconds. Figure 4.3.4 shows the OCRTC2X as driven on the test bed (Wayne, 2002).

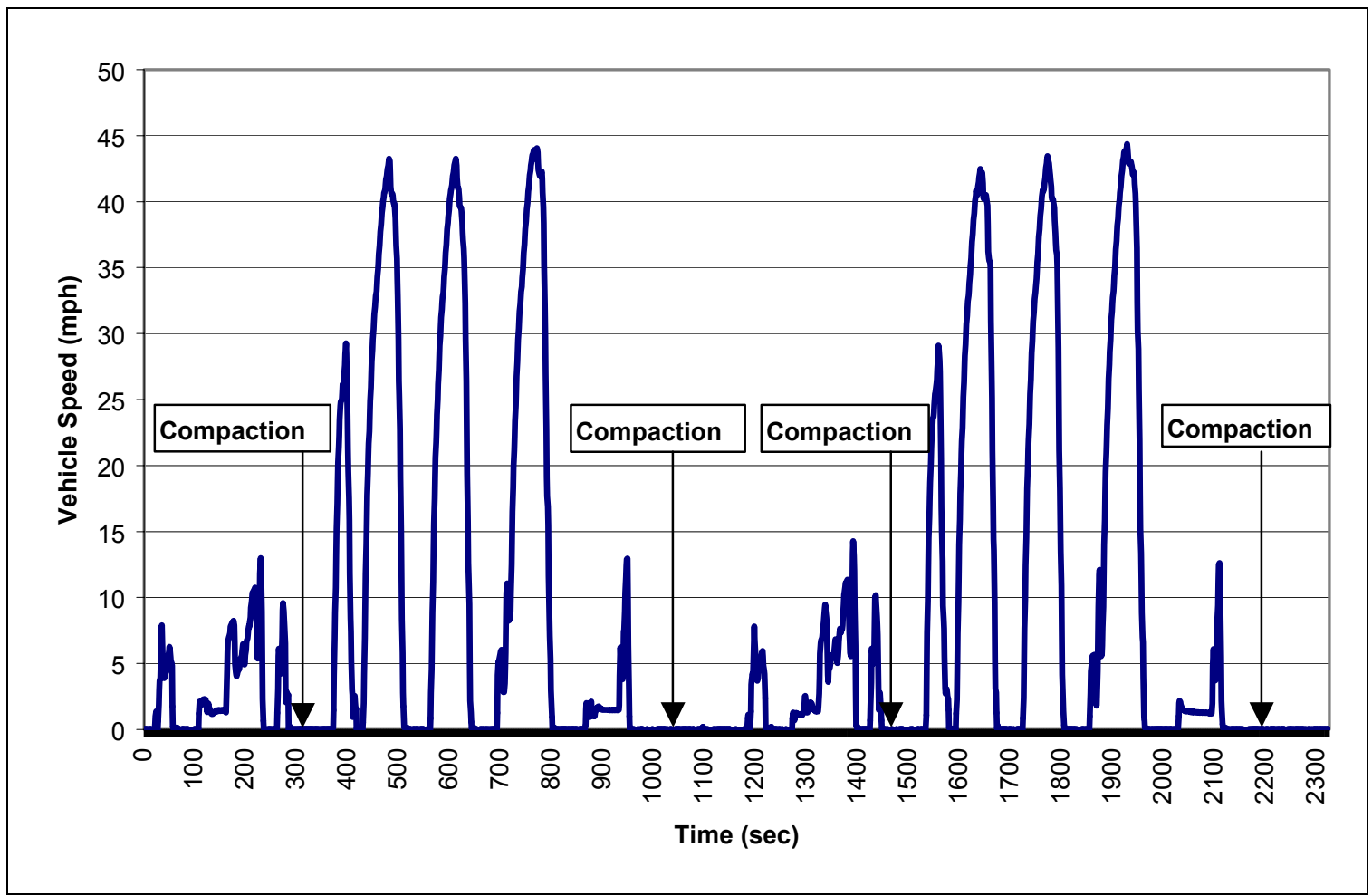

Figure 4.3.4: OCRTC2X developed for the Orange County Department of Sanitation and applied to the NYCDOS vehicles.

\subsubsection{Results}

It is known that comparisons of vehicle emissions collected using different driving schedules cannot be directly compared. However, as the purpose of this study is not to compare emission outputs but rather to compare DPF effectiveness under real-world simulations, this stipulation is being overlooked for the purposes of this study. In an effort to alleviate any discrepancies, all reported emissions reductions are averages taken from all vehicles tested. 


\subsubsection{CO Emissions}

CO emissions were greatly reduced for all vehicles tested. The Engelhard DPX equipped vehicles showed reductions of 85 percent on average, while the JohnsonMatthey CRT equipped vehicles demonstrated reductions of approximately 84 percent on average.

Figure 4.3.5 shows the CO emissions for DPX equipped vehicles, and Figure 4.3.6 shows the $\mathrm{CO}$ emissions from CRT equipped vehicles. In both figures, each bar represents the average of three test runs performed on each vehicle with the respective aftertreatment, an Engelhard DPX, a Johnson-Matthey CRT, or a standard muffler.

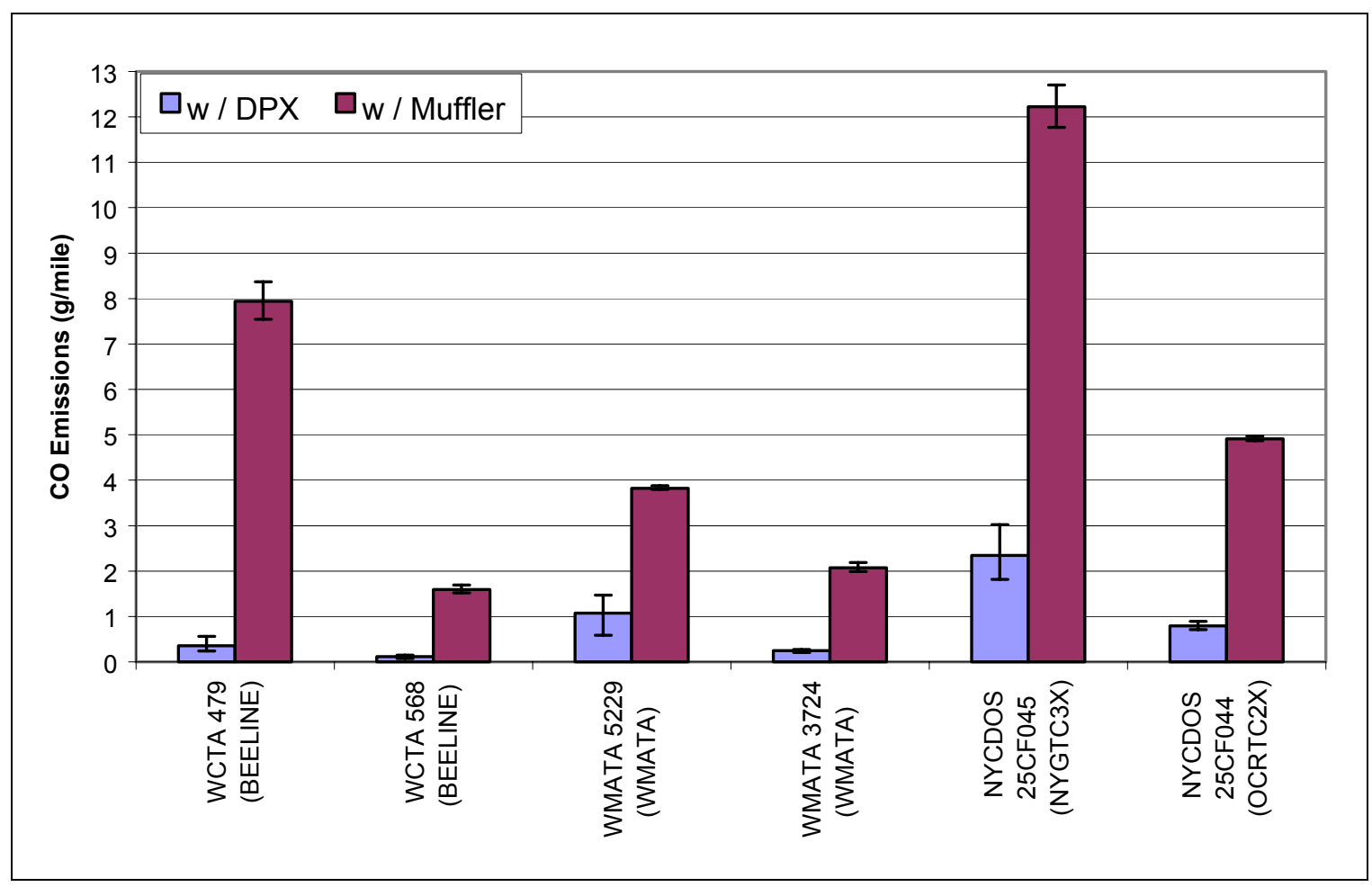

Figure 4.3.5: CO emissions from Engelhard DPX equipped vehicles. 


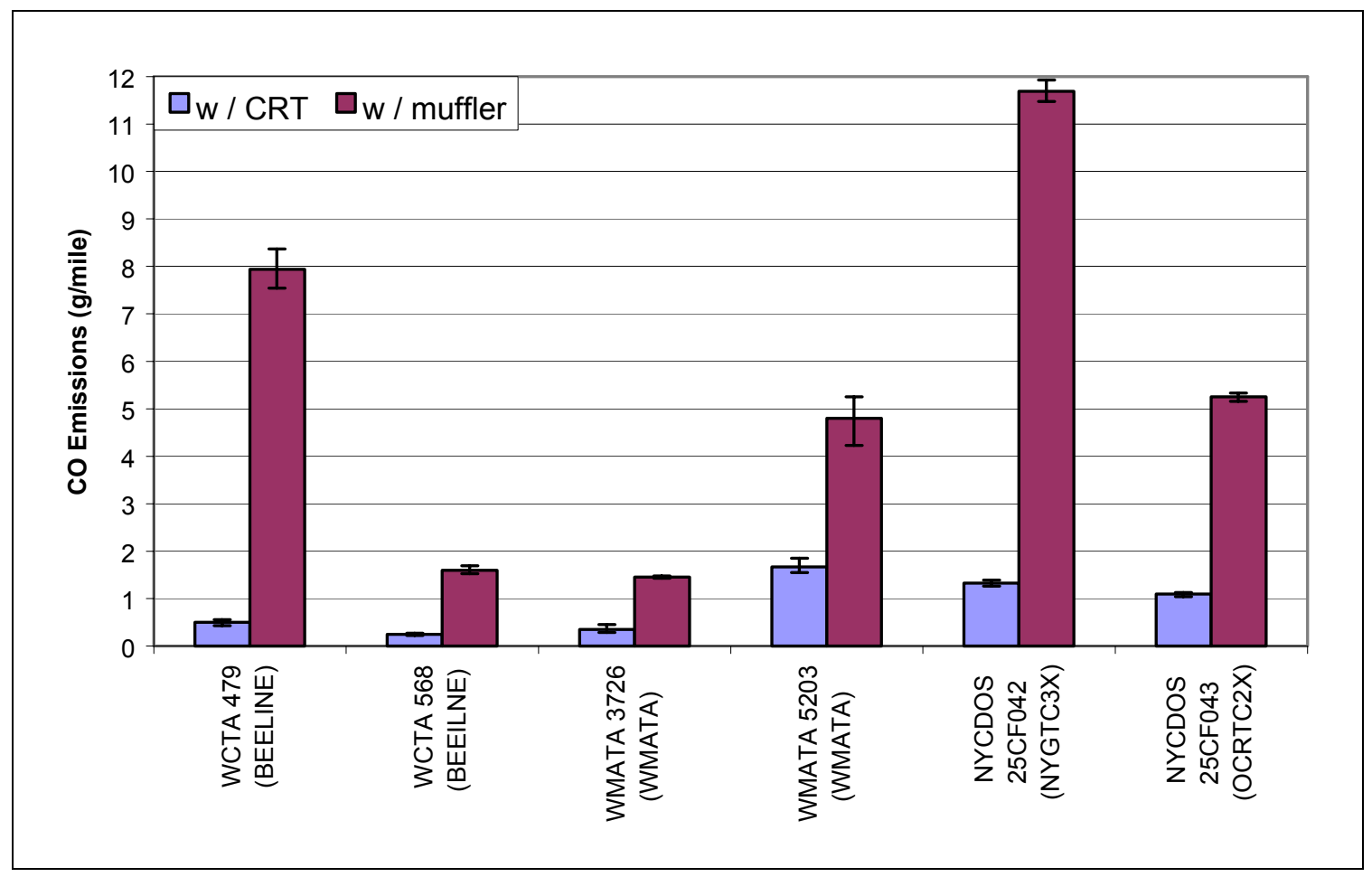

Figure 4.3.6: CO emissions from Johnson-Matthey CRT equipped vehicles.

\subsubsection{HC Emissions}

HC emission outputs were reduced by 76 percent and 81 percent for the DPX and CRT equipped vehicles, respectively, relative to the untreated exhaust. Four of the test vehicles achieved below detectable limit HC concentrations when testing with the diesel particulate filters. WCTA buses 479 and 568 produced below detectable limit HC emission concentrations when testing with both DPF types. Truck NYCDOS 25CF044 produced HC levels below detectable limits with the Engelhard DPX in use, while WMATA bus 3726 produced below detectable limit levels with the Johnson-Matthey CRT in place.

Figures 4.3.7 and 4.3.8 show the HC emissions for the DPX and CRT equipped vehicles respectively. Each bar in these figures represents the average $\mathrm{HC}$ emissions 
produced during three valid test runs performed on each vehicle with the respective aftertreatment.

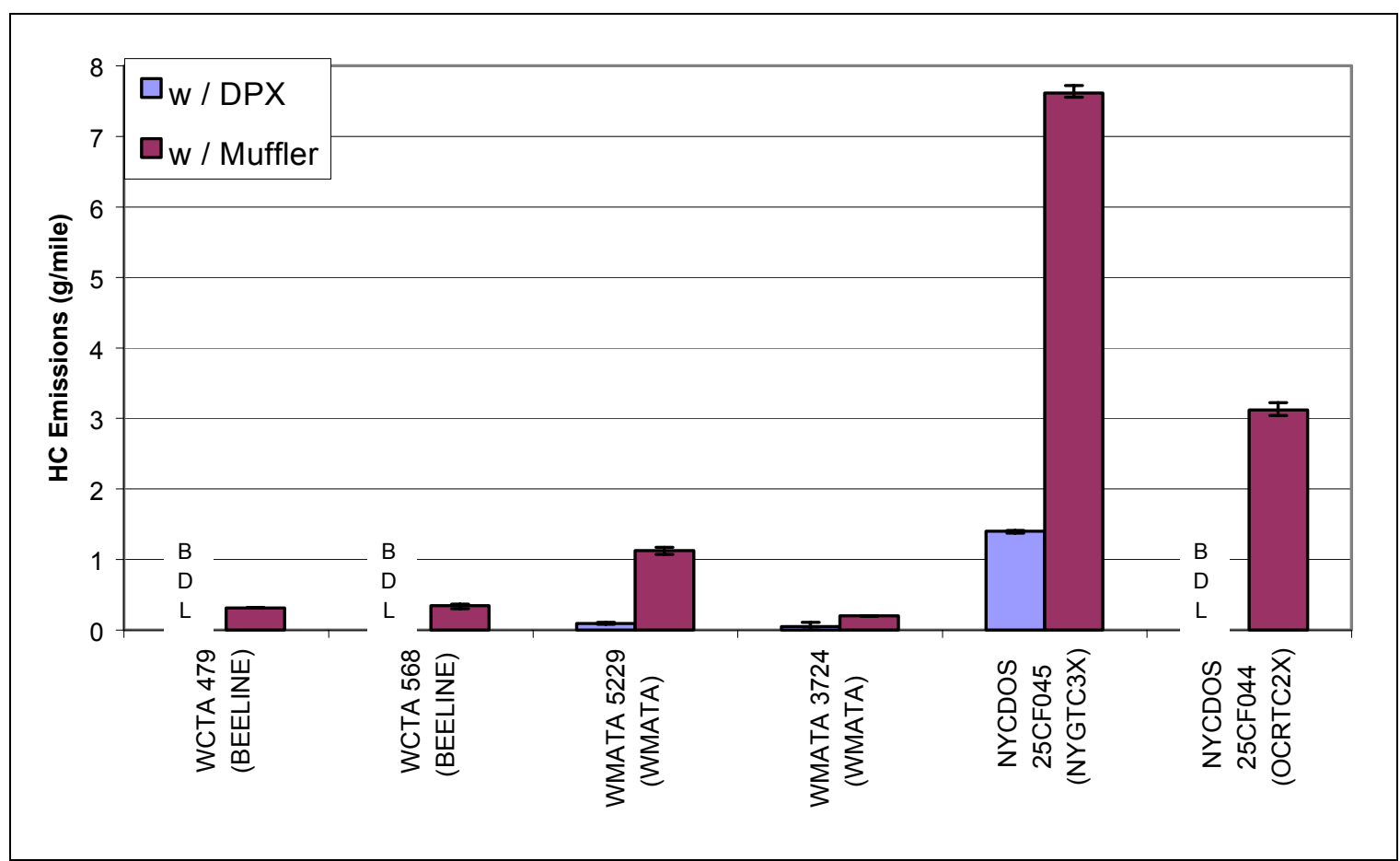

Figure 4.3.7: HC emissions from DPX equipped vehicles.

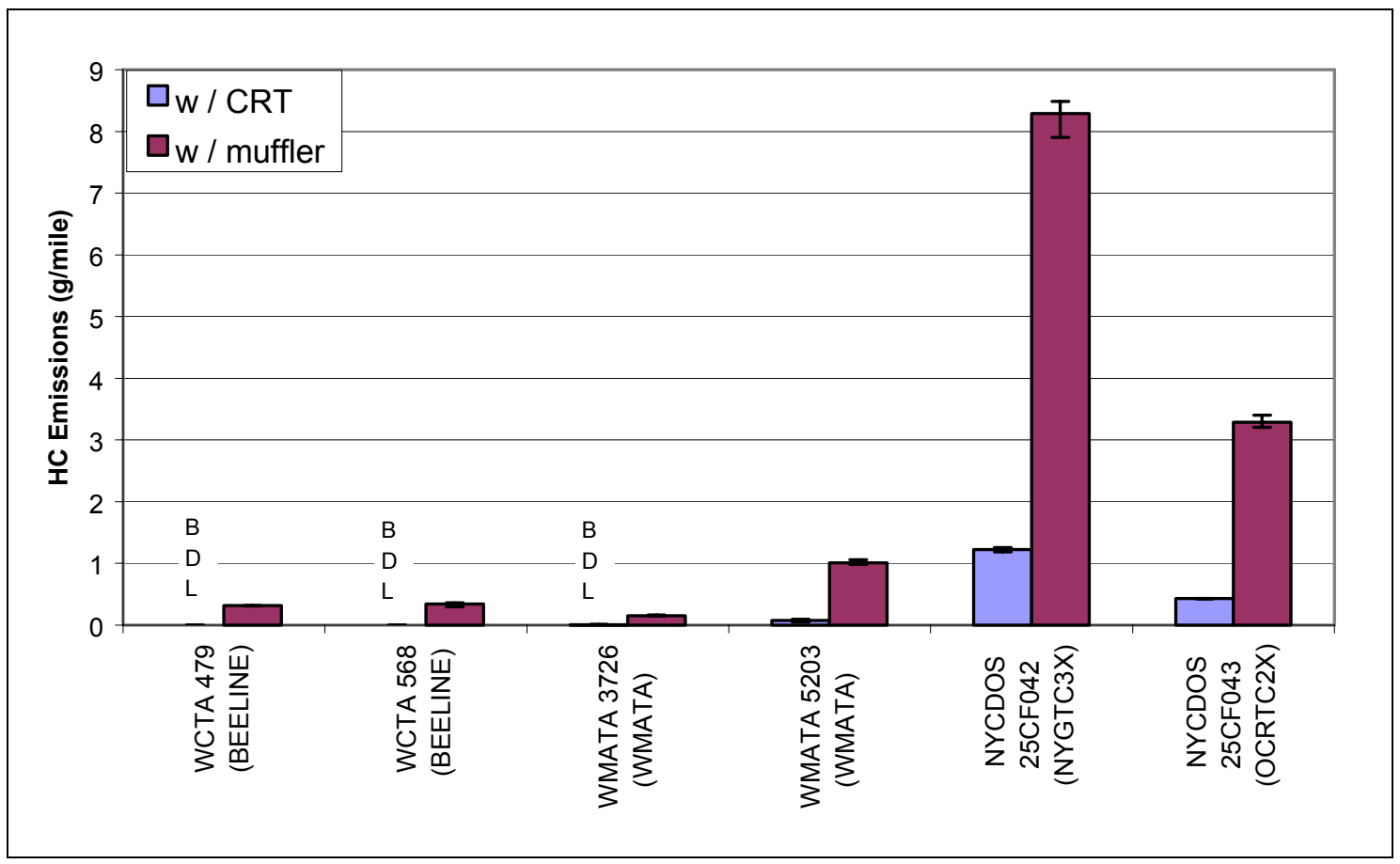

Figure 4.3.8: HC emissions from CRT equipped vehicles. 


\subsubsection{NOx and NO Emissions}

As expected there was no significant change in $\mathrm{NO}_{\mathrm{X}}$ emissions when testing with either the Engelhard DPX or the Johnson-Matthey CRT. There was less than one percent variance in emissions with the particulate filters compared to emissions with the standard mufflers.

When testing with catalyzed particulate filters, NO emissions are of greater concern than $\mathrm{NO}_{\mathrm{X}}$ emissions. $\mathrm{NO}$ is converted to $\mathrm{NO}_{2}$ by the catalyst inside the diesel particulate filter. By using two $\mathrm{NO}_{\mathrm{X}}$ analyzers, the $\mathrm{NO} / \mathrm{NO}_{\mathrm{X}}$ fraction can be quantified. However, due to a failure of one of the chemiluminescent $\mathrm{NO}_{\mathrm{X}}$ analyzers during testing, this was only accomplished for the WCTA fleet vehicles.

Through conversion to $\mathrm{NO}_{2}$, the particulate filters reduced $\mathrm{NO}$ concentrations by 38.5 percent and 42 percent for the DPX and CRT, respectively, for the WCTA vehicles tested. Figure 4.3.9 graphically shows this reduction. In this figure, each bar represents the average $\mathrm{NO}$ or $\mathrm{NO}_{\mathrm{X}}$ concentration recorded by the analyzers over three valid test runs. 


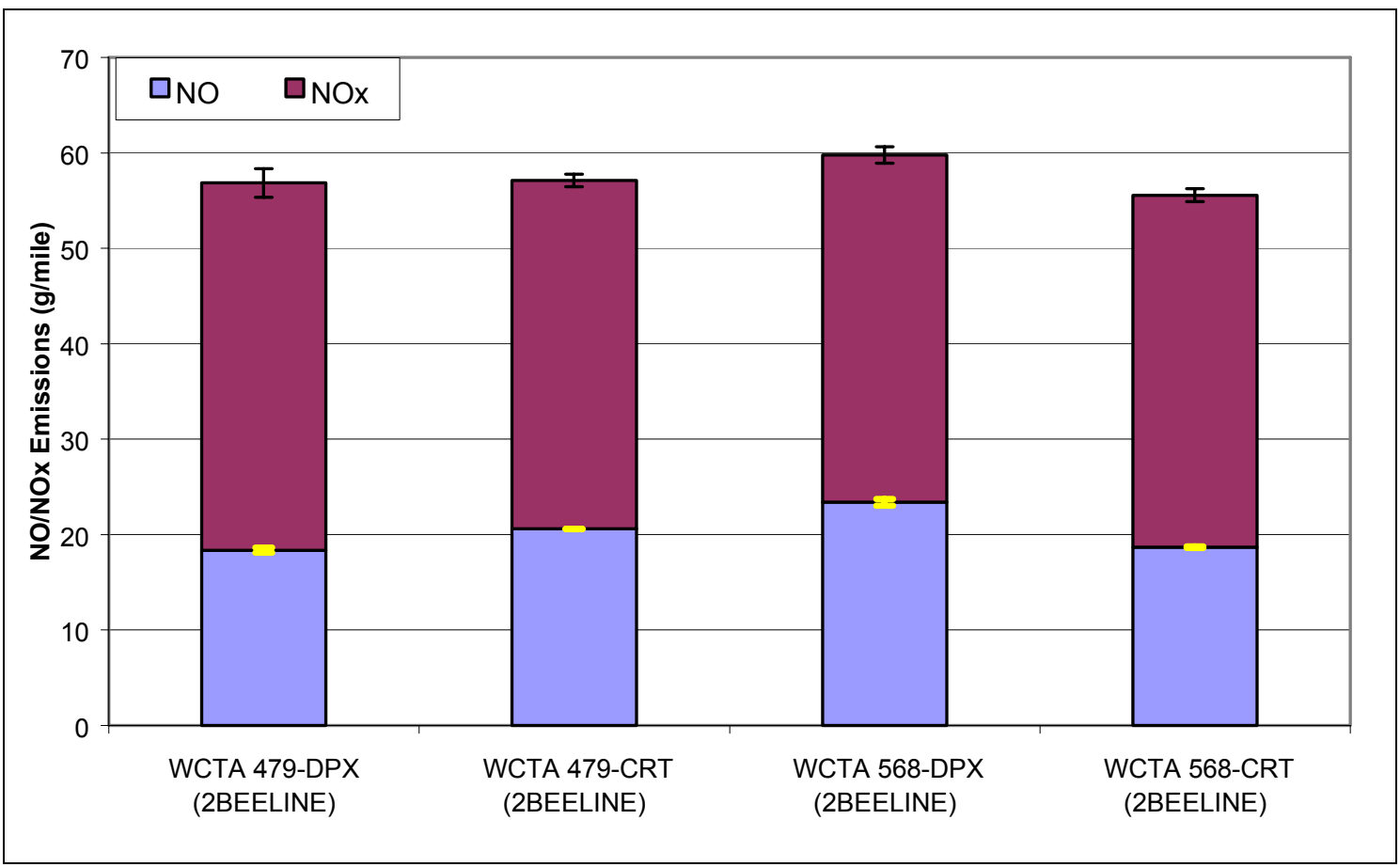

Figure 4.3.9: $\mathrm{NO}$ and $\mathrm{NO}_{\mathrm{X}}$ emissions from the WCTA fleet vehicles tested.

\subsubsection{4 $\mathrm{CO}_{2}$ Emissions / Fuel Economy}

On average carbon dioxide emissions increased slightly when testing with the particulate filters. This increase is attributed to an increase in exhaust backpressure associated with the addition of a diesel particulate filter into the exhaust stream. The average variance was an approximate 2.6 percent increase for the DPX equipped vehicles and approximate two percent increase for the CRT equipped vehicles. It should be noted, however, that the $\mathrm{CO}_{2}$ measurement accuracy, approximately $\pm 2 \%$, could also account for the variance between filter equipped tests and tests using the standard muffler.

The increased backpressure discussed above also had a parasitic effect on the fuel economy of filter equipped vehicles. Average fuel economy dropped by 1.4 percent for Engelhard DPX equipped vehicles and 4.4 percent for Johnson-Matthey CRT equipped vehicles. Figures 4.3.10 and 4.3.11 show the calculated fuel economy for DPX and CRT equipped tests respectively. 


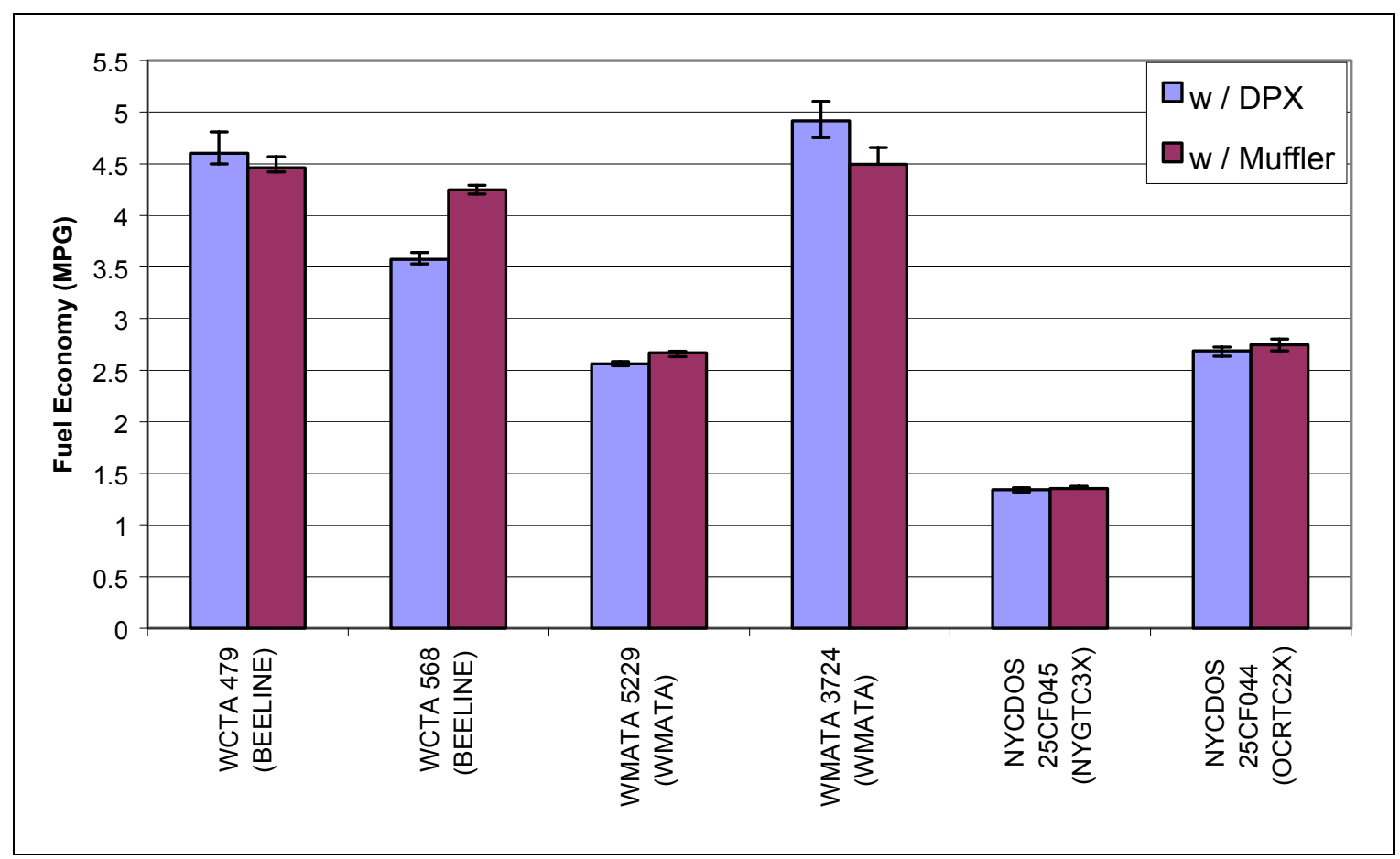

Figure 4.3.10: Fuel economy from Engelhard DPX equipped vehicles.

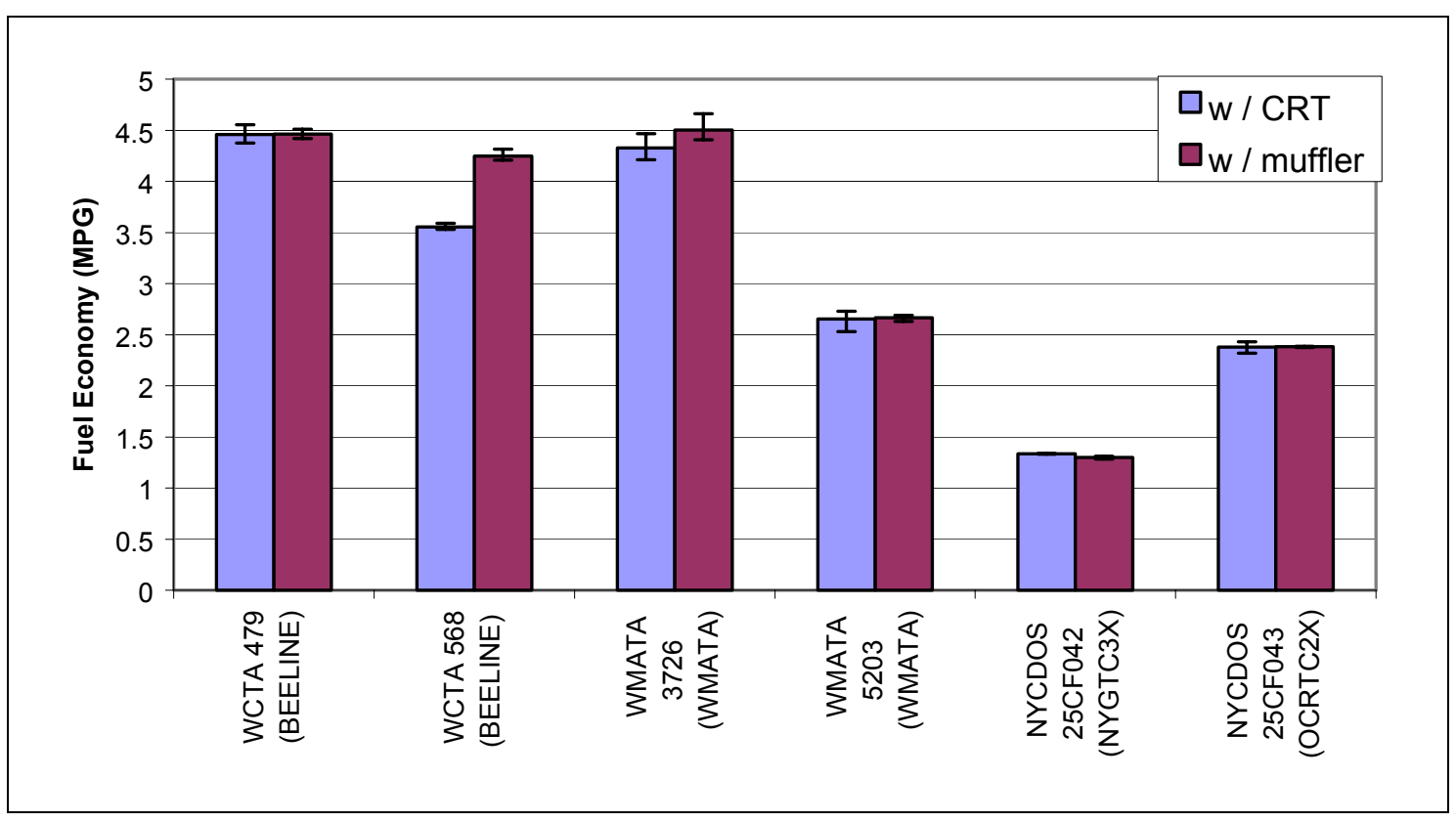

Figure 4.3.11: Fuel economy from Johnson-Matthey CRT equipped vehicles. 


\subsubsection{PM Emissions}

As expected, the greatest emission reduction witnessed was from the particulate matter emissions. The Engelhard DPX equipped vehicles underwent an order of magnitude reduction going from an average emissions of $0.84 \mathrm{~g} / \mathrm{mile}$ with the standard muffler to $0.053 \mathrm{~g} /$ mile with the DPX. This was an approximate 94 percent reduction. The Johnson-Matthey CRT proved slightly less efficient, with only an 82 percent reduction.

Figure 4.3.12 shows the average PM emissions produced from DPX equipped vehicles, while Figure 4.3.13 shows the average PM emissions produced from CRT equipped vehicles. Each bar in these figures represents the average of three test runs performed with each vehicle/aftertreatment configuration.

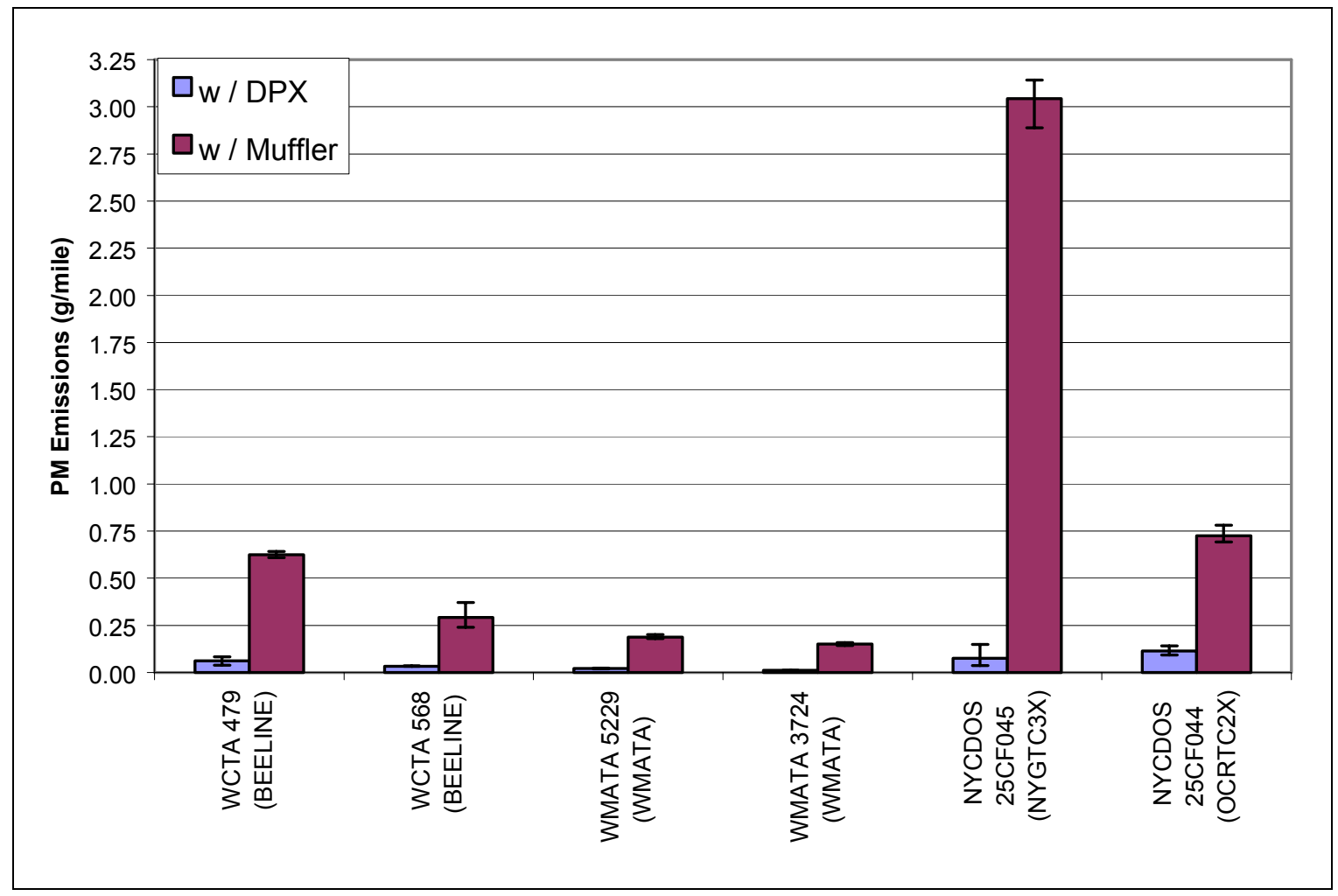

Figure 4.3.12: PM emissions from Engelhard DPX equipped vehicles. 


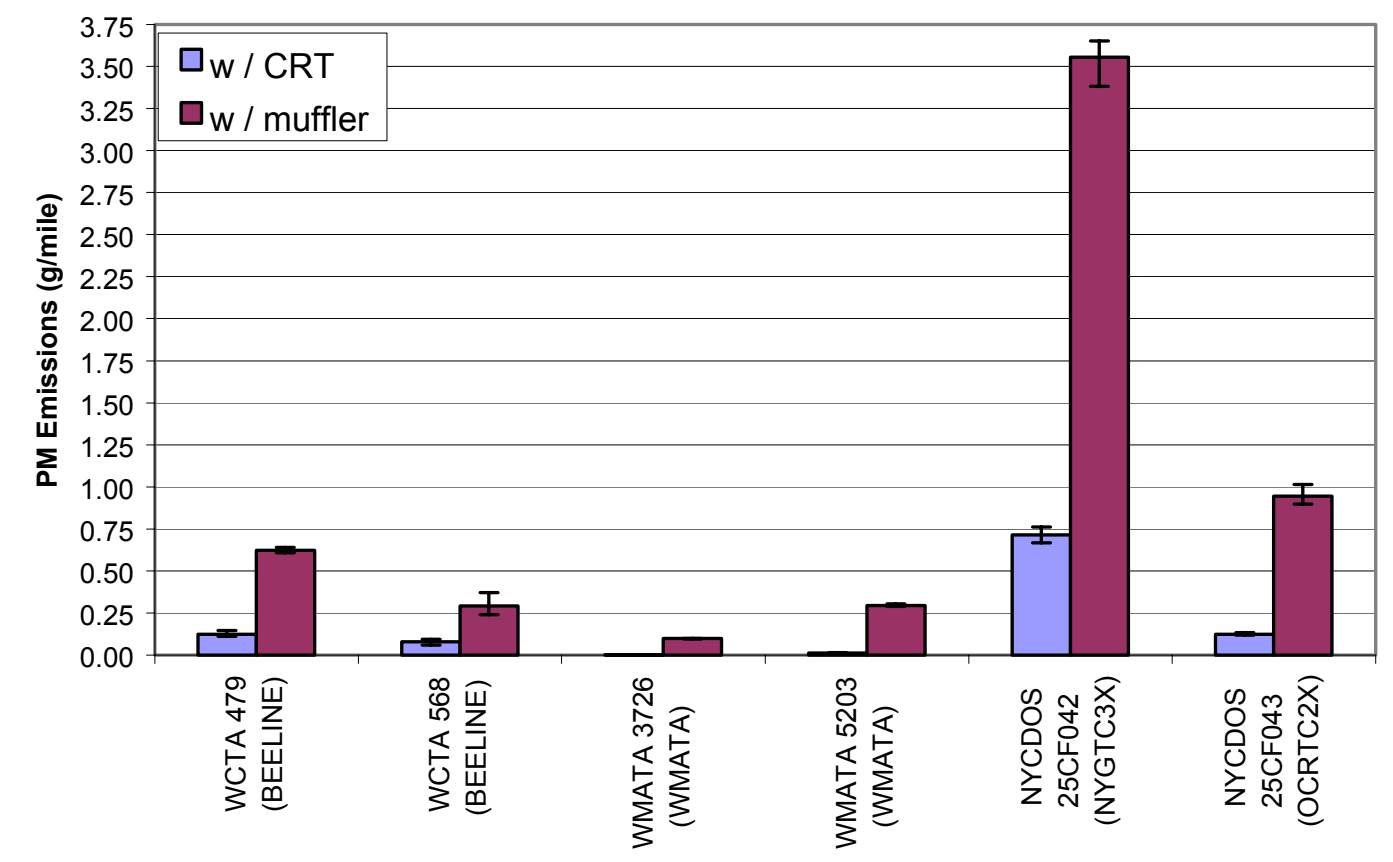

Figure 4.3.13: PM emissions from Johnson-Matthey CRT equipped vehicles. 


\section{Chapter 5 - Conclusions}

\subsection{Cold Start DPF Performance}

Under cold start conditions, the diesel particulate filters proved to be very effective in reducing particulate matter from the exhaust stream, with reduction levels averaging greater than $90 \%$ for all DPFs tested. In the valid TEOM data collected, there was little variance in mass concentration data, suggesting that both the Engelhard DPX and the Johnson-Matthey CRT successfully filter particulate matter prior to the catalyst reaching its light-off temperature.

Based on gaseous emission stabilization, the light-off temperature was determined to be dependent on the post-filter exhaust temperature rather than the pre-filter exhaust temperature, regardless of the fact that the pre-filter temperature stabilized much faster. Gaseous emissions concentrations, including $\mathrm{CO}, \mathrm{HC}, \mathrm{NO} / \mathrm{NO}_{\mathrm{X}}$, stabilized when the post-filter exhaust temperature reached between $400^{\circ} \mathrm{F}$ and $450^{\circ} \mathrm{F}$ for the Engelhard DPX under warm-weather cold start testing and between $330^{\circ} \mathrm{F}$ and $350^{\circ} \mathrm{F}$ under cold-weather cold start testing. The Johnson-Matthey CRT showed emissions stabilization between $375^{\circ} \mathrm{F}$ and $450^{\circ} \mathrm{F}$ under warm-weather cold start testing. The CRT was not tested under cold-weather conditions. After the catalyst light-off temperature was reached, the posttrap exhaust temperature continued to climb to as high as $550^{\circ} \mathrm{F}$ before stabilizing.

Based on the smoke meter data, neither particulate filter type tested had a significant impact on reducing white smoke emissions.

Average integrated carbon monoxide emissions were reduced by $72.7 \%$ for warm-weather cold start tests and 53\% for cold-weather cold start tests using the Engelhard DPX. The Johnson-Matthey CRT reduced CO emissions by $76.9 \%$ during 
warm-weather cold start tests. Hydrocarbon emissions were reduced by $83 \%$ and $78 \%$ by the DPX during warm-weather and cold-weather cold start testing respectively. HC emissions were reduced by $86 \%$ using the Johnson-Matthey CRT. No significant reductions were recorded for $\mathrm{NO}_{\mathrm{X}}$ or $\mathrm{CO}_{2}$ emissions from any of the DPFs tested, however NO emissions were reduced by $30 \%$ and $46 \%$ by the DPX and CRT respectively for warm-weather cold start testing. The $\mathrm{NO} / \mathrm{NO}_{\mathrm{X}}$ fraction was not calculated for the cold-weather cold start testing performed on the WVU Mack tractor truck.

\subsection{Long-Term Durability Evaluation}

The three-year evaluation of diesel particulate filter performance showed a slight degeneration in filter efficiency as accumulated mileage increased. This degeneration is most evident in the carbon monoxide, hydrocarbon, and particulate matter emissions.

CO emissions were most severely affected by the mileage increase. Round one CO reductions were greater than $90 \%$ for both the Engelhard DPX and Johnson-Matthey CRT; however in round two, average CO reductions decreased to $62 \%$ for the DPX and $85 \%$ for the CRT. Reductions again dropped in round three to only a $57 \%$ reduction from the DPX and 74\% from the CRT.

$\mathrm{HC}$ emission reductions remained fairly constant between rounds one and two, with reductions of approximately $99 \%$ for both DPF types. However, when the fuel type was changed from ECD to ECD1, the reduction levels fell to $89 \%$ for the DPX while remaining at $98 \%$ for the $\mathrm{CRT}$. In round three, the $\mathrm{HC}$ emission reductions gained from the DPX fell to $75 \%$ while the CRTs reductions averaged $95 \%$. 
Particulate matter emissions also remained steady from round one to round two, with reductions of greater then $99 \%$ for both DPF types while using the ECD fuel. However, in round three, the PM emissions reductions dropped to $95 \%$ and $97 \%$ for the Engelhard DPX and Johnson-Matthey CRT respectively.

Although the experimental data showed a trend toward diesel particulate filter degeneration relative to accumulated mileage, a definitive life span could not be determined for either the Engelhard unit or the Johnson-Matthey unit because of the discrepancies described in the previous chapter, including the use of multiple fuel types during testing and the lack of vehicle maintenance records.

\subsection{General Performance Evaluation and Manufacturer Comparison}

The general performance evaluation and product comparison showed some strengths and weakness of both the Engelhard DPX and Johnson CRT diesel particulate filters, although the two styles are very comparable.

Average carbon monoxide emission reductions were nearly identical for the two units, with an $85 \%$ reduction from the DPX and an $84 \%$ reduction from the CRT. Additionally, carbon dioxide emission variances were nearly identical, with an increase in $\mathrm{CO}_{2}$ emissions of $2.6 \%$ and $2 \%$ for the DPX and CRT respectively.

Differences in hydrocarbon emission reductions from the two DPF styles were slightly more evident. The Engelhard DPX reduced HC emissions by $76 \%$ while the Johnson-Matthey CRT reduced HC emissions by $81 \%$. 
The greatest difference discovered between the two DPF types was in the area of particulate matter reductions. On average, the Johnson-Matthey CRT reduced PM emissions by $82 \%$ while the Engelhard DPX reduced PM emissions by $94 \%$.

Both the Engelhard DPX and the Johnson-Matthey CRT are very effective aftertreatment devices. As this study has shown, there exists a slight trade-off between $\mathrm{HC}$ reduction and PM reduction between the two units. 


\section{References:}

1. Allansson, R., Cooper, B., thoss, J., Uusimäki, A., Walker, A., Warren, J. (2000). European Experience of High Mileage Durability of Continuously Regenerating Diesel Particulate Filter Technology (SAE 2000-01-0480).

2. Auto Emissions Magazine, Number 14. " $21^{\text {st }}$ Century Diesel: A Clean Future." Fall 1999.

3. Bata, R., Clark, N., Gautam, M., Howell, A., Long, T., Loth, J., Lyons, D., Palmer, M., Rapp, B., Smith, J., Wang, W. (1991). The First Transportable Heavy Duty Vehicle Emissions Testing Laboratory (SAE 912668).

4. Browning, L. H. (1997). Technologies and Costs for On-Road Heavy-Duty Engines Meeting 2004 Emissions Standards (SAE 973256).

5. Chandler, K., Coburn, T., LeTavec, C., Uihlein, J., Vertin, K., Chatterjee, S., Hallstrom, K., Wayne, S., Clark, N., Gautam, M., Thompson, G., Lyons, D. (2002). Year-Long Evaluation of Trucks and Buses Equipped with Passive Diesel Particulate Filters (SAE 2002-01-0433).

6. Chernich, D. J., Jacobs, P. E., Kowalski, J. D. (1991). A Comparison of Heavy-Duty Diesel Truck Engine Smoke Opacities at High Altitude and at Sea Level (SAE 911671).

7. Clark, N., McKain, D., Messer, T., Lyons, D. (1994). Chassis Test Cycles for Assessing Emissions from Heavy Duty Trucks (SAE 941946).

8. Clark, N., Daley, J., nine, R., Atkinson, C. (1999). Application of the New CitySuburban Heavy Vehicle Route (CSHVR) to Truck Emissions Characterization. (SAE 1999-01-1467).

9. Code of Federal Regulations, Title 40, Part 86, Subpart N - Emissions Regulations for New Otto-Cycle and Diesel Heavy-Duty Engines; 86.132-90 Vehicle Preconditioning, 2002.

10. Engelhard. "Engelhard-DPX ${ }^{\mathrm{TM}}$ Catalytic Particulate Filters Overview." 2001. Engelhard . 05 Sept. 2002. <www.engelhard.com>.

11. Evans, J. C. (2001). Influence of Fuel Sulfur Content on Emissions From Diesel Engines Equipped With Oxidation Catalysts. M.S. Thesis, Department of Mechanical and Aerospace Engineering, West Virginia University, Morgantown, WV.

12. Gilbert, M. (2002). Investigation into the Use of a Tapered Element Oscillating Microbalance for Real-Time Particulate Measurement. M.S. Thesis, Department of Mechanical and Aerospace Engineering, West Virginia University, Morgantown, WV.

13. Hall, T. S. (2002). Effects of Vehicle Weight Class and Model Year on Vehicle Contribution to Atmospheric Pollutant Inventories. M.S. Thesis, Department of Mechanical and Aerospace Engineering, West Virginia University, Morgantown, WV.

14. Hammerle, R.H., Ketcher, D., Horrocks, R., Lepperhoff, G., Hüthwohl, G., Lüers, B. (1995). Emissions from Diesel Vehicles with and without Lean $N O_{X}$ and Oxidation Catalysts and Particulate Traps (SAE 952391).

15. Heywood, John B., Internal Combustion Engine Fundamentals. McGraw-Hill, Inc., New York, NY. 1988. 
16. Hoard, J. (2001). Plasma-Catalysis for Diesel Exhaust Treatment: Current State of the Art (SAE 2001-01-0185).

17. Johnson, J. V. (2002). Diesel Emissions Control: 2001 in Review (SAE 2002-010285).

18. Johnson Matthey. "CRT." 2001. Johnson Matthey Catalytic Systems Division. 05 Sept. 2002. <www.jmcsd.com>.

19. Khair, M.K. (1997). Technical and Synergistic Approaches Towards the TwentyFirst Century Diesel Engine (SAE 972687).

20. Khair, M., McKinnon, D. L. (1999). Performance Evaluation of Advanced Emissions Control Technologies for Diesel Heavy-Duty Engines (SAE 1999-013564).

21. Kilcarr, Sean. "Diesel Engines Will Remain the Predominant Power Source for Commercial Trucks." Clean Air: Trucking's Contribution 10 Dec. 2001. $<$ cleanair.fleetowner.com/ar/fleet_diesel_engines_remain/index.htm>.

22. LeTavec, C., Uihlein, J., Segal, J., Vertin, K. (2000). EC-Diesel Technology Validation Program Interim Report (SAE 2000-01-1854).

23. Mori, K., Jyoutaki, H., Kawai, K., Sakai, K. (2000). New Quiescent Combustion System for Heavy-Duty Diesel Engines to Overcome Exhaust Emissions and Fuel Consumption Trade-Off (SAE 2000-01-1811).

24. Okrent, D. A. (1998). Optimization of a Third Generation TEOM ${ }^{\circledR}$ Monitor for Measuring Diesel Particulate in Real-Time (SAE 980409).

25. Richards, R.R., Sibley, J.E. (1988). Diesel Engine Emissions Control for the 1990's (SAE 880346).

26. Rosemount Analytical Model 402 Hydrocarbon Analyzer Instruction Manual 015082132, Rosemount Analytical Inc., LaHabra, California. 1991.

27. Rosemount Analytical Model 868 NDIR Analyzer Instruction Manual 015748003, Rosemount Analytical Inc., LaHabra, California. 1991.

28. Rosemount Analytical Model $955 \mathrm{NO} / \mathrm{NO}_{\mathrm{X}}$ Analyzer Instruction Manual 015555479, Rosemount Analytical Inc., LaHabra, California. 1991.

29. SAE (1997). Fuel Economy Measurement Test (Engineering Type) for Trucks and Buses. Society of Automotive Engineers Standards J1376.

30. Su, T.F., Chang, C., Reitz, R., Farrell, P., Pierpont, A., Tow, T. (1995). Effects of Injection Pressure and Nozzle Geometry on Spray SMD and D.I. Emissions (SAE 952360).

31. Tanin, K.V., Wickman, D., Montgomery, D., Das, S., Reitz, R. (1999). The Influence of Boost Pressure on Emissions and Fuel Consumption of a Heavy-Duty Single-Cylinder D.I. Diesel Engine (SAE 1999-01-0840).

32. Telonic Berkeley Inc., Telonic Berkeley Model 107 Smoke Opacity Meter User's Manual. (January 7, 1999).

33. USDOE, (2002). United States Department of Energy, Office of Transportation Technologies. Advanced Petroleum-Based Fuels, Fuel Properties Database. $<$ www.ott.doe.gov/fuelprops/>

34. Wayne, S., Nine, R. (2002). Cummins Engine DPF Demonstration Program: Final Data Report. Department of Mechanical and Aerospace Engineering, West Virginia University, Morgantown, WV. 
35. Wayne, S., Nine, R., Clark, N., Schiavone, J. (2002). Development of the BeeLine Dynamometer Driving Schedule. Department of Mechanical and Aerospace Engineering, West Virginia University, Morgantown, WV.

36. Yassine, M.K., Tagomori, M., Henein, N., Bryzik, W. (1996). White Smoke Emissions Under Cold Starting of Diesel Engines. (SAE 960249).

37. Zelenka, P., Kriegler, W., Herzog, P., Cartellieri, W. (1990). Ways Toward the Clean Heavy-Duty Diesel (SAE 900602).

38. 2002 Health Assessment Document for Diesel Exhaust. USEPA EPA/600/890/057F. 01 May 2002. U.S. Environmental Protection Agency, Washington, DC. 
Appendix A

Analyzer

Information 
Lab 1 Analyzers

\begin{tabular}{|c|c|c|c|c|c|}
\hline Analyzer & Abbreviation & Manufacturer & Model & Ranges & $\begin{array}{c}\text { Repeatability / } \\
\text { Precision }\end{array}$ \\
\hline \multirow{2}{*}{$\begin{array}{c}\text { High Level Carbon } \\
\text { Monoxide }\end{array}$} & \multirow{2}{*}{$\mathrm{HCO}$} & \multirow{2}{*}{ Beckman Industrial } & \multirow{2}{*}{ Model 868} & 0-1000 ppm & \multirow{2}{*}{ Not Available } \\
\hline & & & & $0-5000 \mathrm{ppm}$ & \\
\hline \multirow{4}{*}{$\begin{array}{l}\text { Low Level Carbon } \\
\text { Monoxide }\end{array}$} & \multirow{4}{*}{ LCO } & \multirow{4}{*}{ Horiba } & \multirow{4}{*}{ AIA-210 LE } & $0-25 \mathrm{ppm}$ & \multirow{4}{*}{$0.2 \%$ Full Scale } \\
\hline & & & & $0-50 \mathrm{ppm}$ & \\
\hline & & & & $0-100 \mathrm{ppm}$ & \\
\hline & & & & $0-200 \mathrm{ppm}$ & \\
\hline \multirow{3}{*}{ Carbon Dioxide } & \multirow{3}{*}{$\mathrm{CO} 2$} & \multirow{3}{*}{$\begin{array}{l}\text { California Analytical } \\
\text { Instruments }\end{array}$} & \multirow{3}{*}{ Model 300} & $3 \%$ & \multirow{3}{*}{$1 \%$ Full Scale } \\
\hline & & & & $9.84 \%$ & \\
\hline & & & & $14.79 \%$ & \\
\hline $\begin{array}{c}\text { Oxide of Nitrogen } \\
\text { Analyzer }\end{array}$ & NOx1 & $\begin{array}{l}\text { California Analytical } \\
\text { Instruments }\end{array}$ & $\begin{array}{l}\text { Model 400- } \\
\text { HCLD }\end{array}$ & 0-3000 ppm & $0.5 \%$ Full Scale \\
\hline $\begin{array}{c}\text { Oxide of Nitrogen } \\
\text { Analyzer }\end{array}$ & NOx2 & $\begin{array}{l}\text { California Analytical } \\
\text { Instruments }\end{array}$ & $\begin{array}{c}\text { Model 400- } \\
\text { HCLD }\end{array}$ & $0-3000$ ppm & $0.5 \%$ Full Scale \\
\hline Hydrocarbon & $\mathrm{HC}$ & Rosemount Analytical & Model 402 & $1-5000$ ppm & $1 \%$ FullScale \\
\hline
\end{tabular}

\section{Lab 2 Analyzers}

\begin{tabular}{|c|c|c|c|c|c|}
\hline Analyzer & Abbreviation & Manufacturer & Model & Ranges & $\begin{array}{c}\text { Repeatability I } \\
\text { Precision }\end{array}$ \\
\hline \multirow{2}{*}{$\begin{array}{c}\text { High Level Carbon } \\
\text { Monoxide }\end{array}$} & \multirow{2}{*}{$\mathrm{HCO}$} & \multirow{2}{*}{ Rosemount Analytical } & \multirow[b]{2}{*}{ Model 880A } & $0-500 \mathrm{ppm}$ & \multirow{2}{*}{ 1\% Full Scale } \\
\hline & & & & $0-5000 \mathrm{ppm}$ & \\
\hline \multirow{4}{*}{$\begin{array}{l}\text { Low Level Carbon } \\
\text { Monoxide }\end{array}$} & \multirow{4}{*}{ LCO } & \multirow{4}{*}{ Horiba } & \multirow{4}{*}{ AIA-210 LE } & $0-25 \mathrm{ppm}$ & \multirow{4}{*}{$0.2 \%$ Full Scale } \\
\hline & & & & $0-50 \mathrm{ppm}$ & \\
\hline & & & & $0-100 \mathrm{ppm}$ & \\
\hline & & & & $0-200 \mathrm{ppm}$ & \\
\hline \multirow{4}{*}{ Carbon Dioxide } & \multirow{4}{*}{$\mathrm{CO} 2$} & \multirow{4}{*}{ Horiba } & \multirow{4}{*}{ AIA-210 LE } & $3 \%$ & \multirow{4}{*}{$0.2 \%$ Full Scale } \\
\hline & & & & $5 \%$ & \\
\hline & & & & $6 \%$ & \\
\hline & & & & $16 \%$ & \\
\hline \multirow{7}{*}{$\begin{array}{c}\text { Oxide of Nitrogen } \\
\text { Analyzer }\end{array}$} & \multirow{7}{*}{ NOx1 } & \multirow{7}{*}{ Rosemount Analytical } & \multirow{7}{*}{ Model 955} & $0-10 \mathrm{ppm}$ & \multirow{7}{*}{$5 \%$ Full Scale } \\
\hline & & & & $0-25 \mathrm{ppm}$ & \\
\hline & & & & $0-100 \mathrm{ppm}$ & \\
\hline & & & & $0-250 \mathrm{ppm}$ & \\
\hline & & & & 0-1000 ppm & \\
\hline & & & & $0-2500 \mathrm{ppm}$ & \\
\hline & & & & $0-10000 \mathrm{ppm}$ & \\
\hline \multirow{7}{*}{$\begin{array}{c}\text { Oxide of Nitrogen } \\
\text { Analyzer }\end{array}$} & \multirow{7}{*}{ NOx2 } & \multirow{7}{*}{ Rosemount Analytical } & \multirow{7}{*}{ Model 955} & $0-10 \mathrm{ppm}$ & \multirow{7}{*}{$5 \%$ Full Scale } \\
\hline & & & & $0-25 \mathrm{ppm}$ & \\
\hline & & & & $0-100 \mathrm{ppm}$ & \\
\hline & & & & $0-250 \mathrm{ppm}$ & \\
\hline & & & & 0-1000 ppm & \\
\hline & & & & $0-2500 \mathrm{ppm}$ & \\
\hline & & & & $0-10000 \mathrm{ppm}$ & \\
\hline Hydrocarbon & $\mathrm{HC}$ & Rosemount Analytical & Model 402 & $1-5000 \mathrm{ppm}$ & $1 \%$ Full Scale \\
\hline
\end{tabular}


Appendix B

Cold Start Data Summary 


\begin{tabular}{|c|c|c|c|c|c|c|c|c|c|c|c|c|c|c|c|c|}
\hline $\operatorname{tent} \mathbf{D}$ & \begin{tabular}{|c|} 
Test fun \\
D
\end{tabular} & WuUfert No. & Wehick Type & $\begin{array}{l}\text { Vericie } \\
\text { Number }\end{array}$ & $\begin{array}{c}\text { Parboulabe } \\
\text { Fater }\end{array}$ & Fuet & $\begin{array}{l}\text { Drivire } \\
\text { schedid }\end{array}$ & $\infty$ & $\mathrm{NOx}$ & no & $n C$ & PM & $\infty 2$ & Mins & weo & BTU \\
\hline & & & & & & & & (onde) & (ghite) & (ghinie) & (otrits) & (gnile) & (ghix) & & & \\
\hline 3012 & 2 & WMATA_-3722-DT-COWCBO & \begin{tabular}{|l} 
Tranes Bus \\
\end{tabular} & $3 \pi 22$ & Hore & D1 & ColuCEO & 0.9900207 & 18.259068 & 17.70700 & 0.2313664 & 0.0561875 & 1909.6193 & 3.3833411 & 49647522 & 25379.91 \\
\hline 3014 & 2 & MMATA-J723-DA-Codac00 & Tranges bus & 323 & Nomen & 01 & $\operatorname{coldct} 00$ & 1 sassion & 17355894 & 17016023 & 0.1435000 & 0.0452606 & 1798319 & 5.4820627 & $5 \times 2382$ & 23540.672 \\
\hline & & & & & & & AVEFIACE & 12821694 & 17808031 & 17362051 & 0.1874333 & 0055737 & 1868.9656 & 4.4377016 & 5.1565722 & 24450632 \\
\hline 3017 & 2 & WMATA.3724U SD1_COWDEO & \begin{tabular}{|l} 
Tranes Bus \\
\end{tabular} & $3 \pi 24$ & DPX & USDOH & ColdCEO & 0.4369592 & 15.392447 & 10.521631 & 0.032207 & 0.0027995 & 1812.4905 & 6.070743 & 5.405178 & 23453512 \\
\hline 3023 & 1 & VMata-3T25:U SD1-Cold000 & Transe bus & 325 & $\cos x$ & uspr & $\operatorname{col} c 00$ & 0.2021503 & 19.006693 & 13746644 & - & 0.0006202 & 1756.4413 & 5.0046028 & 5.6140009 & $2274602:$ \\
\hline & & & & & & & AVEFAOCE & 0.5505087 & 1782957 & 12.134138 & 0.032207 & 0.00520074 & 1785.4659 & 80076727 & 55305300 & 23101.167 \\
\hline 3824 & 2 & 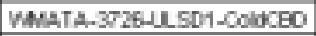 & \begin{tabular}{|l|} 
Tranes Bus \\
\end{tabular} & $3 \pi 28$ & CRT & usDOt & ColdCEO & 0.2500003 & 18.567528 & 10.162495 & 0,0001113 & 0.0024564 & 1875.1769 & 6.1045737 & 5.2653009 & 24259.168 \\
\hline 3020 & 2 & WMATA-3T27_U SD1-ColdCOO & Transet Bus & 327 & करा & uson & $\operatorname{coldc} 00$ & 0,3420007 & 15.48009 & 0.4091150 & 0,0521298 & 0.0060456 & 1722.4391 & 72304916 & 57310719 & 223007620 \\
\hline & & & & & & & AVEFIACE & 02065555 & 17.200300 & 92058052 & 0,0051205 & 0003751 & 17968008 & 8.6775927 & 54251904 & 232733297 \\
\hline 3960 & 1 & WMU-21017-CECO1_WWU-1P & Tractor Truck & 21017 & DPX & ECDI & WMU.1P & 37369507 & 30.004562 & 29.534398 & 22429991 & 0.0416308 & 1902.3623 & 7.6013456 & 5.2026925 & 24962.85 \\
\hline 3901 & 1 & Wu-21017.cecon:aMU:Ap & Tractor Truck & 21017 & CPX & ECOI & WMU:AP & 1.9122305 & 10.029260 & 10.59912 & 0.2677911 & 0.0014786 & 1730,0942 & 11.120739 & 57974863 & 22392008 \\
\hline & & & & & & & AVEFIACE & 28245708 & 24357165 & 24036758 & 1.2555051 & 0.0215527 & 1827.7283 & 23850446 & 55000594 & 23672.821 \\
\hline 3764 & 1 & WMU-21017-CECO1-WWU-1P & Tractor Trusk & 21017 & None & ECOH & WMU-1P & 42903352 & 23.09654 & 23074906 & 1.3185741 & 0.2633255 & 1872.4095 & 11.159514 & 5.3469514 & 24279902 \\
\hline 3705 & 1 & Wu-21017.CECO1:MU:AP & Tractor Truck & 21017 & Norne & $\mathrm{ECOH}$ & WMU:AP & 30017785 & $17.1906 \mathrm{cg} 7$ & 15.104056 & 1.1336472 & 0.2175893 & 1640.741 & 11.127071 & 60719404 & $21300 \mathrm{EA}$ \\
\hline & & & & & & & AVEFIACE & 4 OS10573 & 20.143619 & 19.120431 & 1.2281106 & 0.2404514 & 17605753 & 11.143892 & 57004159 & $2263027 \%$ \\
\hline
\end{tabular}


Appendix C

Durability Study Data Summary 
ROUND 1

\begin{tabular}{|c|c|c|c|c|c|c|c|c|c|c|c|c|c|c|c|c|}
\hline $\operatorname{Tan} 10$ & Tent $\operatorname{man} D$ & Munet No & Velich Type & $\begin{array}{l}\text { Vetide } \\
\text { Number }\end{array}$ & $\begin{array}{c}\text { Purticulat } \\
\text { reter }\end{array}$ & ruat & $\begin{array}{l}\text { Doring } \\
\text { sctiodis }\end{array}$ & $c \infty$ & $\operatorname{mox}$ & No & $M C$ & PM & $\cos$ & Wen & MOO & DTu \\
\hline & & & & & & & & [g/nle & (ginis) & $(g \ln b)$ & (ghates) & $(\ln 6)$ & {$[g(\ln )$} & & & \\
\hline 1452 & 1 & RA CA0-5803-ECD-2xeh/ & Tractor Truck & 5803 & CRT & $E C D$ & 2CSHVR & 0.41 & 297 & Nua & $e$ & 8 & 1979 & 13.45 & 5.07 & 24870 \\
\hline 1452 & 2 & RA CAO-5803-ECO-2xethr & Trastor Truck & 5803 & CRT & $E C D$ & XCSHVR & 0.24 & 31.4 & Nia & $e$ & 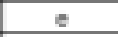 & 1712 & 13.44 & 5.57 & 22058 \\
\hline \multirow[t]{2}{*}{1482} & 3 & 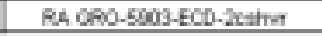 & Trastor Truck & 5003 & CRT & $E C D$ & XCSHVR & 024 & 317 & Nia & e & 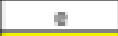 & 1859 & 13.44 & 5.05 & 25001 \\
\hline & & & & & & & AVEtrace & 02560068 & 30.8 & & BCL & $\mathrm{EaL}$ & 1650.6089 & 13.42353 & 523 & 24175353 \\
\hline 1453 & 1 & 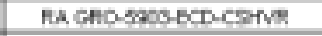 & Trastor Thuck & $\sin$ & nore & $\mathrm{ECD}$ & comen & 10.01 & 203 & NM & 019 & 0.5 & 1575 & $5 \pi$ & 6.19 & 20034 \\
\hline 1400 & 3 & 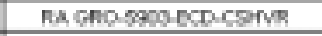 & Tractor Thuck & 500 & none & $E \propto D$ & $\operatorname{cssen} \pi$ & $0 \times 6$ & 20.3 & Nu & 022 & $0, x$ & 1700 & $6 \pi$ & 529 & 20059 \\
\hline 1469 & 4 & RA, GAOS990BECDCSAMR & Tractor Thuck & 5003 & none & $E C D$ & CSAMR & 8.26 & 30 & Nua & 0.7 & 0.25 & 1734 & 672 & 5.47 & 230077 \\
\hline \multirow[t]{2}{*}{1483} & 5 & RA OAO-5960-ECDLCSHVR & Trastor Thack & 5803 & none & $E C D$ & CSHAR & 8.26 & 32.9 & Nua & 0.24 & 0.19 & $1 \pi 6$ & 672 & 5.36 & 23559 \\
\hline & & & & & & & AVEFAACE & 8.8725 & 28.875 & & 0.215 & 03 & 1702.75 & 672 & 5.5775 & 2272075 \\
\hline 1484 & 1 & RAA $0 F 0-5003-C H A B-C S H V R$ & Trastar Truck & 5003 & tane & CARE & CSHAR & 119 & 283 & Nis & 023 & 0.57 & 1918 & 672 & 5.47 & 23913 \\
\hline 1454 & 2 & 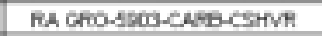 & Trastor Thuck & $\sin$ & $\operatorname{man}$ & cares & conth & 113 & 312 & Nus & 0.25 & 0.22 & lazs & 672 & s.45 & 22018 \\
\hline 1454 & 3 & 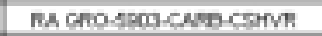 & Trastor Thuck & $\sin$ & nom & caves & com & 95 & 377 & Nu & 022 & 0.27 & 1756 & $5 \pi$ & $\$ 54$ & 23015 \\
\hline 1404 & 4 & RA CWOSEOB CMODCSAMR & Tractor Thuek & 5000 & nane & CAND & $\operatorname{csin} \pi$ & 115 & 304 & Nu & 0.20 & 0.27 & $109 \mathrm{~T}$ & $6 \pi$ & 5.24 & 20750 \\
\hline \multirow[t]{2}{*}{1484} & 5 & 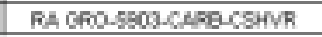 & Tractor Truck & 5803 & nane & CAR 9 & CSARR & 112 & 39.5 & Nua & 0.25 & 0.25 & 1743 & 672 & 67 & 22757 \\
\hline & & & & & & & AVEFAOCE & 11.09 & 35.1 & & 0.238 & 0.356 & 1809.4 & 672 & 55 & 23612 \\
\hline 1487 & 2 & 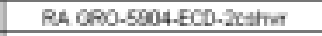 & Trastor Truck & 5004 & CRT & $E C D$ & XCSTVR & 0.44 & 34.5 & Nia & e & 0.0031 & 1700 & 13.45 & 5.58 & 22001 \\
\hline $148 \%$ & 3 & Ren Ceno-5004-ECD-2xation & Irastar Fruck & 5004 & CRT & $E C D$ & 2CSTVR & 000 & 345 & NAM & e & 0.0034 & 1629 & 13.44 & 5.62 & 22052 \\
\hline \multirow[t]{2}{*}{$148 \mathrm{~N}$} & 4 & 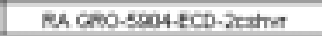 & Trastor Truck & $\operatorname{sen}$ & Cnt & $\mathrm{ECD}$ & $x \cos m$ & 0.23 & 329 & sus & $=$ & $0 \cos 7$ & 1923 & 13.45 & 4.98 & 25495 \\
\hline & & & & & & & AVERACE & 0.750190 & ग9 9006 & & $\infty \mathrm{al}$ & 000273 & 1775 OCO & 13 प्रTET & 5300067 & 234906 \\
\hline 1400 & 1 & RA GAOS9OA-ECDCCPNR & Tractor Thuck & 5804 & none & $E C D$ & CSAnk & 950 & 357 & Nu & 0.27 & 0.15 & $17 \mathrm{~m}$ & $6 \pi$ & 5.32 & 23010 \\
\hline 1458 & 2 & RA GAOSS904-ECDLCOIVR & Tractor Thuck & 5804 & nane & $E C D$ & CSHAR & 896 & 34.6 & Nua & 0.29 & 0.18 & 1750 & 672 & 5.4 & 23049 \\
\hline \multirow[t]{2}{*}{1458} & 3 & FA OAO-S904-ECD-CSHVR & Trastor Thack & 5604 & nane & $E C D$ & CSHWR & 882 & 33.8 & Nia & 0.3 & 0.15 & 1725 & 672 & 5.48 & 23005 \\
\hline & & & & & & & AVEFAOCE & 2.12 & 35.093333 & & 0.2600662 & 0.16 & 1750 6089 & 872 & 5.4 & 23954.667 \\
\hline 1420 & 1 & 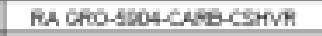 & Trastor fruck & 5004 & tane & cang & CSAMR & 11.1 & $\$ 2$ & NuM & 0.34 & 0.23 & 1821 & 672 & 5.48 & 23571 \\
\hline 1450 & 2 & 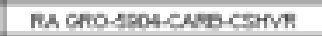 & Trastor Thuck & 5004 & $\operatorname{mon}$ & canes & crim & 119 & 345 & Nus & 0.3 & $0.2 x$ & $17 \%$ & $5 \pi$ & 553 & 23479 \\
\hline 1450 & 3 & RA CWOSBOACAODCSOMR & Trather Thuak & 5004 & nome & CAMD & $\operatorname{css} \pi$ & 104 & 372 & Nu & 0.3 & 0.23 & 1774 & $6 \pi$ & 5.51 & 29147 \\
\hline \multirow{2}{*}{1450} & 4 & RA GFO-SBO4_CAFACSPMV & Tractor Tnuck & 5804 & none & CAR9 & CSAMR & 102 & 39.3 & Nua & 0.36 & 0.19 & 1967 & 672 & 5.05 & 26643 \\
\hline & & & & & & & AVEFAACE & 109 & 37.576 & & 0.3225 & 0.2325 & 1839.75 & 672 & 5.415 & 24010 \\
\hline 1451 & 1 & RA C600-5504-CLAECSHVR & Trastor Truck & 5804 & nane & $\operatorname{CAR} 9$ & CSHMR & 8.49 & 28.5 & Nik & 0.4 & 0.31 & 1674 & 672 & 5.95 & 21818 \\
\hline \multirow[t]{2}{*}{1421} & 2 & 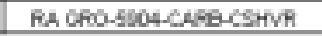 & Trastor Truck & 5004 & fane & CARP & CSHR & 881 & 39.4 & Nik & 0.39 & 0.24 & 1628 & 6.72 & 5.87 & 22125 \\
\hline & & & & & & & AVERAGC & s.5 & 3035 & & asas & 0.275 & 1688 & $8 \pi 2$ & san & 219705 \\
\hline 1415 & 1 & 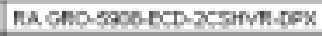 & Trastor Thuck & $=00$ & DFK & $E C D$ & $2 \mathrm{csm}$ & 0.467045 & 7207249 & $\mathrm{Nu}$ & * & * & 1600 \$970 & 1344395 & 59320621 & 21270.344 \\
\hline 1415 & 2 & 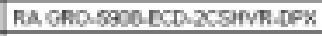 & Tractor Thuck & 5000 & DPK & $E C D$ & 2CSTrR & 0.2501736 & $33.009 \% 6$ & NMA & $\theta$ & $s$ & 1729.967 & 1244151 & 5.5121065 & 20030653 \\
\hline \multirow[t]{2}{*}{1415} & 3 & RA, ORO-S900-ECD.2CSHYR.DPX & Tractor Thuck & 5809 & DPK & $E C D$ & XCSHVR & 0.2218989 & 39.219474 & Nua & $e$ & $s$ & 1667,3976 & 13.44267 & 5.7172103 & 22069.89 \\
\hline & & & & & & & AVERAACE & 0.3159431 & 35.047299 & & BOL & $\mathrm{BOL}$ & 16677943 & 13.442687 & 6.7204796 & 22076869 \\
\hline 1442 & 1 & RA OAO-S9DQECD-2CSHVR-DOX & Trastor Truet & 5000 & DPK & $E C D$ & 2CSHVR & 0.342903 & 29.647787 & NMA & e & 0 & 2139.6412 & $13.4453 \% 4$ & 4.4572048 & 28308.549 \\
\hline 1442 & 2 & RA CAO-SPOE-ECD-SCSHYR-6PX & Trastor Thuck & $\operatorname{sen}$ & DEX & $E C D$ & 2Csenth & $0.4566=113$ & It Baseas & Nin & e & 0 & 21443282 & 13.47791 & 4.4450051 & $2 \operatorname{ses} 67$ \\
\hline \multirow[t]{2}{*}{1442} & 3 & RAGAO-SPOQBCD-2CSHMH-DOX & Trastor Truck & $\sin$ & DFX & $B C D$ & $x \csc m$ & 0.373746 & 3150244 & sus & . & 0.0026439 & 2145938 & 13.45151 & 4.4416207 & 28006.275 \\
\hline & & & & & & & AVTEACE & 0.0060000 & अ16428 & & $\mathbf{B a}$ & 0.002499 & $2142 \mathrm{gen}$ & 1342549 & 44400009 & 2000699 \\
\hline
\end{tabular}


ROUND 2

\begin{tabular}{|c|c|c|c|c|c|c|c|c|c|c|c|c|c|c|c|c|}
\hline $\operatorname{Ten} 10$ & Tetmin & Whunatro & Verecte Type & $\begin{array}{l}\text { Vesticle } \\
\text { Number }\end{array}$ & $\begin{array}{c}\text { Porlecube } \\
\text { Pent }\end{array}$ & Fus & 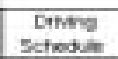 & a : & 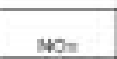 & $\$ 0$ & HC & $\mathbf{m}$ & $\operatorname{sen}$ & Wra & 100 & ETU \\
\hline & & & & & & & & igneson & $(a+n+0)$ & iphentein & ganten? & $(x+\infty)$ & (anda) & & & \\
\hline 1597 & 2 & 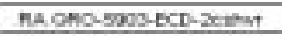 & Trastor These & 5003 & का & 801 & 2teathr & 1.7585303 & 31 - 35010103 & 33236107 & 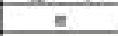 & 0.0013006 & 1005.7380 & 13.4451 & 4300001 & 25058477 \\
\hline 1591 & 3 & 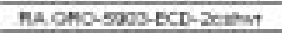 & Trastor Truck & 5000 & का & $\cos 1$ & Beatmr & 1.3513047 & 31369602 & 33.424345 & $=$ & 0.0015701 & 10042347 & 13.448786 & 4.8730243 & 250000174 \\
\hline \multirow[t]{2}{*}{1591} & 4 & na ono-sons-ECD-Jentart & Trastor Truact & 5000 & का & $\cos 1$ & Seatm & 1.7500456 & 31050146 & 36.384318 & 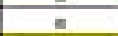 & 0.0021649 & 100040754 & 13.42003 & 43454652 & 25430.193 \\
\hline & & & & & & & AYERACE & 18020300 & 7130074 & 24380058 & $5 x$ & 0 Dotedrar & 100300164 & 13.49505 & 49132635 & 25070251 \\
\hline 1573 & $t$ & 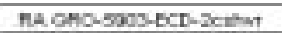 & Trastor Truck & 5000 & का & $B \infty$ & $2 \mathrm{cathr}$ & 1.3450741 & 31500407 & 12.475163 & \pm & \pm & 1074203 & 13.442292 & 5.0815229 & 26030915 \\
\hline 1573 & 2 & RA OMO-SDOS-BCD-3entht & Trastor Theck & 5003 & का & $E D$ & 3eatmr & 1.5746241 & 30.120060 & 1593142 & 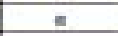 & - & 50749005 & 13.42017 & 305002425 & $24038 \mathrm{mI}$ \\
\hline \multirow[t]{2}{*}{1573} & 3 & RA OMO-SNOS-ECD-JerthM & Traster Truat & 5000 & का & BD & Bentmr & $1.85 T r 340$ & 31313810 & 15 अ7255 & 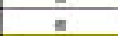 & 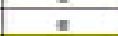 & 10112285 & 13.44a753 & 4.95200005 & 25325432 \\
\hline & & & & & & & AVERACE & 13794343 & 31039680 & 21.450714 & $B x$ & $\mathrm{Ba}$ & 18000.5453 & 13.44500 & 5.0470058 & 26927200 \\
\hline 1574 & 1 & 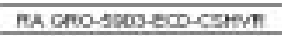 & Trestor Theal & 003 & $m$ & $E D$ & camn & 12000385 & 30,12460 & I7.012007 & 0.3003433 & $05+14$ & 100020030 & 5720014 & 300000000 & 25455.391 \\
\hline 1574 & 2 & 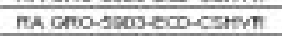 & Trestor Trues & 5003 & Nons & $E D$ & corem & 12511740 & $x=1013$ & 33750145 & 035000350 & 0 ersosus & 1000 masz & 6.72007829 & 4.0455727 & 26023538 \\
\hline \multirow[t]{2}{*}{1594} & 5 & 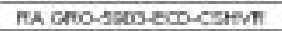 & Tradtor Truel & 5003 & Nons & $E O D$ & contm & 11270900 & 3.192003 & I3ezosts & 0.3563801 & 0 doscola & 19173008 & S7voraz & 4.3273356 & 25007541 \\
\hline & & & & & & & AVETACE & 11 002314 & 35006024 & 34792175 & $0.342316 \pi$ & $0<758417$ & 10039.1418 & $5.221+423$ & 49586304 & 25035.480 \\
\hline 157 & $t$ & FiA Cha-S200-CDCDI-CPMM & Tractor Theal & a] & 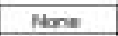 & $\cos 1$ & camm & 12190556 & 37 בrased & 38324503 & 0.4794224 & 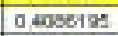 & 1800 915 & 57291760 & 45004004 & 252053.486 \\
\hline 1575 & 2 & FA ChO-S200-CDCDI-CPIM & Tractor Theal & 590 & 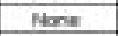 & $\cos 1$ & cant & 12310127 & mastesen & 78.304628 & 0.4000075 & 0 0 40231347 & $1791+160$ & 5.7211002 & 3.3811234 & 20202.873 \\
\hline \multirow[t]{2}{*}{1575} & 3 & TA ChO-S2000CECDI-CYMM & Trastor Trued & 5 & mans & $\cos 1$ & canth & \begin{tabular}{|l|l|}
10000308 \\
\end{tabular} & 30 Datiox & 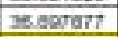 & 0.452258 & 040050091 & 5000.0087 & 57207352 & 4.3500045 & 25035700 \\
\hline & & & & & & & ANERACE & $11774 a 77$ & 37605002 & 17200000 & 0.4741250 & a azsport & 5800.1402 & 5.7223954 & 50772748 & 26067.365 \\
\hline 1570 & 2 & 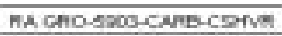 & adtor Truek & m & ase & cang & carm & 1300527 & 23554605 & 30.600920 & 0.454416 & 0 <0зहग11 & 20003773 & 57201735 & 4.0a7itys & 20500580 \\
\hline 1570 & 3 & 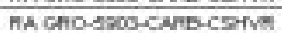 & Tradtor Truek & 5003 & Non: & cang & cartan & 13257400 & 42204731 & 30.56562 & 0.4704536 & 0.154396 & 20273907 & 57247201 & 4.9010004 & $2 E+43<502$ \\
\hline \multirow[t]{2}{*}{1570} & 4 & WA CHO-g2003 CANDCSPNV & Tractor Treak & $=$ & ne & Cang & carmin & 13540005 & 41835002 & 41291142 & D.416asts & 03456044 & 1001 sase & 5.720005 & 50125403 & 25030.443 \\
\hline & & & & & & & AYERACE & 13275782 & 41.3400 & 40.551677 & D.508E) & 0.3058509 & 2013016 & 57293780 & 49372007 & 26297536 \\
\hline 1810 & 2 & 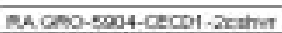 & Tractor Truek & 34 & II & ECDI & 2artm & ast & 407 & 437 & $\bar{x}$ & 0.0142 & 1730 & 13.44 & 551 & 22913 \\
\hline 1010 & 3 & $\operatorname{shcmos.59}$ & Tractor Treal & & & ECDI & 2 zatur & 11 & & $2 x$ & a & & & & & 23100 \\
\hline \multirow[t]{2}{*}{1010} & 4 & The Cono-5004-CeCOI-2rathr & Tractor Trued & 5004 & CKT & ECDA & 2antwr & 1.02 & $x+3$ & 227 & 0.031 & 0.000 & 1742 & 13.44 & 547 & 20005 \\
\hline & & & & & & & AYERACE & 1.2760008 & 379 & 300 & 00106 & a poserat & 1740 I1933 & 1344 & 5.4760600 & $20054 \cos$ \\
\hline 1019 & 2 & 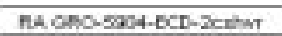 & Tractur Trued & 5004 & CNT & $E C D$ & 2antmr & 210 & 39.4 & 730 & $\bar{x}$ & 0.0072 & 1007 & 13.45 & 354 & 22070 \\
\hline 1019 & 3 & 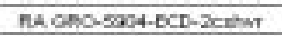 & Tradtor Trued & 500 & CNT & $E \Phi$ & zentmr & 200 & nas & 202 & 00002 & 0.0028 & 1020 & 13.44 & 55 & 22514 \\
\hline \multirow[t]{2}{*}{1019} & 4 & naomo-s & Tras & & c & $\mathrm{Eg}$ & $2=n t m r$ & 1.81 & 391 & 205 & $\bar{x}$ & 0.0034 & 1794 & 13.45 & 543 & 25297 \\
\hline & & & & & & & AVERACE & 20580004 & 39 979303 & 43 exaบ3 & 00002 & 0.00436007 & 1713 & 13.46867 & 5 sseever & 22715067 \\
\hline 1050 & 2 & Racho-spotecol-csien & Tradter Trual & 50004 & nans & ECDI & cramn & $3+3$ & 279 & 27 & 0.55 & 0.17 & 1206 & $6 \pi$ & 4.98 & 25012 \\
\hline 1050 & 3 & nacho-spot-ocol-csien & Tracter Trual & & 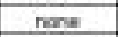 & ECDI & camn & 20 & 29.1 & 277 & 09 & Q.16 & 1925 & 672 & 4.34 & 26070 \\
\hline \multirow[t]{2}{*}{1020} & 4 & 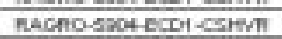 & Trastor Thued & 2000 & 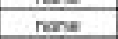 & ECDA & canth & 200 & 2015 & 204 & 05 & 0.17 & 1930 & 672 & 493 & 25007 \\
\hline & & & & & & & AVERACR & 2 2ereonest & 295 & 277 & 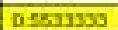 & 0.1080657 & 10930007 & 672 & 49160047 & 29005506 \\
\hline 1024 & \pm & 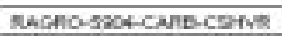 & Tractar Trued & 5004 & nane & cang & cramn & 4.02 & 300 & 200 & 0.46 & DI & 1950 & 672 & 5.13 & 25292 \\
\hline 1024 & 2 & 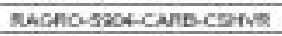 & Tractir Truat & & & cang & conen & 3 & & & 0.40 & $a$ & $=$ & E & 3 & $24+90$ \\
\hline \multirow[t]{2}{*}{1021} & 3 & 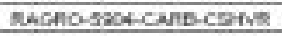 & Tradian Thual & 로 & $\mathrm{re}$ & cante & caren & 370 & 277 & 278 & $0 s$ & 0.17 & 1930 & 671 & 5.12 & $2 \operatorname{sen}$ \\
\hline & & & & & & & AYERACE & 300 & 3013909 & 202 & 040 & 0.1 secent & 1001 II3) & 5710067 & 521 & 24231.390 \\
\hline+500 & 2 & manoss & Thuse: & st & D & $e 00$ & 2antwr & 4.3255420 & 27 s1soces & 24.44063 & $0.005 s i 52$ & a 0005407 & 1901297 & 13.497006 & 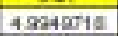 & 2525000000 \\
\hline 1500 & 3 & 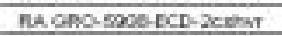 & Tractor Truek & $5 x$ & $=$ & $\operatorname{sen}$ & zeatm & 4,4760000 & 27 sos000 & 21 steans & 00000446 & a Doecesat & 1097374 & 19.40000 & 30060006 & 25201.63 \\
\hline \multirow[t]{2}{*}{$15 x$} & 4 & 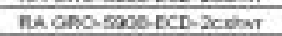 & Tratar Truek & 59 & [D. & $E D$ & $2 \mathrm{entmr}$ & 43004455 & $27.12542 x$ & 214 ग8Ca23 & $x$ & 0 a 0006724$]$ & toge.14t1 & 13.425261 & 5.01002002 & $25143 \mathrm{eDE}$ \\
\hline & & & & & & & AVERAOC & 4 SEISA7P & 27320073 & 24 ssotat & 0.0042780 & 0007409 & 10072000 & 13.44422 & $50060 \mathrm{~ns}$ & 252002045 \\
\hline tos & 2 & 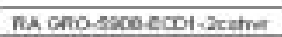 & Trantor Truek & 5000 & D & ECDI & 2antwr & 39005304 & 4งetตI? & 45.2009 & 0.0404259 & $0.01+0009$ & 21171477 & $13.45+160$ & 4.7324105 & 2743.271 \\
\hline & 3 & nA Cho socoecol-zeather & Trastor Truek & sg & D & ECDA & 2astur & 3.970005 & \& 5 Mavers & $x \operatorname{sen} 147$ & 00053449 & $x$ & 2177.0238 & 19 442667 & $4.00004=$ & $202+6.866$ \\
\hline \multirow[t]{2}{*}{$\frac{m}{t u}$} & 5 & ietrer & Trador Truak & & DFA & $\mathrm{ECDS}$ & $2 \mathrm{estm}$ & 3 seasane & $4 \pi 9$ & 3950544 & 00005291 & $0.0124 \times 99$ & & 44600 & 47477927 & $27517+24$ \\
\hline & & & & & & & AYThaoe & 3e149540 & <5 9a7114 & 20 mateat & $0 \cos 2442$ & 0 머2493 & 213063 & $14417 \times x$ & 4 saxses & $2 \pi 723917$ \\
\hline tset & 7 & 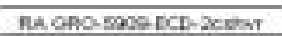 & Traser Truek & 5003 & $D F x$ & $E D$ & Desthr & $4+\cot 272$ & अ 137002 & $24.2405 \mathrm{NE}$ & $=$ & $0.00456 \pi x^{2}$ & fowagnos & 13.000004 & 4.006000 & $2 \operatorname{saz} 7 \pi$ \\
\hline 15 & 2 & 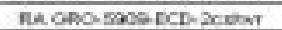 & Traser Trai] & & & & 2astm & 4730009 & 20601124 & 206445010 & - & 0.0040005 & 18002445 & 442007 & Coxsat & $2000+18$ \\
\hline & 1 & 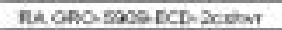 & Trasar Truak & st & D. & e & $2=\operatorname{sen} t$ & 47063130 & 27 ม37045 & $21-2004$ & 0.0013729 & 0.0053012 & 2003.1440 & 13440009 & 4 oncetion & $27000 \mathrm{~kg}$ \\
\hline \multirow[t]{2}{*}{+5} & - & $\operatorname{maC}$ & 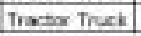 & 5 & D & $\underline{\varepsilon}$ & $2 \mathrm{sethm}$ & & \begin{tabular}{|l|l|}
27520016 \\
\end{tabular} & 21,65000 & $=$ & 0.0055009 & $2000 \mathrm{nas}$ & 13.47100 & 40905024 & $2 \operatorname{com} 59$ \\
\hline & & & & & & & ANTEAOC & 4 mesmazs & 22228504 & 228078001 & 0.0013729 & a Dosti6? & 20002234 & 13.45sias & 47464033 & 20004200 \\
\hline
\end{tabular}


ROUND 3

\begin{tabular}{|c|c|c|c|c|c|c|c|c|c|c|c|c|c|c|c|c|}
\hline Test 10 & Teet man & Whuper No. & Veriche Tyre & $\begin{array}{l}\text { Vetich } \\
\text { Nunber }\end{array}$ & $\begin{array}{c}\text { Partculat } \\
\text { Pater } \\
\end{array}$ & Fus & $\begin{array}{l}\text { Owing } \\
\text { schedes }\end{array}$ & $\infty$ & $\mathrm{NO} \mathrm{x}$ & 100 & $\mathrm{HC}$ & PM & $\infty 2$ & Was & MPO & BNu \\
\hline & & & & & & & & (ghine) & (otrite) & (otite) & (pinte) & (gande) & (ahile) & & & \\
\hline 2175 & 1 & 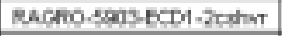 & Tractor Trues & $\sin 3$ & Cot & ECOI & zxathet & 313920 & 30 oses: & sa nscest & $\mathbf{x}$ & 0004651 & $12004+4519$ & 13.4462 & 5 noosed & 29704.334 \\
\hline 2177 & 2 & RACFFo-S903-ECDI-2Cohis & Tractor Truas: & 5803 & CRT & $E C O H$ & $2 \mathrm{cech}$ & 28623001 & 33.044716 & 18.051449 & $x$ & 0.0001097 & 1945.9666 & 13.447009 & 5.1520039 & 25997.959 \\
\hline \multirow[t]{2}{*}{2175} & 3 & 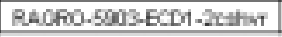 & Tractor Trual & 5003 & CRT & ECOI & 2tath & 287800091 & 33.018654 & 20.412771 & $x$ & $x$ & 1908.3679 & 13.442688 & 50030101 & 2545520 \\
\hline & & & & & & & Averace & 2800034 & 3300004 & 24054639 & BOK & 00000543 & 10054051 & $13445 \times 3$ & 51002274 & 29455341 \\
\hline 2176 & 2 & FACAO-5900-CLPO-CSHMR & Trastor Truas: & 5803 & Nane & CAPO & CSHVR & 11.25141 & 35.427059 & 35.907104 & 0.4326764 & 0.5890282 & 1569.3309 & 6.716921 & 5.0557003 & 25679.342 \\
\hline 2178 & 3 & 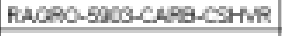 & Iracter Iruas & 5003 & Nane & $\operatorname{cose}$ & CSAvR & 11278983 & 34.440625 & 32.456834 & 0.3257538 & 0.5585067 & 19253163 & 67265162 & 5.1683331 & 25118.736 \\
\hline \multirow[t]{2}{*}{29176} & 4 & 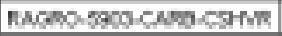 & Trador Truas & 5003 & Nane & $C M D$ & corve & 11254167 & 35544724 & 20.700053 & 0.2746989 & 0.5502006 & 10622509 & 67193145 & 5.0724009 & 20580.36 \\
\hline & & & & & & & AVERACE & 11261453 & 35.137428 & $34.05510 \pi$ & 0.3443754 & $0.5862+02$ & 1951906 & 67216506 & 50098001 & 25453.48 \\
\hline 2172 & 1 & 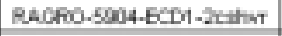 & Iractar Truas & 5904 & CRT & Econ & 2 tathot & 22500042 & 25950312 & 28586439 & 0.0433289 & 0.0424165 & 19329242 & 13.47732 & 5.1836497 & 25000339 \\
\hline 2172 & 2 & 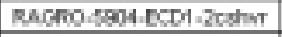 & Tractor Truce & 5804 & CRT & $\mathrm{eCOH}$ & $2 \mathrm{rahm}$ & 1.8095606 & 20790019 & 20.773050 & $x$ & 0.0130986 & 1007.4000 & 13.497851 & 5.750120 & 24237.127 \\
\hline \multirow[t]{2}{*}{2172} & 3 & RAOCF0-5904-ECDI-2Cehw & Tractor Truse & 5904 & CRT & ECOI & 2 zehor & 1.4696905 & 29.056057 & 18.459551 & 0.0176689 & 0.0057033 & 1849.5406 & 13.449604 & 5.4256008 & 23927.541 \\
\hline & & & & & & & AVERACE & 1.7428151 & 2790523 & 24 605842 & 0.0306978 & 0.0204065 & $16 \cos 3112$ & 13.45252 & 5323538 & 24300.018 \\
\hline 2173 & 3 & RACAO-S9OL_CAPOCSAMV & Tractor Truak & 5804 & Nones & $\cos$ & CSIVR & 98969607 & 22.973045 & 2630462 & 0.2704010 & 0.0614545 & 1949.951 & 67276500 & 5.1094275 & 25400.326 \\
\hline 2173 & 4 & RAOAO-5904-CAP9-CSHMR & Tractor Truast & 5904 & nane & $C A 9 \theta$ & CSHVR & 9.7494897 & 31.607718 & 31.116076 & 0.3515319 & 0.4460587 & 1911.8041 & 6.7242341 & 5.21099 & 24914.547 \\
\hline 2173 & $s$ & 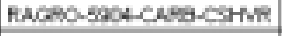 & Tractor truas & 50004 & Nane & coses & CSAvR & 9525083 & $34 \cos 36$ & 31 650625 & 0.372583 & 0.422007 & 1208.7353 & 67144324 & 5.1681811 & 28123201 \\
\hline \multirow[t]{2}{*}{2173} & 6 & RACAOAGOL_CAPOCSAMR & Tractor Truat & 5804 & Nane & $\cos \theta$ & COMR & 78005103 & 34.994605 & 34,630004 & 0.37001 언 & 0.4100507 & 1910.5747 & 67191291 & 5.2210014 & 24061.154 \\
\hline & & & & & & & AVERAOE & 92602139 & 30.917392 & 30.447691 & 0.3440162 & 0.4354249 & 1905.2659 & 87213651 & 5.1770452 & 25009.300 \\
\hline 21т & 1 & 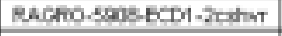 & Tractor truas & 5008 & $\mathrm{DFF}$ & ECOn & itghot & 37371707 & 18593414 & 1834279 & 0.14720002 & 0.00 eness & 2100.185 & 13444021 & 47002902 & 27237598 \\
\hline 2178 & 2 & 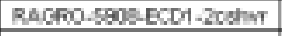 & Trastor Truak & 5008 & DPK & $E C O H$ & $20 \mathrm{chor}$ & 36179066 & 18.047695 & 13.900032 & 0.0478127 & 0.0066824 & 20656906 & 13.443131 & 40006913 & 26763.607 \\
\hline \multirow[t]{2}{*}{2178} & 3 & RAO060-5908-ECDI-2K=hist & Tractor Truas & 5908 & DPK & ECOI & 2tather & 3.8795229 & 18.296558 & 14.781916 & 0.0552443 & 0.0061345 & 2054.3704 & 13.447544 & 48783838 & 20622.596 \\
\hline & & & & & & & Averace & 374453 & 18300009 & 15575915 & 00986722 & 000605 & 20040003 & 13444927 & $4 \operatorname{5in} 1215$ & $2 \pi 0745$ \\
\hline 2179 & 1 & RACAO-990Q-CAPG-CSHMR & Tractor Truas: & 5808 & Nane & CAPO & CSMVR & 9,39062 & 20.873652 & 21,342028 & 0.2219746 & 0.8864437 & 2033.9626 & 6.7204001 & 4.9026937 & 26479729 \\
\hline 2179 & 2 & RACOAO-5900-CA99-CSHMR & Tracber Truat & 5008 & Nane & $\operatorname{cose}$ & CSMVR & 23277655 & 19.833852 & $19.29600 \mathrm{~V}$ & 0.1755163 & 0.5969732 & 20423322 & 67223544 & 48039003 & 28584.891 \\
\hline \multirow[t]{2}{*}{2179} & 3 & 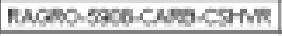 & Tractor Truack & 5005 & Nanes & $\mathrm{CNO}$ & $\mathrm{cos} n$ & 90562807 & 2076244 & 21231737 & 0.3091456 & 0.9002734 & 200130616 & 67142792 & 45120003 & 20200576 \\
\hline & & & & & & & AVERAGE & 9.4543011 & 20.099915 & 20.623191 & 0.2365455 & 0.5805301 & 2049.3655 & 67190405 & 4 e6s0115 & 26601.055 \\
\hline 2191 & 1 & RACF00-5000-ECDI-2LAthT & Iractor Truas & 5000 & $D P X$ & ECOI & 2tathot & 4341958 & 17.636612 & 16.744553 & $\mathbf{x}$ & 0.0739142 & 2174.3501 & 13.445058 & 46005207 & 29182.225 \\
\hline 2191 & 2 & 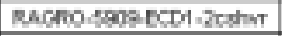 & Tractor Trues: & 509 & DPK & $\mathrm{ecOn}$ & $2 \mathrm{xath}$ & 35627301 & 17252794 & 1726730 & $x$ & 0.0207422 & 2004.6503 & 13.43987 & 4 Eocoent & 27007201 \\
\hline 2191 & 3 & RACGF0-5908-ECDT-2Cehar & Trastor Truos & 5809 & DPK & $E C O 1$ & $2 \mathrm{ceh}$. & 3.1374662 & 16.995108 & 16.366294 & $x$ & 0.0209411 & 2043.5769 & 13.443261 & 4.5048491 & 26469.094 \\
\hline \multirow[t]{2}{*}{2191} & 4 & 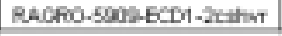 & Iractar Iruas & 5000 & 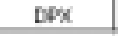 & Econ & 2tathor & 34255007 & 18.132547 & 18.580001 & $x$ & 0.0700338 & 2108.6672 & 13.44903 & 47527612 & 27314949 \\
\hline & & & & & & & AVORACE & 30169504 & 17304205 & 16742344 & BOL & 0.0505020 & 21020069 & 1344250 & 4767728 & 27263.117 \\
\hline 2194 & 7 & RACAO-5909-CAPQ-CSHMR & Tractor Truast & 5909 & Nane & CAPO & CSHVR & 6.8090044 & 18.876093 & 19.606553 & 0.5571984 & 0.5342293 & 20011.6905 & 67208395 & 49637595 & 26153.973 \\
\hline 2194 & है & 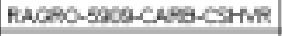 & Iractar fruas & $\operatorname{sen}$ & Nane & $\operatorname{coses}$ & CSAvR & 63677683 & $192785+1$ & 19.853436 & $0.595 x+63$ & 0.4207001 & 2008.8631 & 6.719083 & 4970005 & 20063899 \\
\hline \multirow[t]{2}{*}{299} & 9 & 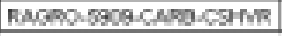 & Tractor Trues & 6009 & None & $\cos$ & CSMR & 7.674211 & 10.929444 & 19.1820003 & 0.5420673 & 0.020653 & 2046.092 & 67207693 & 40751315 & 20009.436 \\
\hline & & & & & & & AVERADE & 65577379 & 19.028258 & 19.435900 & 0.5976507 & 0.4511941 & 2021.8245 & $6723+605$ & 49396619 & 26209098 \\
\hline
\end{tabular}


Appendix D

General Performance Evaluation Data Summary 


\begin{tabular}{|c|c|c|c|c|c|c|c|c|c|c|c|c|c|c|c|c|}
\hline Tet $D$ & Terthing & munent is & Worlich Trpe & $\begin{array}{l}\text { Pleet - Veticle } \\
\text { Number }\end{array}$ & $\begin{array}{c}\text { Parbouidat } \\
\text { rase }\end{array}$ & Fum & $\begin{array}{l}\text { Donirg } \\
\text { Schedth }\end{array}$ & $\infty$ & $N N_{\alpha}$ & no & $r$ & PM & 002 & $M h=$ & NeS & BTy \\
\hline & & & & & & & & (ghing) & (anthe) & $(\cos l o)$ & fog/nit) & $(g \log 20)$ & (Dive) & & & \\
\hline 8900 & 4 & 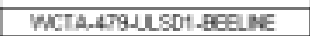 & Transteus & WCTA 499 & Rente & Usot & EEAUE & 79007500 & 39466919 & 37.053734 & 0,3126004 & 065232539 & 22001418 & 66052906 & 4.451369 & 266006064 \\
\hline 3900 & 5 & WCTA.479UUSOT-BeeANE & Tromet $\theta_{\text {us }}$ & WCTA 479 & Nense & USOT & EEARE & 83057574 & 39.613102 & 97659115 & 0.3160755 & 05411537 & 22204167 & 854949 & 4.4194055 & 265002509 \\
\hline \multirow[t]{2}{*}{3000} & $B$ & WCIA-4THULSDI-AEALE & Irumit Aut & WCTA 4V & Netre & USOt & EtELE & 7545762 & 30067939 & 39.820383 & $\bar{x}$ & 0 - & 21760354 & $8.054 \times 0$ & 4 Sodran & 25550552 \\
\hline & & & & & & & Averase & 792700 & $53 \times 0000$ & $375014 ; 4$ & 0 अवक्य & 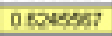 & 2186840 & Es:60\%? & 44 त्याक & 200009 \\
\hline 3911 & 1 & WCTA-APRUSOT-ZCCEUVE & Trenst bus & WCTA 479 & करT & Usot & ZOCLWNe & 0.5540762 & $3 \times 2705$ & 37232117 & $\theta$ & 0.144777 & 22865,7000 & 13300006 & 4.3762459 & 2907506 \\
\hline 3911 & 2 & WCTA-A7B-USSO-ZEETUE & Tronsteus & WCTA 479 & CRT & Usot & ZBEELDE & $0.4305 E 96$ & 36 cr2952 & 20.583145 & 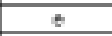 & 0.117266 & 216 T15C6 & 13.400574 & $4569 \% 738$ & 26003 ST3 \\
\hline \multirow[t]{2}{*}{3911} & 3 & WCTA-APS-USOI-ZAETUE & Trmeteras & WCTA 479 & करT & USOI & ZHEELAE & 0.5198285 & 38.12786 & 20.624088 & $t$ & 0.11129 & 227.9669 & 13360743 & 4.4429307 & 26749.490 \\
\hline & & & & & & & Averwase & $0.501 E 568$ & 3855450 & 20 529:16 & 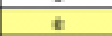 & 0.124451 & 2214 2031 & 13366714 & 4.4592955 & 26659344 \\
\hline \$ins & 2 & WCTASBULSDI tranE & Trunct bus & WCTASE & Norn & USD & Eetire & 1,5207306 & $5264+16$ & इ13엉 & 0.3000721 & 0301098 & 23455049 & ESI0006 & 42019544 & $39 \times 482$ \\
\hline 3915 & 3 & 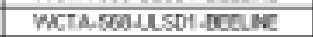 & Trunst bus & WCTA EOT & Nerose & usot & Eeruke & 1,5097866 & 29006917 & 29275344 & 0.3650129 & 0,263005 & 220451056 & 65960609 & 4.315014 & 26686279 \\
\hline \multirow{2}{*}{3915} & 4 & WCTA.SEDLLSOT-BeEAE & Tronst eus & WCTA S6 & Nones & Usot & EEAUE & 1.899137 & 3.562059 & 31.3006 & 0.3636667 & 02406145 & 23360065 & 6.5368359 & 42169732 & 30090,691 \\
\hline & & & & & & & AVERACE & 1.5932196 & 31350997 & 30.289472 & 0.3427372 & 02901394 & 2322.057 & 65543605 & 42468939 & 30000594 \\
\hline 3219 & 1 & WCTA-SBE-LSDI-ZEEAIE & Irifut Ant & WCTA SE8 & करा & USOD & ZHEELEE & 028537 & 36.065534 & I597Ms91 & $\varepsilon$ & $0.0606+2) 5$ & 27502043 & 1359352 & 35000072 & 36553352 \\
\hline \$19 & 2 & 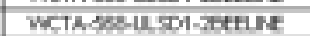 & Trumet bus & WCTASE & का & USDI & Aretine & 0.309402 & 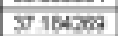 & 10777456 & 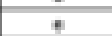 & 0 D611172 & 27998 & 1350016 & $35 \times 6773$ & X:115\% \\
\hline \multirow[t]{2}{*}{3919} & 3 & WCTA-SBSUSST-ZSCEUE & Trunst Dus & WCTA WDO & का & Usot & zocture & 0.2409107 & $3 \times 99162$ & 10.612002 & 8 & 00600094 & $2780 \mathrm{sec}$ & 13 sen:23 & 3500518 & 36189.965 \\
\hline & & & & & & & AVERECE & 0.245259 & 36.072372 & 18.695179 & $\theta$ & 000960424 & 27602646 & 1351855 & 3.5518954 & 36662.609 \\
\hline $\operatorname{sen} 2$ & 3 & 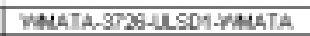 & Trometeys & TELTA 372B & ane & USOT & WWLATA & 1.Arazi45 & 16163737 & $x$ & 0.1832596 & 00066397 & 223829272 & 4.2262915 & 4.4004579 & 26967309 \\
\hline $\operatorname{sen} 2$ & 4 & 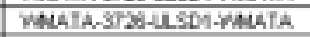 & Irimit But & WMERTA 3725 & Nere & USOt & WWATA & 1.4285261 & 1816716 & $x$ & 0.1450473 & 0.0007278 & 2115.4552 & 42564250 & 46622382 & 2720215 \\
\hline \multirow[t]{2}{*}{ ख्रा } & 5 & 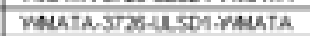 & Trumet bus & WMETA JTZS & Nerne & 4501 & WWATA & 1.07257 & 16 c01105 & $x$ & D.147006s & 01001772 & $22272 \times 27$ & $4 \geq 5938$ & 4434234 & 26004546 \\
\hline & & & & & & & Avouce & 1.44596 & 16134106 & $x$ & 0.150079 & 0 ceotal? & 2182673 & 12206000 & 45010427 & 20006396 \\
\hline 3006 & 7 & WMAT. & Qus & 26 & CRT & sot & WWMATA & 0.300347 & 19406052 & 1919023 & 0 & 0,0000449 & 22969159 & 8550037 & 4.3010387 & 29687941 \\
\hline 3000 & 2 & WMATA-97ZF-USOI-2MMMTA & Trumet & WHATA G72S & CRT & USOI & ZMMATA & 0.454727 & 19.521905 & 19.478128 & 0 & 00000728 & 23456774 & 8.4749699 & 42097821 & 30041713 \\
\hline \multirow[t]{2}{*}{3000} & 3 & 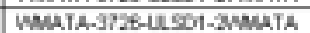 & Frumet Aut & Whate 3728 & करा & ustot & ZMMaTh & 0.2358064 & 18794114 & 8.5M75: & 60000045 & 0.00005044 & $2220 \mathrm{Wr}$ & 85606258 & 4.4670058 & 26500701 \\
\hline & & & & & & & Averese & 0 अm:291 & 1934144 & a signtes & $0003 \times 15$ & 0 cocts: & 22841201 & BSISASA & 4501472 & 28043454 \\
\hline 3500 & 1 & STA & ass & MATA 5200 & करT & SDI & ZMMATA & 1.5990000 & 39.500091 & $x$ & 0.041239 & 00000953 & PEAG & 0.606023 & 27001975 & 47304600 \\
\hline 3720 & 2 & WMATA-SZOCOUSOT-ZWMATA & Transt Qus & WMATA 52003 & CRT & Usot & ZMMATA & 1.54549 & $865 \% 5833$ & $x$ & 0,0926949 & 00040099 & 3614.4464 & 8.614758 & 27301581 & क5785.57 \\
\hline \multirow[t]{2}{*}{3700} & 4 & WMATA-52OB-USOI-2MMATA & Trumetavs & WELATA 5203 & CRT & USOT & ZWMATA & 1.8443567 & 3540705 & $x$ & 0,0289009 & 0.014318 & 3901.257 & 86450491 & 25293028 & 50500879 \\
\hline & & & & & & & Averace & 1.0544205 & 35104143 & $\frac{x}{x}$ & 0.0746816 & 0 ติ2774 & 37234467 & BESASOON2 & 26532124 & 46197046 \\
\hline श्यक्त & 1 & wave & Trumetass & Whentas5203 & Norsen & $\mathrm{LSDT}$ & WWATA & 42234506 & 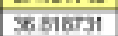 & $\frac{n}{x}$ & 0 क्रश०ण & 0.000008 & 30631017 & $428 \times 5$ & 288604 & $450 \times 518$ \\
\hline 3702 & 2 & SDI:PMatha & Trenst bus & wast & Nono & Usot & WWATA & $48 \mathrm{se} 5$ & 36113207 & $x$ & 10000019 & 0.2600063 & 76050591 & 4.3000674 & 26023154 & 47020 \\
\hline \multirow[t]{2}{*}{3782} & 3 & WNATA_5203-UL SDA.YMEATA & Tranest Qus & WMETA 5200 & none & Usot & WWLATA & 5.2430072 & 30762332 & $x$ & 0.9944161 & 02699342 & 37448868 & 4239449 & 2629065 & 49584.57 \\
\hline & & & & & & & ANGRAR & 4.79985023 & 36504757 & $\frac{x}{x}$ & 1.0114161 & 0.295222 & 38808519 & 4.2761899 & 26667095 & 47503563 \\
\hline 3728 & 1 & WYCDOS- $2 S C$ & Fiefune Truat: & WrCOOS ZSOFO4 & 9 & 8 & MYGTCIX & 13957316 & 12422823 & 100238445 & 1.2546627 & 0.68605007 & 785385306 & 1.143632 & 13519147 & 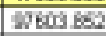 \\
\hline \multirow{2}{*}{ 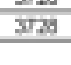 } & 3 & 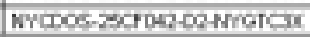 & hefues Truds & WrCDOS $250 \mathrm{OCA}$ & का & 02 & NWGTCIX & 13287719 & 120 क्यक्त? & $90 \times 5347$ & 1.18232 & 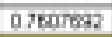 & 75827051 & 11427212 & 1 표영 & करण 22I \\
\hline & & & & & & & Avouce & 1.32407 & 120.96042 & 89 T64149 & 1.2216004 & 07140049 & 7512278 & & 1.200685 & $\$ 2300509$ \\
\hline 3730 & 1 & wrod & Fefuge Trudk & 850504 & Niones & $\overline{02}$ & morotcix & 11.475049 & 129.44873 & 119.61689 & 79004464 & 33606995 & 78168186 & 1.1361711 & 12925435 & 10043228 \\
\hline 3730 & $\frac{1}{2}$ & WrCDOS-2SCFOE2-002-WWOTC $3 x$ & Fiefrube Truad & WrOCOOS 250 F042 & nione & 02 & syotcax & 1190057 & 12794699 & 117.75555 & 8.477252 & 36521904 & 7861.0069 & 1.1427004 & 12897501 & 101285.82 \\
\hline \multirow[t]{2}{*}{3730} & 3 & WYCDOS-SCFFOE2-002-WWOTCS & Fiefuie Truas: & Wrocoos 250 Fo42 & Note & 02 & MYGTCax & 11.672001 & 126.773 & 11859204 & 8.4972751 & $363+1226$ & 7700.2500 & 1.1550016 & 1 S125ang & 20041.458 \\
\hline & & & & & & & Averwas & $11 \mathrm{ean} \times \mathrm{cos}$ & $120 \cos 27$ & 117 93002 & 82803045 & 3050729 & 7801 ERSS & $11445 \mathrm{~s}$. & 1 2009238 & 100000010 \\
\hline 5.32 & 1 & OCKTCZXX & Teruse Truck & W & $c$ & 02 & OShTCZX & 1.1101504 & 40762003 & 37221741 & 0.4008014 & Q11919 & $400 \%$ SED & 5.174006 & 23770019 & swoer 709 \\
\hline 3732 & 2 & FYCOOS-2SCF0E3-02-0CRTC2X & Fistuse Trudk & Wroco0s 2SOFO43 & करT & 02 & OCRTCZX & 1.006231 & 46227062 & 35.020947 & 0.4330413 & 0.13420939 & $4250+57$ & 5.167369 & 28069174 & 54463565 \\
\hline \multirow[t]{2}{*}{3732} & 3 & WYCDOS-2SCF0E $3-02-0$ CRTC2X & Fitfuse Trudk & WrocoOs $250 F 043$ & CRT & $\infty$ & OCATC2X & 1.1234468 & 45749191 & 34.258228 & 0.4225917 & 0.1190283 & 4164.5044 & 5.1696213 & 2.4293927 & 534963204 \\
\hline & & & & & & & Averuace & 1.0006104 & 48900519 & S5. & $0.40054+9$ & 0.1241591 & 42775425 & $5,175 \times 877$ & 2376004 & 546585586 \\
\hline 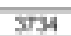 & 1 & $62 x$ & Fefume Trudk & W & FE & क2 & och?czix & 515T23 & 45171263 & $40 \mathrm{arg} 2$ & $3200 \times 2005$ & 1015358 & 4374.4517 & 519 & 2520108 & 5471342 \\
\hline 303 & 2 & 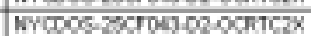 & Refuse Trudk & Wropos 260004 & None & 02 & OCh7c2x & 5.3230472 & 4606067 & 4). 6790002 & 20622003 & 0.905354 & 4285.365 & 5.2000067 & 2.000012 & S4655,302 \\
\hline \multirow[t]{2}{*}{3734} & 3 & WYCDOS-2SCFOC $3-02-0 C R T C 2 X$ & Fervese Truak & Wroc000s 2sSCO4043 & None & 02 & OCR & 5.2577448 & 47650006 & 4439930 & 3.396663 & 0.5040959 & 43438472 & 5.2116914 & 23800711 & 54460043 \\
\hline & & & & & & & AVERARE & 5.248195 & 47.156284 & 43.991393 & 32282754 & 0.945600 & 4251.2214 & 52040127 & 2385163 & 54549599 \\
\hline
\end{tabular}




\section{DPX Equipped Vehicles}

\begin{tabular}{|c|c|c|c|c|c|c|c|c|c|c|c|c|c|c|c|c|}
\hline Tetid & Test finno & murel ko. & Werick frpe & $\begin{array}{l}\text { Feet - Veficich } \\
\text { Nuntert }\end{array}$ & $\begin{array}{c}\text { Parsolaber } \\
\text { Fater }\end{array}$ & Fuet & $\begin{array}{c}\text { Dowine } \\
\text { schedue } \\
\end{array}$ & $\infty$ & $N_{0}$ & no & $\mathrm{HC}$ & BM & 0 & $M=1$ & wo & ETu \\
\hline & & & & & & & & (phitis) & (ghte) & (athes) & $(p \min )$ & $(g \sin )$ & (phite) & & & \\
\hline Fins & 1 & 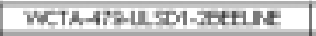 & \begin{tabular}{|l|} 
Tromet ans \\
\end{tabular} & WстA 479 & COPX & 4.51 & atretine & 0.273448 & 4037204 & की & * & 0 ocestosis & $2185 \$ 149$ & $13545 \mathrm{mag}$ & 44395920 & 22400.143 \\
\hline 305 & 2 & 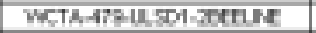 & Trunest bus & WCTA 479 & $\cos x$ & USDI & \begin{tabular}{|l|} 
atetine \\
\end{tabular} & $0.2000 \mathrm{~s}$ & 2502006 & 10622813 & 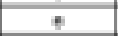 & 00609775 & 20501300 & 1374904 & 40003347 & 20885509 \\
\hline \multirow[t]{2}{*}{3905} & 4 & WCTA-ATEUSPA-ZCCHUR & Trenst bus & WCTA 479 & $\cos x$ & Usot & \begin{tabular}{|l|} 
zoctune \\
\end{tabular} & 0.5006004 & 30400152 & 10.110225 & $\theta$ & 00000096 & 21665711 & 13040064 & 44906224 & 2000273 \\
\hline & & & & & & & AVERere & 0.3575171 & 3940606 & 18.30093 & 8 & 00619174 & 2148.069 & 13130005 & 46013989 & 27780296 \\
\hline 3900 & 4 & WCTA.479LLSO1-BeELAE & \begin{tabular}{|l|} 
Trenet eys \\
\end{tabular} & WCTA 479 & Nenes & Usot & EETURE & 79007502 & 89.466919 & 37.639734 & 0.3126004 & 065232539 & 2200.1418 & 660629003 & 4.451369 & 26600.674 \\
\hline 3900 & 5 & WCTA.4TYUSOT-BEANE & \begin{tabular}{|l|} 
Troneteus \\
\end{tabular} & WCTA 479 & nenes & USOI & EETUE & 83967574 & 8961302 & 37.659115 & \begin{tabular}{|l|}
$0.3+60755$ \\
\end{tabular} & 06411537 & 2220.4167 & 654969 & 4.4194055 & 26802529 \\
\hline \multirow[t]{2}{*}{3000} & 6 & WCTA.4TMULSOT-EeELE & 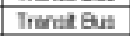 & WCTA 479 & Fiche & USOI & EEALE & 75457621 & 89067939 & 39.828383 & $x$ & 0.6000828 & 21760354 & 6.684300 & 4500 Tavi & 26529.559 \\
\hline & & & & & & & Avereacs & 7937652 & $5036500 \%$ & 37561424 & 0 अवसे & 0.52555987 & $2 n 963647$ & 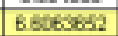 & 4.4531872 & 26620901 \\
\hline sists & 2 & WCTA-SBSULDI-4TANE & \begin{tabular}{|l|} 
Trumet bus \\
\end{tabular} & WCTA 580 & Narese & USDI & Ettive & 15207306 & $52564+16$ & 51504 & 0.3000072 & 0.370038 & 23435049 & EESW0EO & 4 2010344 & 302482 \\
\hline$\$ 15$ & 3 & 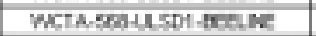 & Trunet bus & WCTA 50 & Norm & USDT & Betive & 1 sampes & 29002917 & 23276344 & $0 . x \times 39$ & $0,78500 \%$ & 2784508 & 55100003 & 4315014 & 28005271 \\
\hline \multirow{2}{*}{3915} & 4 & 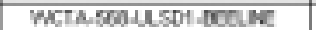 & Transt bus & WCTA ERD & Nenes & USD & cerule & 1 कמजม & अ $80 \times 50$ & 31.0006 & 0.767069 & 0 200645 & 22000005 & $650600 \%$ & 4216072 & $30080 \mathrm{~kg}$ \\
\hline & & & & & & & \begin{tabular}{|l|} 
ANERere \\
\end{tabular} & 1.9932166 & अ 360997 & 30.209472 & $0.34273 \% 2$ & 02929394 & 2322.057 & 65543005 & 42660039 & 30000596 \\
\hline 3916 & 2 & WCTA-SBR-USOT-ZEETUE & Trenstaus & WCTA EBB & $\cos x$ & Usot & \begin{tabular}{|l|} 
ZBEELEE \\
\end{tabular} & 0.1093913 & 36.127045 & 35.941769 & $\theta$ & 00061377 & 2784.3994 & 13.60691 & 35469206 & 36013.066 \\
\hline 3916 & 3 & WCTA-S58-ULSO-2ERTURE & \begin{tabular}{|l|} 
Tromet aus \\
\end{tabular} & WCTA 568 & cep $x$ & USOI & \begin{tabular}{|l|} 
ZGEELAE \\
\end{tabular} & 0.1492279 & 85662167 & 23.050547 & $t$ & 000625715 & 2711.3456 & 13 3\%69 & $3,642300 \%$ & 35060.965 \\
\hline \multirow[t]{2}{*}{3916} & 4 & WCTA-SBE-USSO-ZAETUVE & Trimat Eus & WCTA 568 & $\cos x$ & USOT & Z FEELAE & 0,0788302 & 39354432 & 23720747 & $t$ & $00036 \mathrm{my}$ & 27921123 & 13566918 & 35582571 & 36202558 \\
\hline & & & & & & & AVERACE & 0.1118145 & $563045+4$ & 23395647 & 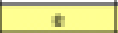 & 0.0035394 & 2764.9554 & $135 \%$ SONO & $35 / 24222$ & $35 \times 61547$ \\
\hline $5 \pi 4$ & 1 & WMUATh-S228 & \begin{tabular}{|l|} 
frimut bus \\
\end{tabular} & 20 & CPX & 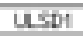 & zomith & $1.42 \operatorname{con} 6 \sigma^{2}$ & 427782 & $x$ & 0.1074000 & 0 - $198 \times 8$ & 30120003 & asovon 4 & $258+0232$ & 45431445 \\
\hline 574 & 2 & WMUTh-S7Z & Trmutars & WMUTA 5729 & & $45 \mathrm{DI}$ & Fourth & 1.1622865 & 4010058 & $x$ & 0 Dot452 & 0 01924 & 3804 CO18 & & 47218 & 50006.23 \\
\hline \multirow[t]{2}{*}{974} & 3 & WMUTh-528 & Trunst ous & WhetA 5229 & $\pi n$ & Ust & Fmath & 0.50Mrate & $39 \operatorname{sen} 124$ & $x$ & $000 x \times 62$ & 0 corast42 & 2000306 & DASCECDI & 2 .5441075 & 50005410 \\
\hline & & & & & & & Averese & 1,0734360 & 40 STEQ77 & $x$ & 00917002 & 000000999 & 3045165 & Bsorosos & \begin{tabular}{|l|}
25603442 \\
\end{tabular} & 46001.001 \\
\hline 357 & 1 & WMAST & 05 & 29 & ane & Usot & \begin{tabular}{|l|} 
WWATA \\
\end{tabular} & 3.8770696 & 89456539 & $x$ & 1.1742205 & 0.2016925 & 37438712 & 4.29606593 & 2630060 & 46651277 \\
\hline $3 \pi 7$ & 2 & WALATA-5229ALSDH.YMAATA & Troneat aus & 5229 & Niene & USOT & WWATA & 3.7935406 & 38424782 & $x$ & 1.0732263 & 0.1791557 & 3647.551 & 43938049 & 27004969 & 47299.617 \\
\hline \multirow[t]{2}{*}{$3 m 7$} & 3 & WALATA. 522 & \begin{tabular}{|l|} 
Trunet \\
\end{tabular} & 5229 & Nene & USOI & WWATA & 3.7974569 & 86500299 & $x$ & $1.12 \$ 159$ & 0.1603496 & 3699.507 & 4.3206422 & 26697245 & 47644.637 \\
\hline & & & & & & & AVERAOE & 3.8225123 & 38500007 & $x$ & 1.1255878 & $0.166 \mathrm{~m} 2$ & 3253649 & 4.3122021 & 26670254 & 4 Tras:51 \\
\hline $5 x$ & 1 & WM & 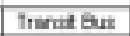 & $x$ & 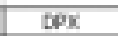 & USDT & 2manta & 0.3008008 & 16060053 & $\frac{x}{x}$ & 6 & 60010242 & $201 B 7 \sigma 0 \omega$ & & $4 \operatorname{asn} 232$ & \\
\hline Iक्र & 2 & WMUTA-372 & Trmet aus & 3724 & $\cos x$ & USDI & Whath & 0.2714729 & 16 BकOSOS & $x$ & $0.06 \times 28$ & 0 - 100527 & 20071502 & $86344 \times 06$ & 47520015 & 260065 \\
\hline \multirow{2}{*}{375} & 3 & WMAT & Trunet bus & man & CFX & $\mathrm{Usp}$ & Fmosth & 0200257 & & $x$ & Doxencer & & 1804790 & & 5.041927 & 28004910 \\
\hline & & & & & & & Avorese & 0.2457500 & 1790003 & $x$ & 0.047765 & 00107423 & 20100002 & 0,000027 & 49139394 & 20005205 \\
\hline 3596 & 3 & WAMAT & \begin{tabular}{|l|} 
Trenst aus \\
\end{tabular} & 3734 & $n$ & Usot & WWATA & 20237646 & $186656 \pi 9$ & $x$ & 0.1943669 & & 222300512 & & 7248 & 26002600 \\
\hline 3796 & 4 & 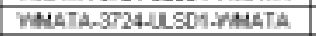 & \begin{tabular}{|l|} 
Tronet aus \\
\end{tabular} & VMALTA 3724 & Fione & Usot & WWATA & 15007073 & 17700399 & $x$ & 0.2005153 & 0.1435912 & 2217.5224 & 4390007 & 4.4659285 & 26930766 \\
\hline \multirow[t]{2}{*}{3798} & 5 & WHEATA, $3724-U$ SON-WAEATA & Trunataus & WALATA 3724 & Niente & USOI & WWEATA & 2.1911636 & 17660628 & $\frac{\pi}{x}$ & 0.1956504 & 0.1487832 & 21425665 & 4.2592507 & 46004424 & 27765.156 \\
\hline & & & & & & & AVERAOE & 20538139 & 18 GQ615 & $x$ & a.128996 & 0.1500115 & 219435600 & 4305350 & 4.4950946 & 2943287 \\
\hline 3719 & 2 & WYCDOS-ZSC & Fisfuie Trud: & oro45 & & 6 & Nyotcix & 2.1230176 & 11554144 & 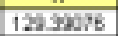 & \begin{tabular}{|l|l|}
1.4117553 \\
\end{tabular} & 0.0400537 & 78582554 & 1.12 tzóns & 150025 & 39420.75 \\
\hline ज्ञा & 3 & कात्रा & hefumes Trud & Wrcoos zscro4s & CFX & 02 & MWGTCIX & 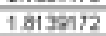 & 115 51574 & 12854452 & 13742445 & 0 Dostans & TSSS D41 & 1.1 उAEATA & $13 x-5074$ & 2084593 \\
\hline \multirow[t]{2}{*}{ 펙 } & 4 & 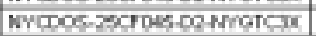 & Tefunes Truds & Wrapos 750045 & CFX & 02 & Dratcix & $3927 \% 72$ & $11370 \% 9$ & 12700473 & 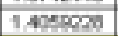 & 0146725 & 74651004 & $113 \times 9216$ & 1 36107? & SBST12 LOT \\
\hline & & & & & & & Avoence & $2.30 \mathrm{kW5}$ & 1150 & 120.32557 & 1.397305 & $0.07 \times 68$ & 75734000 & 12 & 000 & senes 500 \\
\hline 3722 & 1 & 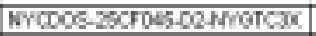 & Fisfuse Truok & Wroco0s ZsCoros & & 02 & BNotcax & 127 & 119 अअ9 & 129 लब & 7 7.5515137 & 3.1616454 & 7470.5946 & 3439 & 136 47719 & 5686963 \\
\hline 3522 & 2 & TC $3 x$ & Fisfues Truck & 2500045 & Nene & $\infty 2$ & MYG & 12.215476 & 12126515 & 1307782 & 7.7150005 & 30660077 & 75066897 & 1.1360607 & & 96459.997 \\
\hline \multirow[t]{2}{*}{3722} & $\frac{\pi}{3}$ & 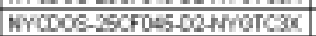 & Fisfues Truak & Wrico0os 250F045 & Nente & $\infty 2$ & Mrotcix & 11.798148 & 119.5512 & 128.85127 & 7.5929468 & 26687794 & 74698564 & 1.1469098 & 13545485 & 96962945 \\
\hline & & & & & & & AVERAOE & 12227541 & 12024934 & 1295481 & 7611156 & 30422775 & 74623563 & 1.1435829 & 13521479 & 56143.652 \\
\hline 3724 & 1 & O2-0CKICDX & Fisfuie Irud: & Wrocoss $250 F 044$ & $\cos x$ & $\omega_{2}$ & OCRIC2XX & 0.9244548 & 45676328 & 30.647085 & $\frac{x}{x}$ & 0.1400525 & 33602673 & 50377025 & 26557734 & 40521587 \\
\hline 524 & 2 & WYCDOS-ZCCPU4.02-0ChICZX & Feffuine Trud & Wrcoos 250 ro44 & $\operatorname{cox}$ & 62 & Ochtc2X & 0.765316 & 4350205 & & $\bar{x}$ & & 3798516 & 5162054 & 27002225 & 45001501 \\
\hline \multirow[t]{2}{*}{524} & 3 & WYCDOE $>$ SCROA-02-OChTCZX & Fefumen Truad: & Wrapos 750 PO4 & CFX & 02 & OChrczX & 0.0051260 & 42564702 & 2828008 & $x$ & 0 coocoss & 373046 & 5.27800029 & 27223475 & 4775900 \\
\hline & & & & & & & Avouce & 0.7096002 & 4379022 & 2931015 & $\bar{x}$ & 01149007 & 7704950 & 51400001 & 2 row7s & 50x:71 \\
\hline$\sqrt{3 / 2}$ & $T$ & 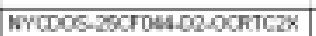 & Refuse Truck & Th & $\operatorname{man}$ & $\overline{D 2}$ & OChic2X & 49060012 & 4327655 & की. & 3045 & 06000055 & 3601.742 & 5.2443075 & 27005113 & 46619069 \\
\hline 3526 & $\frac{1}{2}$ & WYCDOS-2SCF044-02-0CKTCZX & Fistues Truak & Wroco0s 2500044 & Nente & 02 & OChic $2 x$ & 4.8963594 & 43550157 & 40.7393 & 3.1042418 & 07000916 & 37198342 & 5.2430667 & 27227132 & 47746.309 \\
\hline \multirow[t]{2}{*}{3726} & 3 & 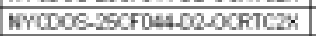 & Fistues Truak & Wroco0os 2SOFO44 & nione & 02 & OCATC2X & 4 ET29\&2 & 43661725 & 40.812763 & 32227 & 07601971 & 37065254 & 5.27 & 27307348 & 47606234 \\
\hline & & & & & & & AVERAOE & 49120042 & $43.4720 \mathrm{rg}$ & 40.670225 & $3.1226 \mathrm{~T} 62$ & 0.7255248 & 3868.7004 & 52546249 & 27473218 & 47324.16 \\
\hline
\end{tabular}

